National and Global Petroleum Assessment

\title{
U.S. Geological Survey Assessments of Continuous (Unconventional) Oil and Gas Resources, 2000 to 2011
}

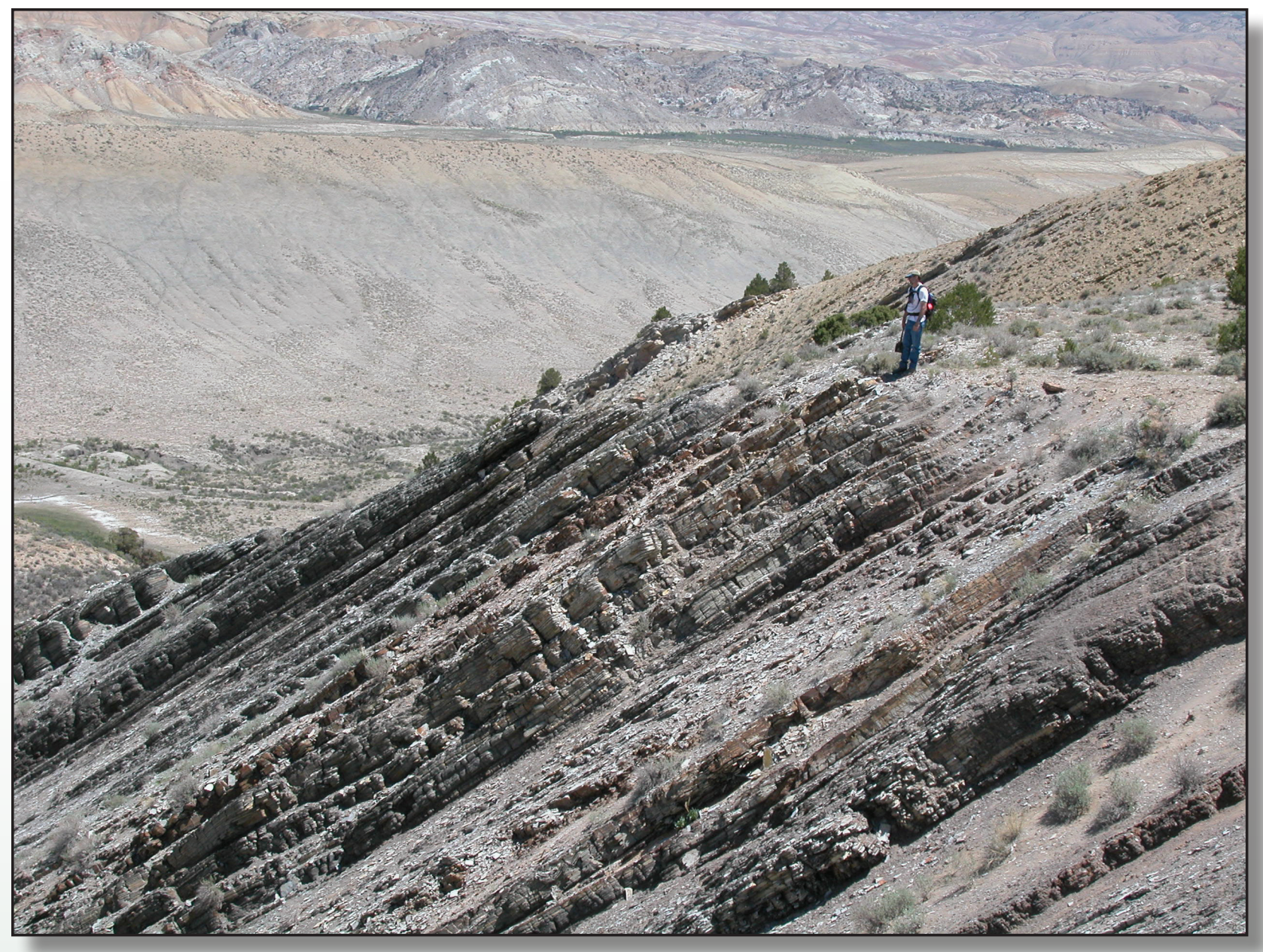

Digital Data Series 69-MM 
Cover: Dipping beds of the Mowry Shale at the east end of Irish Canyon, Colorado. Photo by Christopher J. Schenk, June 7, 2004. 


\section{U.S. Geological Survey Assessments of Continuous (Unconventional) Oil and Gas Resources, 2000 to 2011}

By U.S. Geological Survey U.S. Continuous Resources Assessment Team

National and Global Petroleum Assessment

Digital Data Series 69-MM 


\title{
U.S. Department of the Interior SALLY JEWELL, Secretary
}

\section{U.S. Geological Survey \\ Suzette M. Kimball, Acting Director}

\author{
U.S. Geological Survey, Reston, Virginia: 2015
}

For more information on the USGS - the Federal source for science about the Earth, its natural and living resources, natural hazards, and the environment—visit http://www.usgs.gov or call 1-888-ASK-USGS.

For an overview of USGS information products, including maps, imagery, and publications, visit http://www.usgs.gov/pubprod/.

Any use of trade, firm, or product names is for descriptive purposes only and does not imply endorsement by the U.S. Government.

Although this information product, for the most part, is in the public domain, it also may contain copyrighted materials as noted in the text. Permission to reproduce copyrighted items must be secured from the copyright owner.

Suggested citation:

U.S. Geological Survey U.S. Continuous Resources Assessment Team, 2015, U.S. Geological Survey assessments of continuous (unconventional) oil and gas resources, 2000 to 2011: U.S. Geological Survey Digital Data Series DDS-69-MM, 46 p., http://dx.doi.org/10.3133/ds69MM.

ISSN 2327-638X (online)

ISSN 2333-0481 (CD/DVD) 


\title{
Members of U.S. Geological Survey U.S. Continuous Resources Assessment Team
}

\author{
Lawrence 0. Anna \\ Michael E. Brownfield \\ Ronald R. Charpentier \\ James L. Coleman \\ Steven M. Condon \\ Troy A. Cook \\ Russell F. Dubiel \\ Thaddeus S. Dyman \\ Thomas M. Finn \\ Romeo M. Flores \\ Paul C. Hackley \\ Joseph R. Hatch \\ Mitchell E. Henry \\ Timothy C. Hester \\ Robert D. Hettinger \\ Debra K. Higley \\ David W. Houseknecht \\ Ronald C. Johnson \\ Mark A. Kirschbaum \\ Timothy R. Klett \\ Robert C. Milici \\ Philip H. Nelson \\ Mark J. Pawlewicz \\ Krystal M. Pearson \\ Ofori N. Pearson \\ Janet K. Pitman \\ Richard M. Pollastro \\ Jennie L. Ridgley \\ Laura N.R. Roberts \\ Stephen B. Roberts \\ William A. Rouse \\ Robert T. Ryder \\ Christopher J. Schenk \\ Richard G. Stanley \\ Christopher S. Swezey \\ Marilyn E. Tennyson \\ Peter D. Warwick
}





\section{Contents}

Members of U.S. Geological Survey U.S. Continuous Resources Assessment Team .....................iii

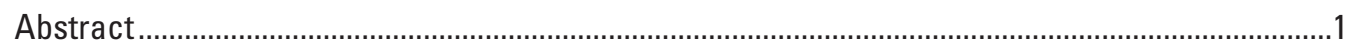

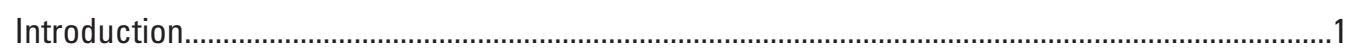

Data Resources

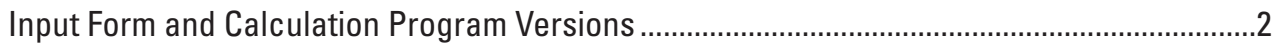

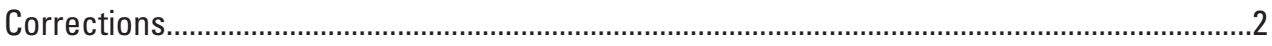

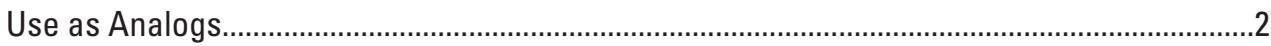

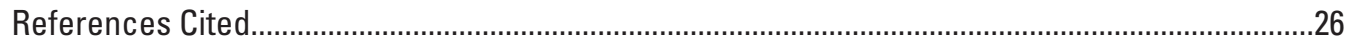

Appendix 1. Publications Presenting Results of Assessments Used in this Report ....................27

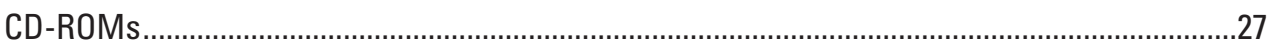

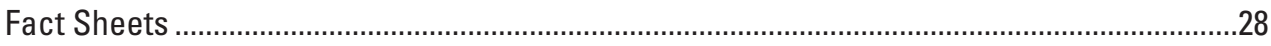

Appendix 2. Structure of the Files Presented in this Report .......................................................31

\section{Figures}

1. Cloud plot for estimated area of cells (drainage areas) in United States

shale-gas assessment units . .3

2. Cloud plot for estimated area of cells (drainage areas) in United States coalbed-gas assessment units............................................................................................4

3. Cloud plot for estimated area of cells (drainage areas) in United States tight-gas assessment units ..............................................................................................

4. Cloud plot for estimated area of cells (drainage areas) in United States continuous-oil assessment units .

5. Cloud plot for estimated percent of untested area in sweet spots in United States shale-gas assessment units.

6. Cloud plot for estimated percent of untested area in sweet spots in United States coalbed-gas assessment units ....................................................................

7. Cloud plot for estimated percent of untested area in sweet spots in United States tight-gas assessment units

8. Cloud plot for estimated percent of untested area in sweet spots in United States continuous-oil assessment units .............................................................10

9. Cloud plot for EURs in United States shale-gas assessment units ................................11

10. Cloud plot for EURs in United States coalbed-gas assessment units..............................12

11. Cloud plot for EURs in United States tight-gas assessment units ..................................13

12. Cloud plot for EURs in United States continuous-oil assessment units ..........................14 


\section{Tables}

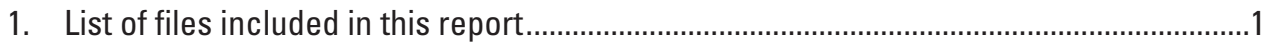

2. Input data for estimated area of cells (drainage areas) for United States shale-gas assessment units, values in acres..

3. Input data for estimated area of cells (drainage areas) for United States coalbed-gas assessment units, values in acres

4. Input data for estimated area of cells (drainage areas) for United States tight-gas assessment units, values in acres.

5. Input data for estimated area of cells (drainage areas) for United States continuous-oil assessment units, values in acres...

6. Input data for estimated percent of untested area in sweet spots for United States shale-gas assessment units.

7. Input data for estimated percent of untested area in sweet spots for United States coalbed-gas assessment units

8. Input data for estimated percent of untested area in sweet spots for United States tight-gas assessment units

9. Input data for estimated percent of untested area in sweet spots for United States continuous-oil assessment units

10. Input data for estimated ultimate recovery distributions for United States shale-gas assessment units, values in billions of cubic feet of natural gas

11. Input data for estimated ultimate recovery distributions for United States coalbed-gas assessment units, values in billions of cubic feet of natural gas

12. Input data for estimated ultimate recovery distributions for United States tight-gas assessment units, values in billions of cubic feet of natural gas

13. Input data for estimated ultimate recovery distributions for United States continuous-oil assessment units, values in millions of barrels of oil 


\title{
U.S. Geological Survey Assessments of Continuous (Unconventional) Oil and Gas Resources, 2000 to 2011
}

\author{
By U.S. Geological Survey U.S. Continuous Resources Assessment Team
}

\begin{abstract}
From 2000 to 2011, the U.S. Geological Survey conducted 139 quantitative assessments of continuous (unconventional) oil and gas accumulations within the United States. This report documents those assessments more fully than previously done by providing detailed documentation of both the assessment input and output. This report also compiles the data into spreadsheet tables that can be more readily used to provide analogs for future assessments, especially for hypothetical continuous accumulations.
\end{abstract}

\section{Introduction}

The U.S. Geological Survey (USGS) conducted 139 quantitative assessments of oil and gas potential in continuous (unconventional) accumulations from 2000 to 2011. This report provides documentation of the input and output for those assessments in one place and in a more complete fashion than previously published. All of these assessments units (AUs) were for areas within the United States, excepting one that was an extension of a coalbed methane trend into northeast Mexico.

All the assessments documented in this report were conducted using the same quantitative methodology. The basic model for this methodology is explained in Schmoker (2003). The input form and operational procedure can be found in Klett and Schmoker (2003). The program itself is available and extensively documented in Crovelli (2012). Additional information is given in Klett and Charpentier (2003).
These assessments were previously documented in a series of publications, the list of which is presented in Appendix 1. For some of the assessments, the only previous documentation was a summary of the results in a short USGS Fact Sheet. The present report provides more extensive documentation for those assessments than was previously available.

Since 2011, the USGS has continued to assess continuous oil and gas resources in the United States and internationally. These assessments, however, used a different methodology (Charpentier and Cook, 2010) that has been modified from the methodology that was used previously. None of these newer assessments are included in this report.

\section{Data Resources}

This report contains extensive documentation of the USGS assessments of continuous accumulations of oil and gas resources. Both the input and output information of the assessments are included. The data are in a collection of spreadsheet tables (table 1), in both Microsoft Excel format and tabdelimited format. Descriptions of the variables in each table are presented in Appendix 2.

The geographic boundaries of 184 AUs are included in this report as a set of GIS (geographic information system) files. Two AUs (50310261, the Winnipeg-Icebox Continuous Gas AU, and 50640561, the Elvins Shale Gas AU) did not have geographic boundaries established and thus are not included.

Table 1. List of files included in this report.

\begin{tabular}{|c|c|c|}
\hline Microsoft Excel File Name & Tab-delimited File Name & Contents \\
\hline Main Input.xlsx & Main Input.tab & Data from input forms \\
\hline Ecosystem Allocations.xlsx & Ecosystem Allocations.tab & Allocations to ecosystem \\
\hline Federal Land Allocations.xlsx & Federal Land Allocations.tab & Allocations to Federal agency \\
\hline Land Ownership Allocations.xlsx & Land Ownership Allocations.tab & Allocations to land ownership category \\
\hline State Allocations.xlsx & State Allocations.tab & Allocations to state \\
\hline Continuous Results.xlsx & Continuous Results.tab & Assessment results \\
\hline Code List.xlsx & Code List.tab & Main code list \\
\hline Ecosystem Codes.xlsx & Ecosystem Codes.tab & Code list for ecosystem names \\
\hline Cloud Plots.xlsx & Cloud Plots.tab & Data for constructing cloud plots \\
\hline
\end{tabular}


U.S. Geological Survey Assessments of Continuous (Unconventional) Oil and Gas Resources, 2000 to 2011

\section{Input Form and Calculation Program Versions}

These assessments took place over the course of more than a decade, and refinements to both the input form and calculation program were made during the same period. The input form was changed more frequently than the program. In 2003, the input form was revised to accommodate the change in parameter inputs from median values to modal values. Other changes to the input form were primarily made to include additional ancillary variables.

The program for calculating the estimates is named "ACCESS," and several versions exist (Crovelli, 2012). The unnumbered version, originally described in Crovelli (2000), was not used for any official USGS assessments. The first version actually used for assessments is herein termed "version 1," which was used from 2000 to 2002. Version 1 differed from the previous ACCESS version in that it included a variable for "Percentage of total assessment-unit area that is untested." Each triangular distribution (used to describe the probability distribution of an input variable) was described by the minimum, median, and maximum values. ACCESS version 2 was used from 2003 to 2008. Each triangular distribution was described by the minimum, mode, and maximum values. ACCESS version 3 was used from 2009 to 2011. An error was identified in version 2: gas-oil ratio inputs in continuous oil AUs were set as a triangle with minimum, mode, and maximum as 240,320 , and 960 , and the program ignored any other input. The error correction was the only change made in version 3 . Because the error only affected coproduct volumes and only in oil AUs, there was only minor effect in a few assessments.

Both the input form version and the version of the program used to run the calculations (for AUs that were quantitatively assessed) are documented in Microsoft Excel and tabdelimited files named "Main Input." File Main Input includes all the variables for each version of the input form. Thus, some variables will not be populated in file Main Input for a specific AU because that variable was not on the input form used in that assessment.

\section{Corrections}

Corrections were made to some values in the data tables. Some of these were minor and corrected typographical errors or enforced consistency in naming conventions. The list of codes used in these assessments is included as file "Code List." Codes in the various original files were checked and changed for consistency where necessary.

Changes were also made to the data tables to ensure that allocation percentages added up correctly. The sum of the land ownership allocations should be 100 percent, and the sum of the Federal land allocations should be the percent of Federal land in file "Land Ownership Allocations."

A few corrections were more significant, and these are highlighted in green in the Microsoft Excel versions of the spreadsheets. The most significant corrections are for those values on the original input forms that were different from those values actually used in the resource calculations. Almost all of these are a result of the error in version 2 of the ACCESS program, as explained above.

AUs that were defined but not quantitatively assessed are included in the "Main Input" and allocation-related files, but not in the "Continuous Results" or "Cloud Plots" files. These unassessed AUs are highlighted in purple in the Microsoft Excel versions of the spreadsheets. Although some of the original input forms for these unassessed AUs had some values filled in (such as allocation unit names and area percentages), these values were never checked as they would have been for a quantitative assessment. Therefore, these values are not included in the Main Input file. Only the header information for unassessed AUs is included in the Main Input file.

\section{Use as Analogs}

This report is not only intended to more fully document the assessments of continuous oil and gas resources, but also to provide the information in such a way as to facilitate its use as analog data for subsequent assessments. U.S. Geological Survey Oil and Gas Assessment Team (2012) documented the variability of estimated ultimate recovery (EUR) distributions from these assessments to provide a set of analogs for EURs. In that report, the data were presented in two forms: in tables and in graphs termed "cloud plots." These two forms of data presentation are also provided herein, not only for estimated EUR distributions but also for estimated cell sizes and estimations of the percent of undrilled areas that would be both successful and in sweet spots.

Use of these data for analogs necessitates several cautionary statements. All the distributions are taken from the assessment input distributions. They represent the estimated distributions for undrilled portions of the AU in question. Generally, the distributions for undrilled portions were closely based on data for the drilled portions. Changes from the drilled to the undrilled portions could, however, result from changes in drilling/completion practice or differences in the geology between drilled and undrilled areas. The undrilled portions of the AU were estimated as if drilled using what was the current "best practice" at the time of the assessment. (Dates of the assessments can be found in the "Main Input" file.) Whereas the wells drilled prior to the assessment may have been a mixture of vertical and horizontal wells, the undrilled areas would be estimated as if drilled by either vertical or horizontal wells, whichever was the "best practice" at the time of the assessment.

The three variables most useful as analogs are EUR distributions, cell sizes, and percent of undrilled areas that would be both successful and in sweet spots. For each of these variables, the 139 AUs are divided into four groups by reservoir type (shale gas, coalbed gas, tight gas, and continuous oil). Twelve cloud plots (figs. 1 to 12) and 12 tables (tables 2 to 13) summarizing these data are provided in the next sections of this report. The data for the plots are in the Cloud Plots file in the Excel folder of the online downloads directory. 


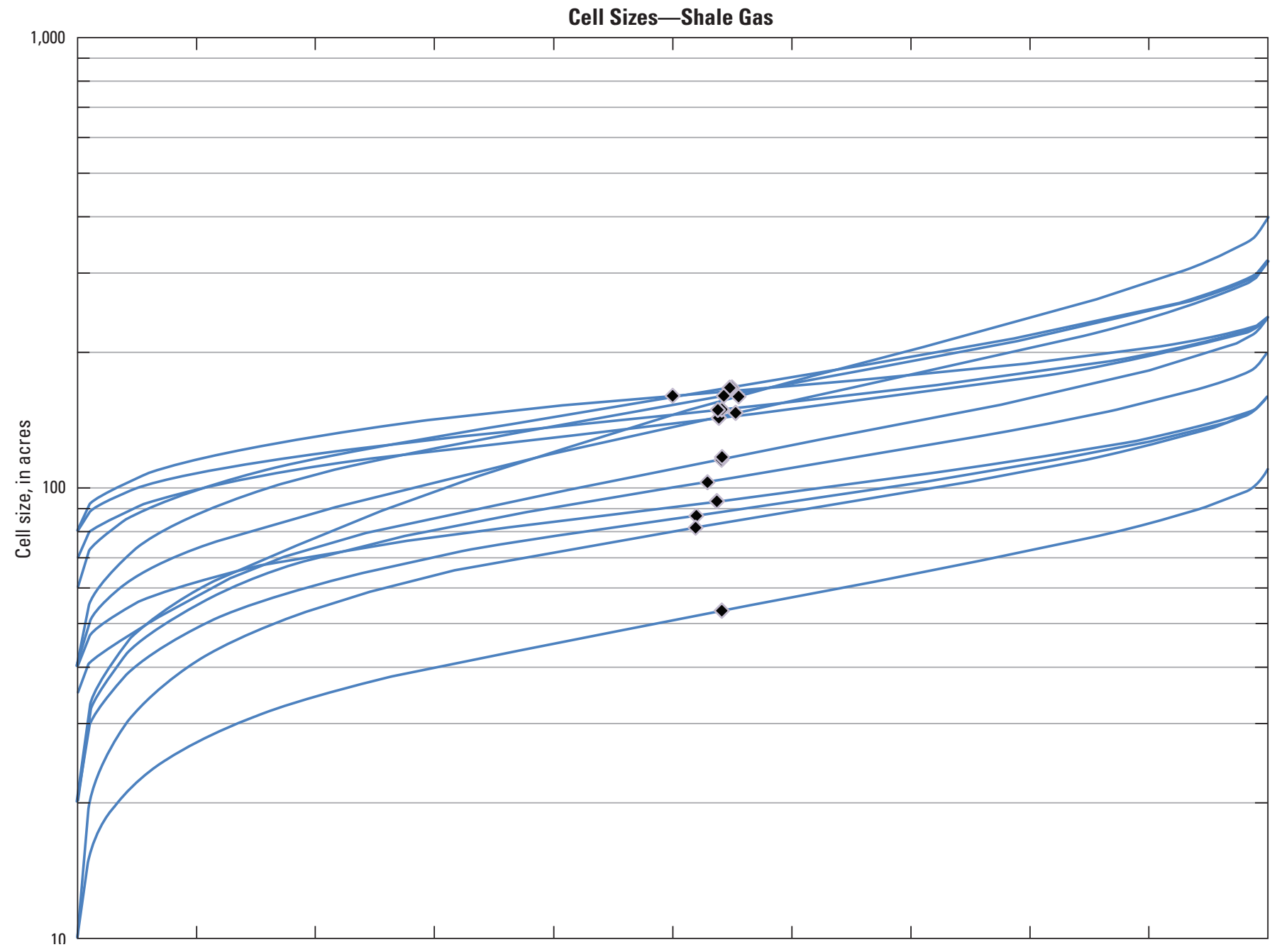

Figure 1. Cloud plot for estimated area of cells (drainage areas) in United States shale-gas assessment units. Each curve represents one assessment unit and is based on the input data in table 2. Black diamonds show the mean value for each curve. 


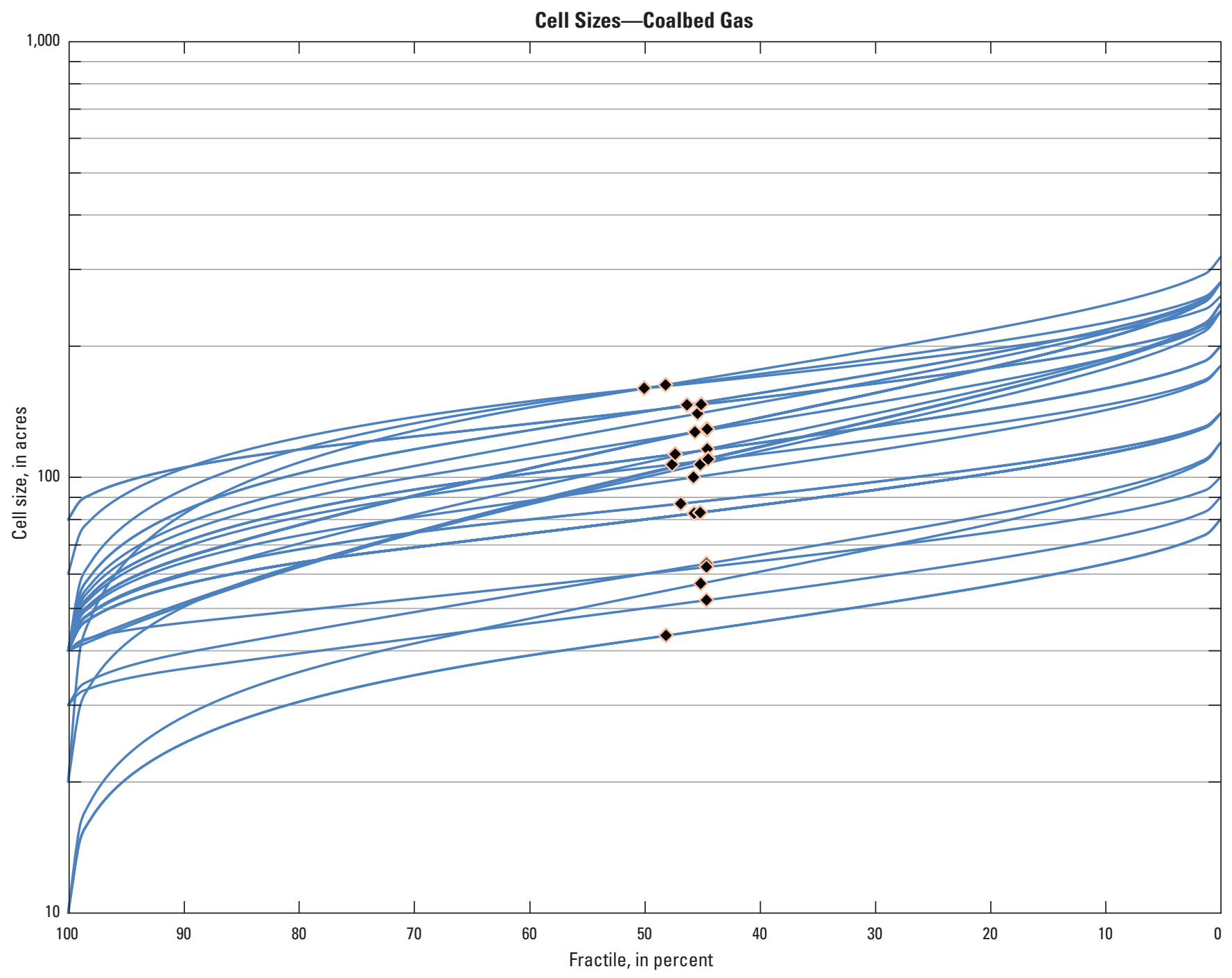

Figure 2. Cloud plot for estimated area of cells (drainage areas) in United States coalbed-gas assessment units. Each curve represents one assessment unit and is based on the input data in table 3. Black diamonds show the mean value for each curve. 


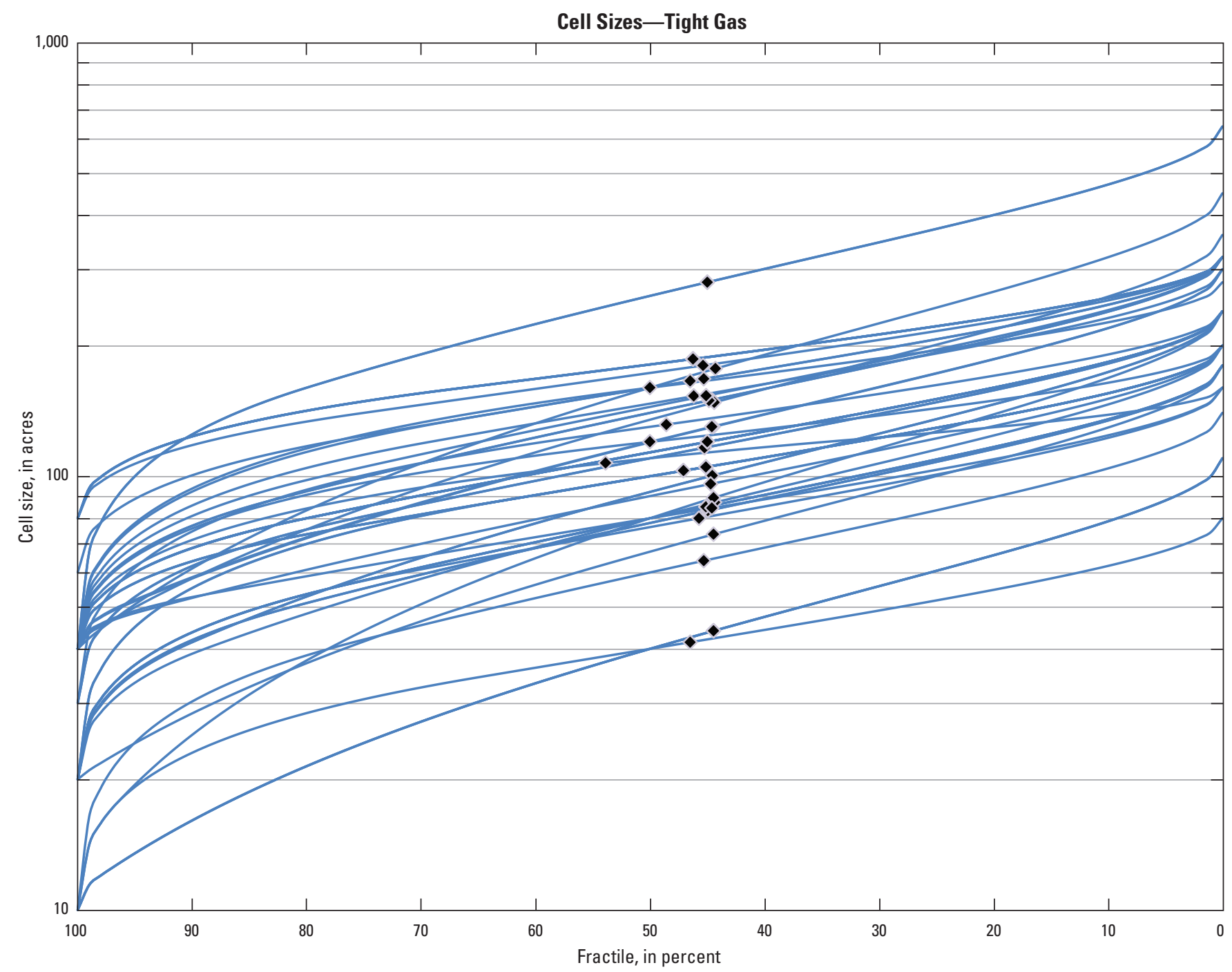

Figure 3. Cloud plot for estimated area of cells (drainage areas) in United States tight-gas assessment units. Each curve represents one assessment unit and is based on the input data in table 4. Black diamonds show the mean value for each curve. 


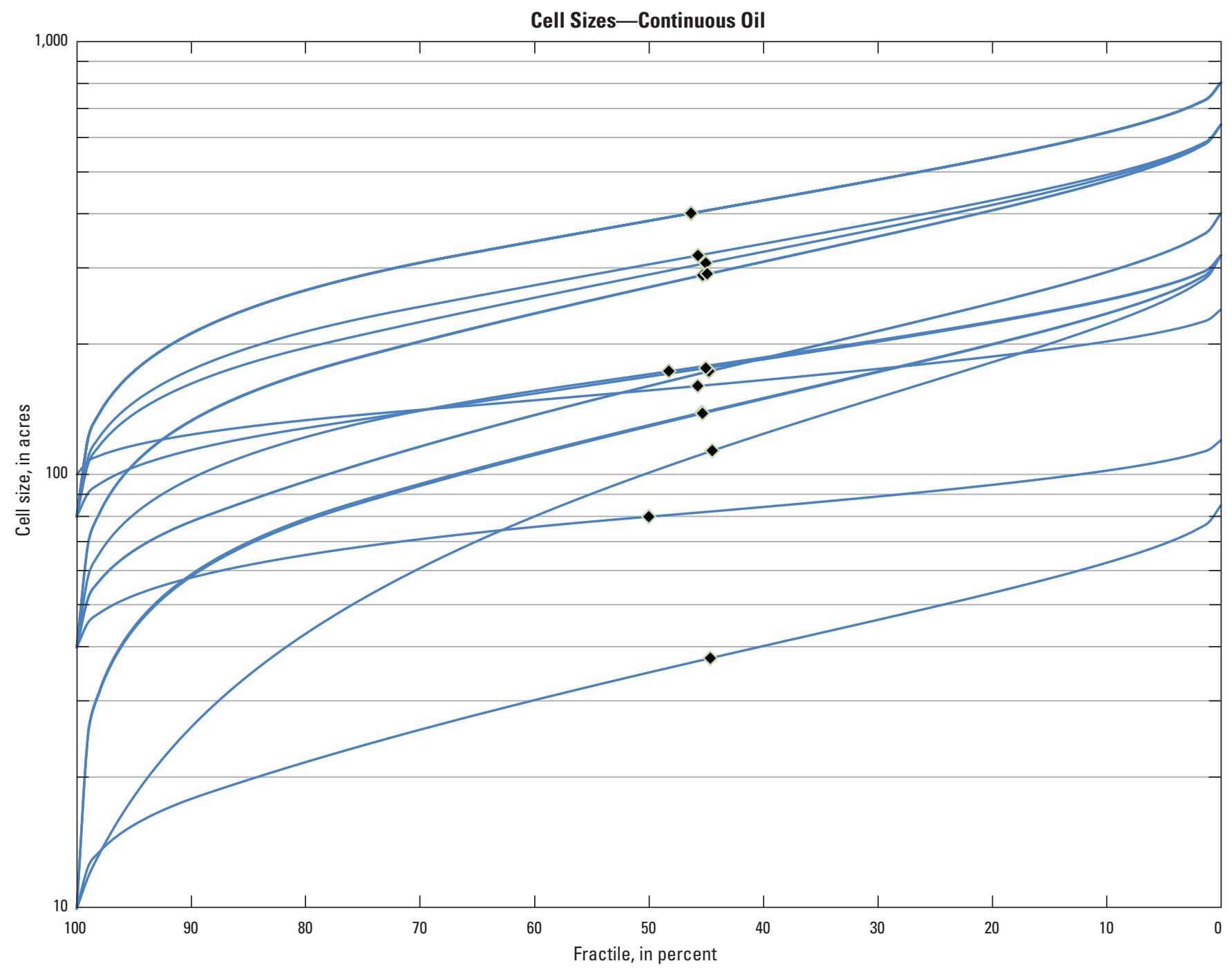

Figure 4. Cloud plot for estimated area of cells (drainage areas) in United States continuous-oil assessment units. Each curve represents one assessment unit and is based on the input data in table 5. Black diamonds show the mean value for each curve. 


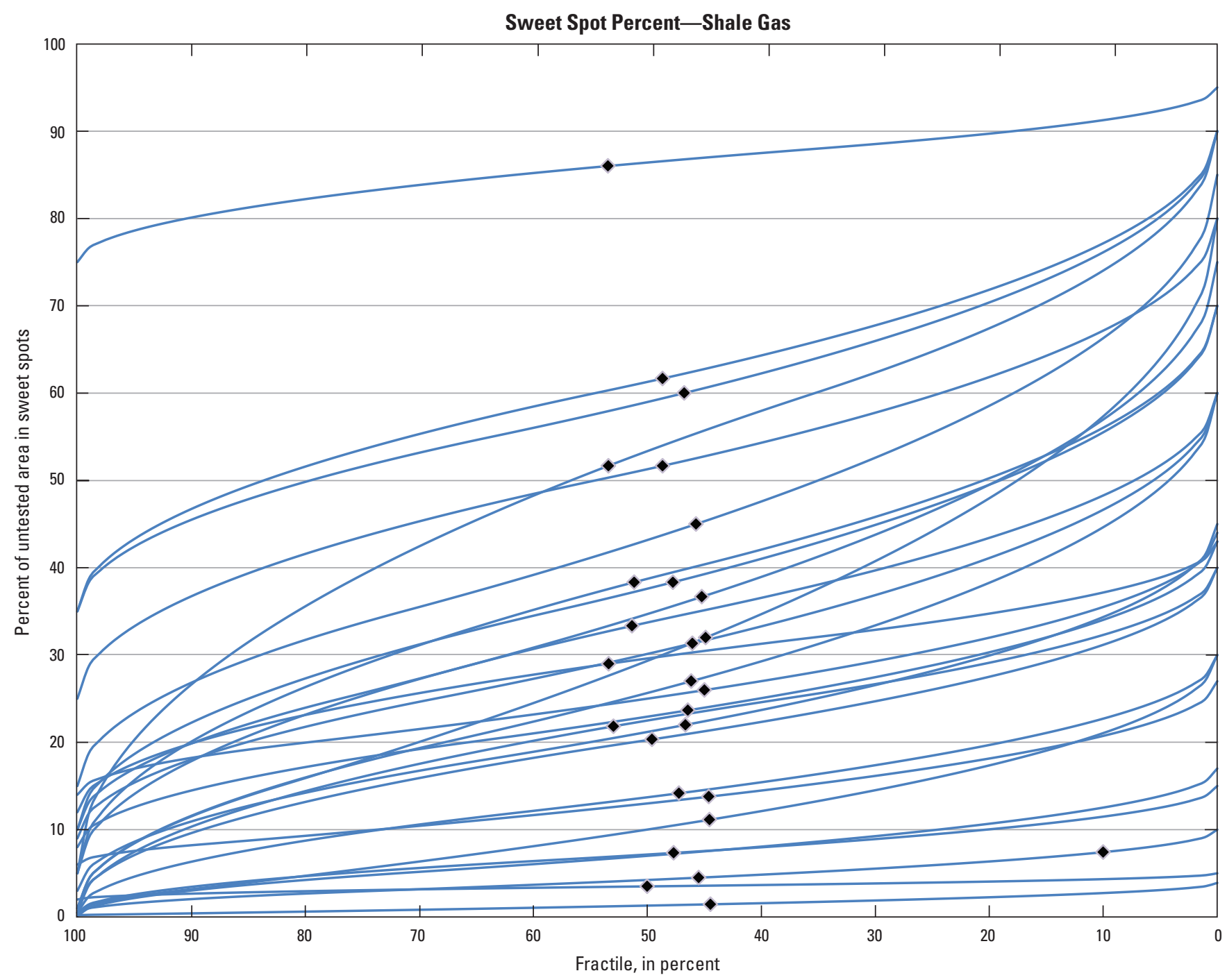

Figure 5. Cloud plot for estimated percent of untested area in sweet spots in United States shale-gas assessment units. Each curve represents one assessment unit and is based on the input data in table 6. Black diamonds show the mean value for each curve. 
U.S. Geological Survey Assessments of Continuous (Unconventional) Oil and Gas Resources, 2000 to 2011

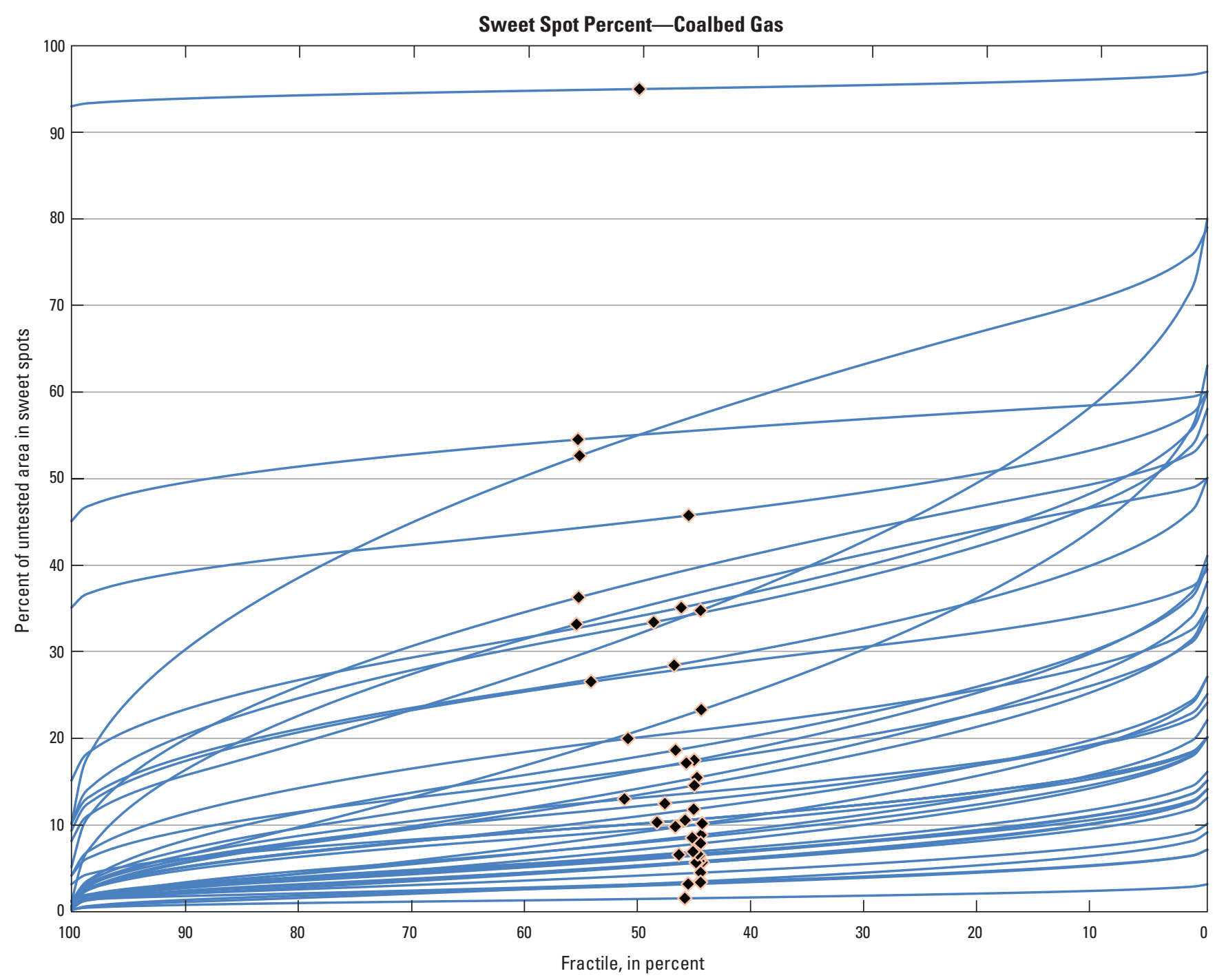

Figure 6. Cloud plot for estimated percent of untested area in sweet spots in United States coalbed-gas assessment units. Each curve represents one assessment unit and is based on the input data in table 7. Black diamonds show the mean value for each curve. 


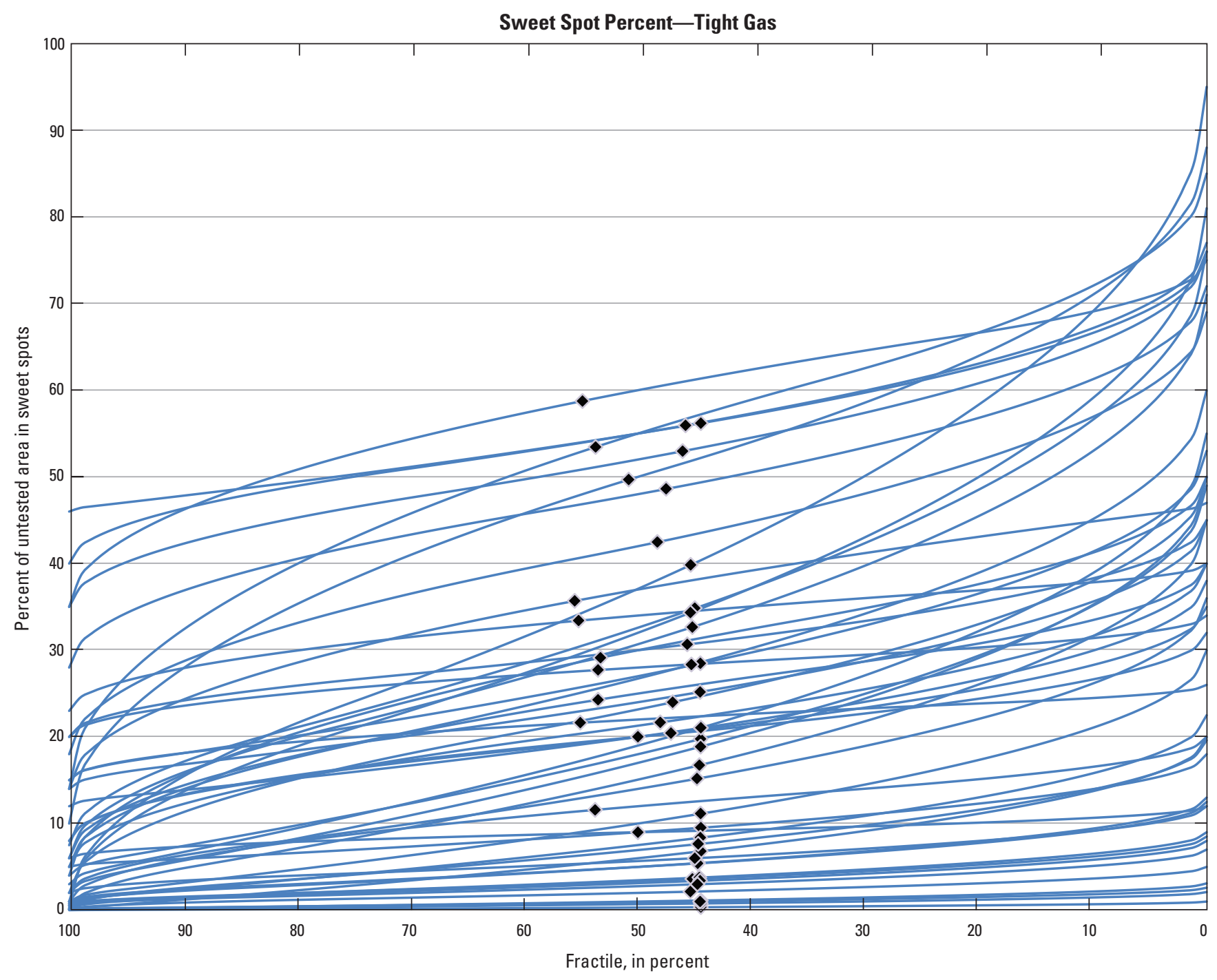

Figure 7. Cloud plot for estimated percent of untested area in sweet spots in United States tight-gas assessment units. Each curve represents one assessment unit and is based on the input data in table 8. Black diamonds show the mean value for each curve. 


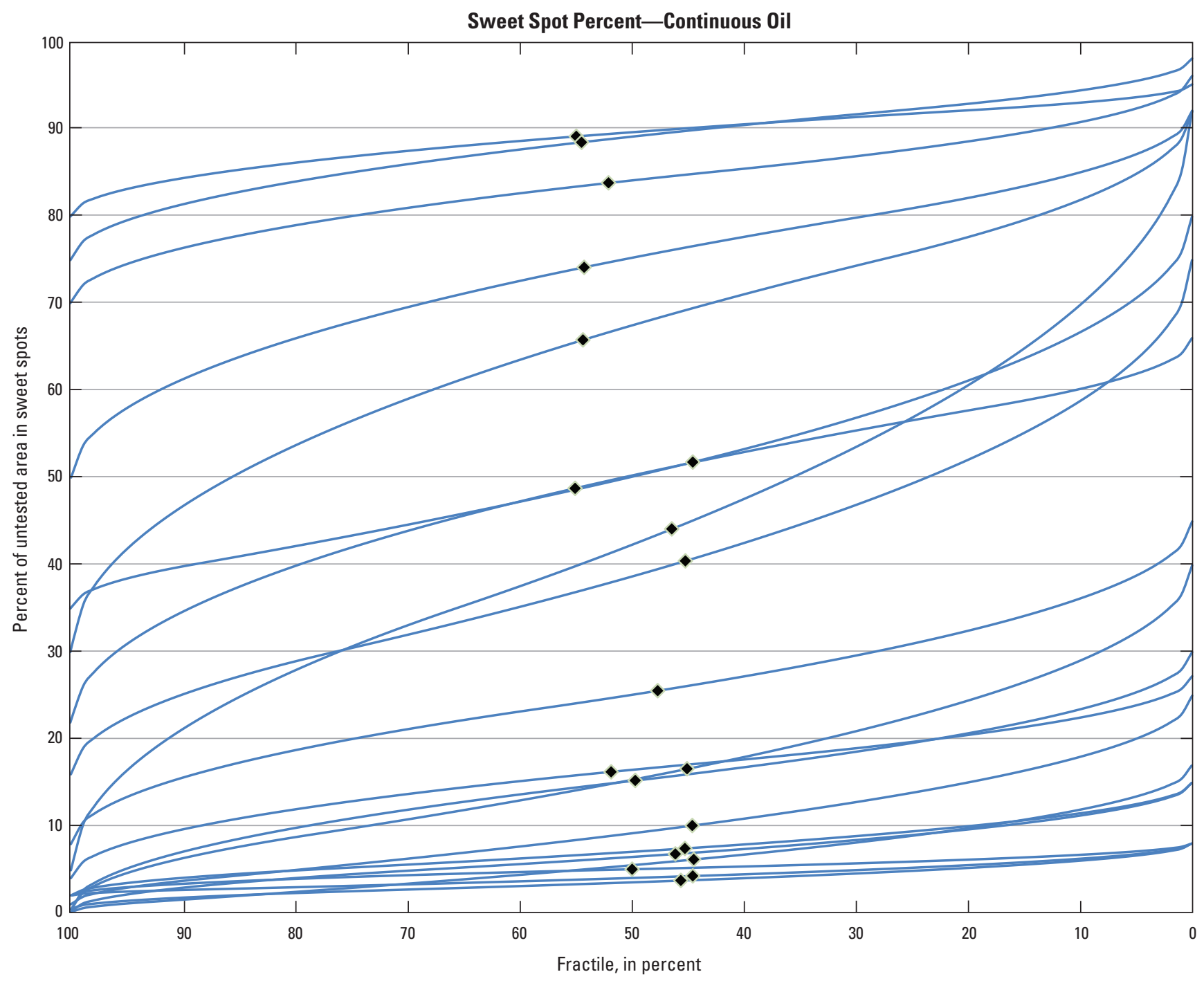

Figure 8. Cloud plot for estimated percent of untested area in sweet spots in United States continuous-oil assessment units. Each curve represents one assessment unit and is based on the input data in table 9. Black diamonds show the mean value for each curve. 


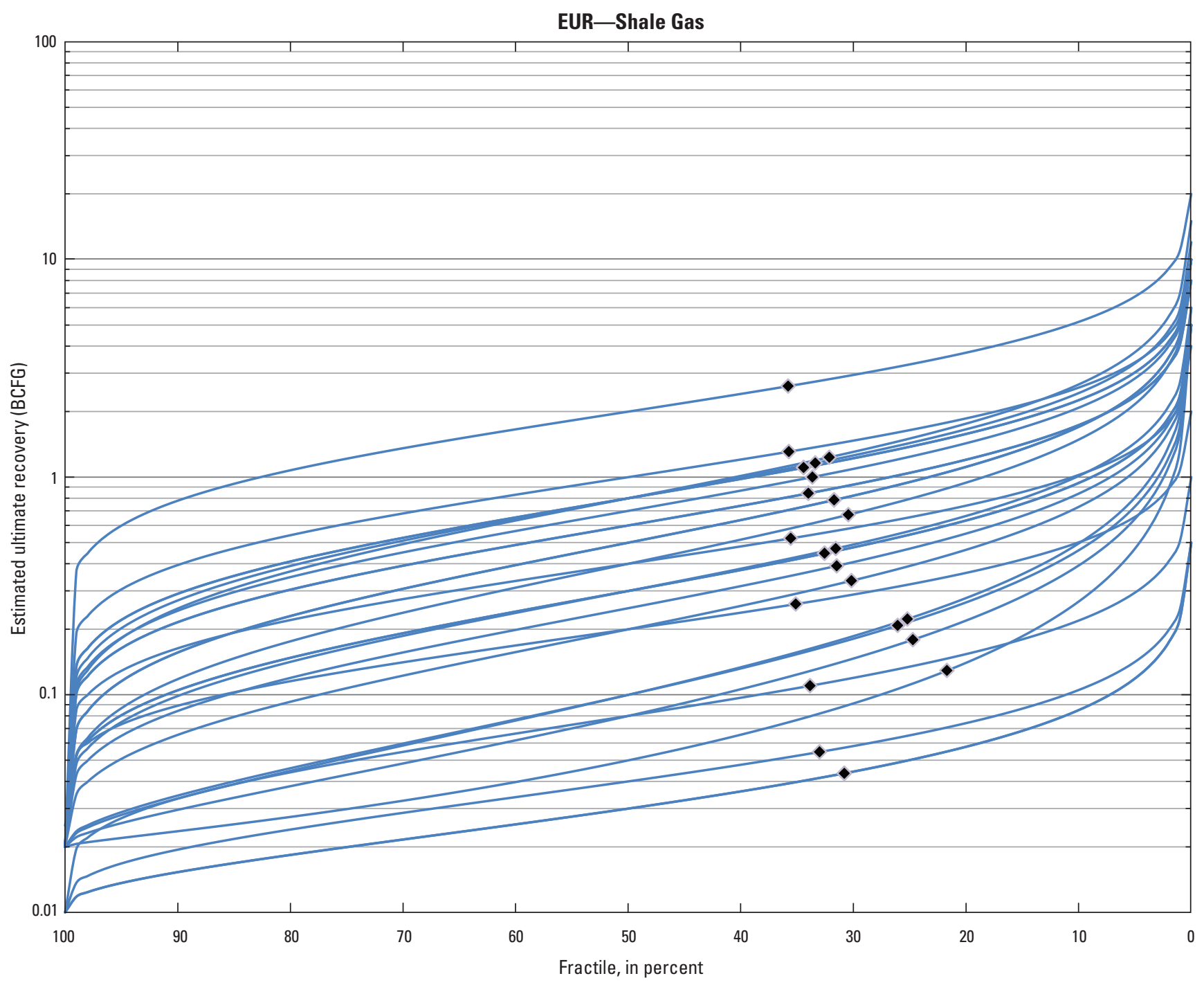

Figure 9. Cloud plot for EURs in United States shale-gas assessment units. Each curve represents one assessment unit and is based on the input data in table 10. Black diamonds show the mean value for each curve. [EUR, estimated ultimate recovery; BCFG, billions of cubic feet of gas] 


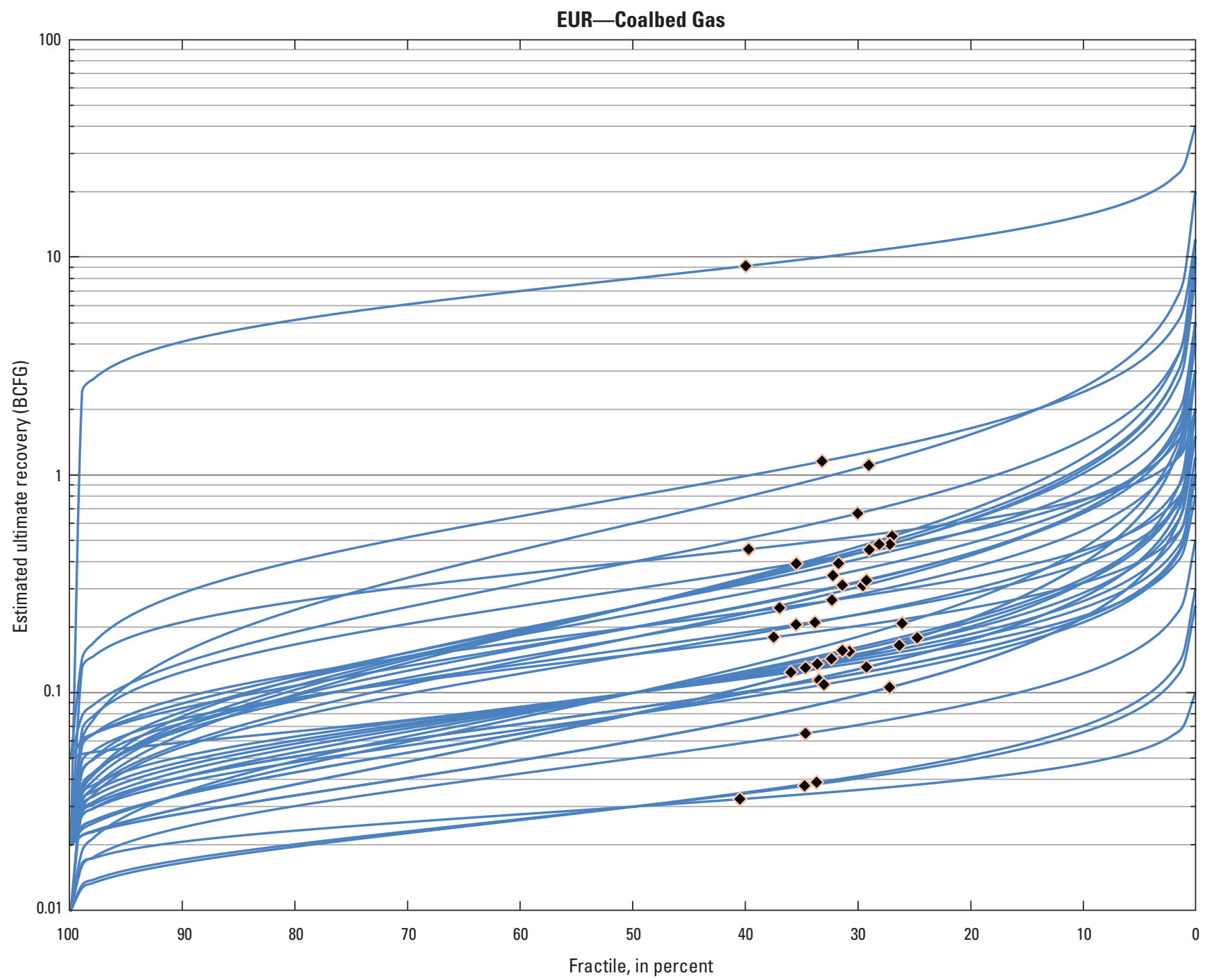

Figure 10. Cloud plot for EURs in United States coalbed-gas assessment units. Each curve represents one assessment unit and is based on the input data in table 11. Black diamonds show the mean value for each curve. [EUR, estimated ultimate recovery; BCFG, billions of cubic feet of gas] 


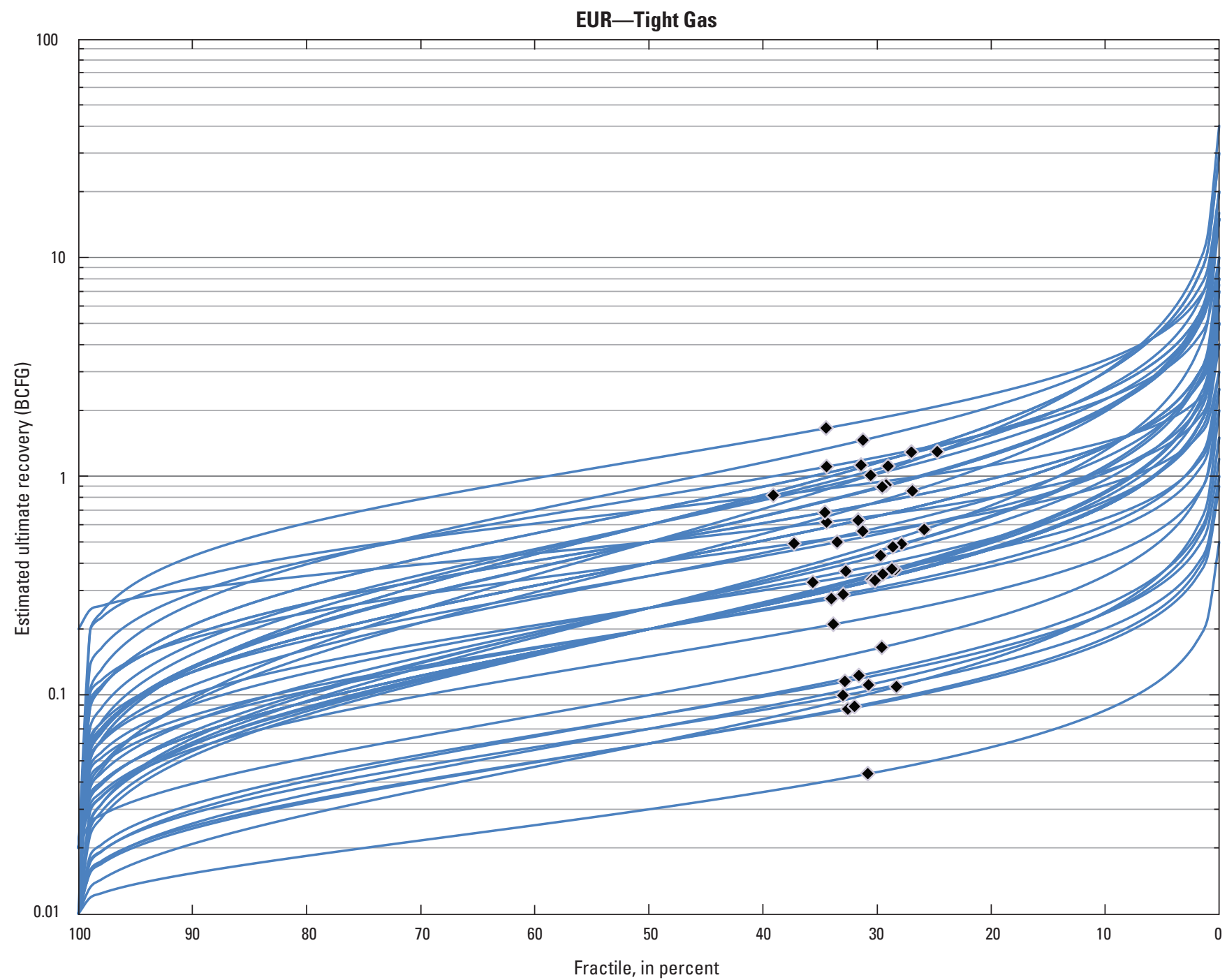

Figure 11. Cloud plot for EURs in United States tight-gas assessment units. Each curve represents one assessment unit and is based on the input data in table 12. Black diamonds show the mean value for each curve. [EUR, estimated ultimate recovery; BCFG, billions of cubic feet of gas] 


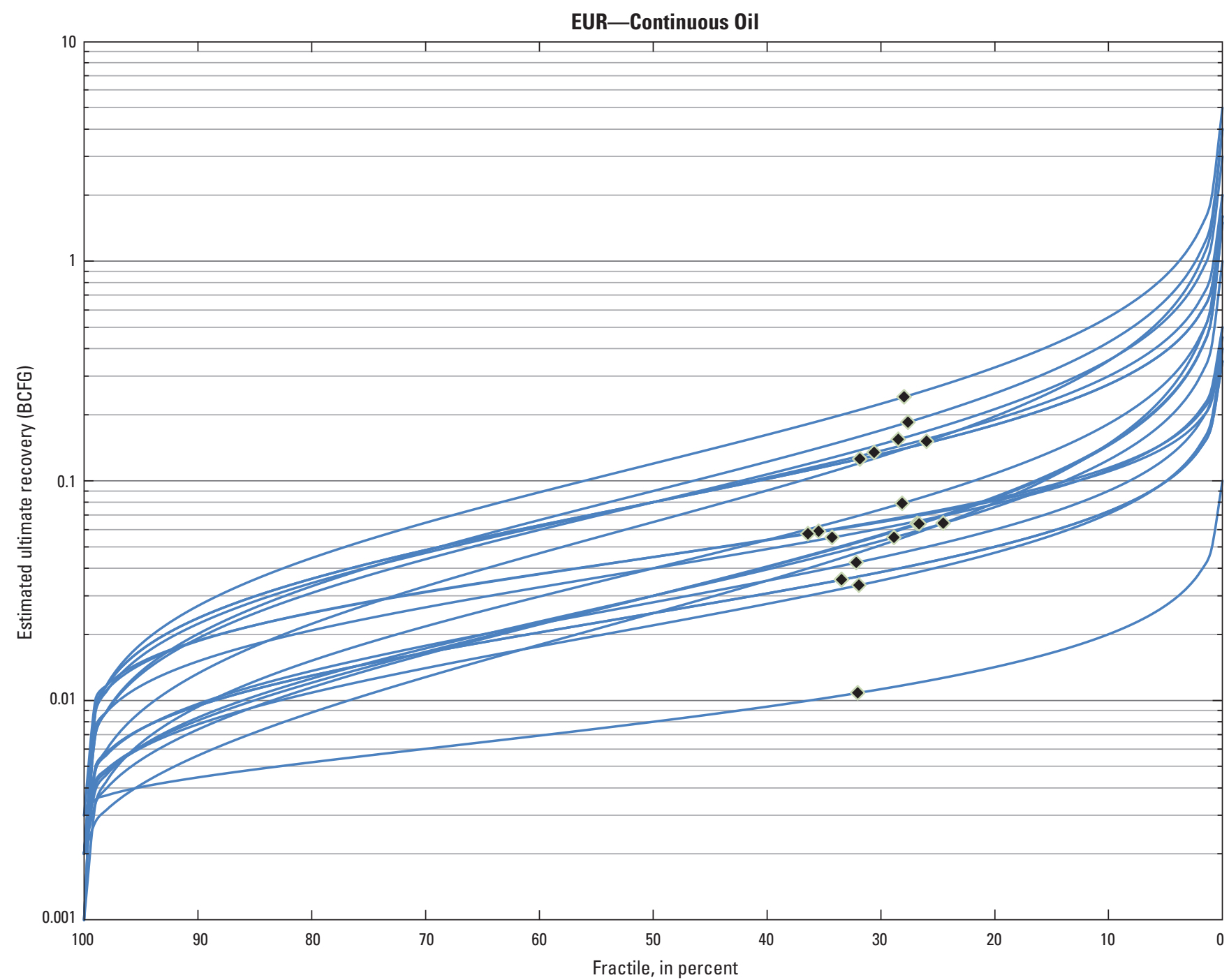

Figure 12. Cloud plot for EURs in United States continuous-oil assessment units. Each curve represents one assessment unit and is based on the input data in table 13. Black diamonds show the mean value for each curve. [EUR, estimated ultimate recovery; MMB0, millions of barrels of oil] 
Table 2. Input data for estimated area of cells (drainage areas) for United States shale-gas assessment units, values in acres.

[AU, assessment unit]

\begin{tabular}{|c|c|c|c|c|c|c|c|}
\hline $\begin{array}{c}\text { AU } \\
\text { number }\end{array}$ & AU name & Province & $\begin{array}{c}\text { Year } \\
\text { assessed }\end{array}$ & $\begin{array}{c}\text { Minimum } \\
\text { cell } \\
\text { area }\end{array}$ & $\begin{array}{c}\text { Mode } \\
\text { of cell } \\
\text { area } \\
\end{array}$ & $\begin{array}{c}\text { Maximum } \\
\text { cell } \\
\text { area }\end{array}$ & $\begin{array}{c}\text { Mean } \\
\text { cell } \\
\text { area }\end{array}$ \\
\hline 50580161 & Woodford Shale Gas & Anadarko Basin & 2010 & 60 & 120 & 320 & 166.67 \\
\hline 50620261 & Woodford Shale Gas & Arkoma Basin & 2010 & 60 & 120 & 320 & 166.67 \\
\hline 50620262 & Chattanooga Shale Gas & Arkoma Basin & 2010 & 60 & 120 & 320 & 166.67 \\
\hline 50620364 & Caney Shale Gas & Arkoma Basin & 2010 & 40 & 120 & 320 & 160.00 \\
\hline 50490161 & Haynesville Sabine Platform Shale Gas & Gulf Coast Mesozoic & 2010 & 80 & 128 & 240 & 149.33 \\
\hline 50490163 & Mid-Bossier Sabine Platform Shale Gas & Gulf Coast Mesozoic & 2010 & 80 & 128 & 240 & 149.33 \\
\hline 50490165 & Maverick Basin Pearsall Shale Gas & Gulf Coast Mesozoic & 2010 & 80 & 128 & 240 & 149.33 \\
\hline 50490167 & Eagle Ford Shale Gas & Gulf Coast Mesozoic & 2010 & 80 & 128 & 240 & 149.33 \\
\hline 50670467 & Foldbelt Marcellus & Appalachian Basin & 2011 & 80 & 128 & 240 & 149.33 \\
\hline 50670468 & Interior Marcellus & Appalachian Basin & 2011 & 80 & 128 & 240 & 149.33 \\
\hline 50670469 & Western Margin Marcellus & Appalachian Basin & 2011 & 20 & 90 & 240 & 116.67 \\
\hline 50670463 & Devonian Siltstone and Shale & Appalachian Basin & 2002 & 20 & 86.36 & 240 & 115.45 \\
\hline 50670464 & Marcellus Shale & Appalachian Basin & 2002 & 20 & 88.89 & 200 & 102.96 \\
\hline 50440161 & Delaware/Pecos Basins Woodford Continuous Shale Gas & Permian Basin & 2007 & 40 & 80 & 160 & 93.33 \\
\hline 50440162 & Delaware/Pecos Basins Barnett Continuous Shale Gas & Permian Basin & 2007 & 40 & 80 & 160 & 93.33 \\
\hline 50440163 & Midland Basin Woodford/Barnett Continuous Gas & Permian Basin & 2007 & 40 & 80 & 160 & 93.33 \\
\hline 50630561 & Devonian Antrim Continuous Gas & Michigan Basin & 2004 & 20 & 80 & 160 & 86.67 \\
\hline 50670462 & Northwestern Ohio Shale & Appalachian Basin & 2002 & 10 & 74.67 & 160 & 81.56 \\
\hline 50450161 & $\begin{array}{l}\text { Greater Newark East Frac-Barrier Continuous Barnett } \\
\text { Shale Gas }\end{array}$ & $\begin{array}{l}\text { Bend Arch- } \\
\text { Fort Worth Basin }\end{array}$ & 2003 & 10 & 40 & 110 & 53.33 \\
\hline 50450162 & Extended Continuous Barnett Shale Gas & $\begin{array}{l}\text { Bend Arch- } \\
\text { Fort Worth Basin }\end{array}$ & 2003 & 10 & 40 & 110 & 53.33 \\
\hline
\end{tabular}


Table 3. Input data for estimated area of cells (drainage areas) for United States coalbed-gas assessment units, values in acres.

[AU, assessment unit]

\begin{tabular}{|c|c|c|c|c|c|c|c|}
\hline $\begin{array}{c}\text { AU } \\
\text { number }\end{array}$ & AU name & Province & $\begin{array}{c}\text { Year } \\
\text { assessed }\end{array}$ & $\begin{array}{c}\text { Minimum } \\
\text { cell } \\
\text { area }\end{array}$ & $\begin{array}{c}\text { Mode } \\
\text { of cell } \\
\text { area }\end{array}$ & $\begin{array}{c}\text { Maximum } \\
\text { cell } \\
\text { area } \\
\end{array}$ & $\begin{array}{c}\text { Mean } \\
\text { cell } \\
\text { area }\end{array}$ \\
\hline 50220181 & Fruitland Fairway Coalbed Gas & San Juan Basin & 2002 & 20 & 149.33 & 320 & 163.11 \\
\hline 50640481 & Desmoinesian-Virgilian Coalbed Gas & Illinois Basin & 2007 & 60 & 160 & 260 & 160.00 \\
\hline 50350281 & Mesaverde Coalbed Gas & Wind River Basin & 2005 & 40 & 120 & 280 & 146.67 \\
\hline 50350282 & Meeteetse Coalbed Gas & Wind River Basin & 2005 & 40 & 120 & 280 & 146.67 \\
\hline 50410182 & Vermejo Coalbed Gas & $\begin{array}{c}\text { Raton Basin- } \\
\text { Sierra Grande Uplift }\end{array}$ & 2004 & 80 & 120 & 240 & 146.67 \\
\hline 50010181 & Nanushuk Formation Coalbed Gas & Northern Alaska & 2006 & 40 & 100 & 280 & 140.00 \\
\hline 50210581 & Kaiparowits Plateau & Paradox Basin & 2011 & 40 & 67 & 280 & 129.00 \\
\hline 50200181 & Northern Coal Fairway/Drunkards Wash & Uinta-Piceance & 2000 & 40 & 66.67 & 280 & 128.89 \\
\hline 50200281 & Uinta Basin Blackhawk Coalbed Gas & Uinta-Piceance & 2000 & 40 & 66.67 & 280 & 128.89 \\
\hline 50340281 & Mesaverde-Meeteetse Formation Coalbed Gas & Big Horn Basin & 2008 & 40 & 100 & 240 & 126.67 \\
\hline 50200183 & Southern Coal Fairway & Uinta-Piceance & 2000 & 40 & 57.96 & 250 & 115.99 \\
\hline 50010182 & Prince Creek-Tuluvak Formations Coalbed Gas & Northern Alaska & 2006 & 40 & 100 & 200 & 113.33 \\
\hline 50010183 & Sagavanirktok Formation Coalbed Gas & Northern Alaska & 2006 & 40 & 100 & 200 & 113.33 \\
\hline 50340282 & Fort Union Formation Coalbed Gas & Big Horn Basin & 2008 & 40 & 100 & 200 & 113.33 \\
\hline 50200182 & Central Coal Fairway/Buzzards Bench & Uinta-Piceance & 2000 & 40 & 41.39 & 250 & 110.46 \\
\hline 50200185 & Southern Coal Outcrop & Uinta-Piceance & 2001 & 40 & 41.39 & 250 & 110.46 \\
\hline 50360281 & Frontier-Adaville-Evanston Coalbed Gas & Wyoming Thrust Belt & 2003 & 40 & 40 & 250 & 110.00 \\
\hline 50220182 & Basin Fruitland Coalbed Gas & San Juan Basin & 2002 & 20 & 61.82 & 240 & 107.27 \\
\hline 50311081 & Fort Union Coalbed Gas & Williston Basin & 2008 & 40 & 100 & 180 & 106.67 \\
\hline 50040381 & Eocene Coalbed Gas & $\begin{array}{l}\text { Western Oregon- } \\
\text { Washington }\end{array}$ & 2009 & 40 & 80 & 180 & 100.00 \\
\hline 50370981 & Wasatch-Green River Coalbed Gas & Southwestern Wyoming & 2002 & 40 & 68 & 140 & 82.67 \\
\hline 50650281 & Warrior Basin & Warrior Basin & 2002 & 30 & 40 & 120 & 63.33 \\
\hline 50670581 & Pocahontas Basin & Appalachian Basin & 2002 & 40 & 46.67 & 100 & 62.22 \\
\hline 50470381 & Wilcox Coalbed Gas & Gulf Coast Cenozoic & 2007 & 10 & 40 & 120 & 56.67 \\
\hline 50670582 & Eastern Dunkard Basin & Appalachian Basin & 2002 & 30 & 36.67 & 90 & 52.22 \\
\hline 50470281 & Cretaceous Olmos Coalbed Gas & Gulf Coast Cenozoic & 2007 & 10 & 40 & 80 & 43.33 \\
\hline 53000281 & Rio Escondido Basin Olmos Coalbed Gas & Burgos Basin & 2007 & 10 & 40 & 80 & 43.33 \\
\hline
\end{tabular}


Table 4. Input data for estimated area of cells (drainage areas) for United States tight-gas assessment units, values in acres.

[AU, assessment unit]

\begin{tabular}{|c|c|c|c|c|c|c|c|}
\hline $\begin{array}{c}\text { AU } \\
\text { number }\end{array}$ & AU name & Province & $\begin{array}{c}\text { Year } \\
\text { assessed }\end{array}$ & $\begin{array}{c}\text { Minimum } \\
\text { cell } \\
\text { area }\end{array}$ & $\begin{array}{l}\text { Mode } \\
\text { of cell } \\
\text { area }\end{array}$ & $\begin{array}{c}\text { Maximum } \\
\text { cell } \\
\text { area }\end{array}$ & $\begin{array}{c}\text { Mean } \\
\text { cell } \\
\text { area }\end{array}$ \\
\hline 50340263 & Cody Sandstone Continuous Gas & Big Horn Basin & 2008 & 40 & 160 & 640 & 280.00 \\
\hline 50280162 & Eagle Sandstone and Claggett Shale East & North-Central Montana & 2000 & 80 & 158.99 & 320 & 186.33 \\
\hline 50280163 & Eagle Sandstone and Claggett Shale West & North-Central Montana & 2000 & 80 & 158.99 & 320 & 186.33 \\
\hline 50280165 & Greenhorn-Lower Belle Fourche & North-Central Montana & 2000 & 80 & 158.99 & 320 & 186.33 \\
\hline 50370561 & Almond Continuous Gas & Southwestern Wyoming & 2002 & 40 & 40.58 & 449 & 176.53 \\
\hline 50200161 & Deep (6,000 feet plus) Coal and Sandstone Gas & Uinta-Piceance & 2000 & 60 & 123.08 & 320 & 167.69 \\
\hline 50330461 & Shallow Continuous Biogenic Gas & Powder River Basin & 2002 & 40 & 137.14 & 320 & 165.71 \\
\hline 50280161 & Judith River Formation & North-Central Montana & 2000 & 40 & 160 & 280 & 160.00 \\
\hline 50350261 & Frontier-Muddy Continuous Gas & Wind River Basin & 2005 & 40 & 120 & 300 & 153.33 \\
\hline 50620161 & Arkoma-Ouachita Foredeep Continuous & Arkoma Basin & 2010 & 40 & 100 & 320 & 153.33 \\
\hline 50370261 & Mowry Continuous Gas & Southwestern Wyoming & 2002 & 40 & 50.77 & 300 & 130.26 \\
\hline 50340261 & $\begin{array}{l}\text { Muddy-Frontier Sandstone and Mowry } \\
\text { Fractured Shale Continuous Gas }\end{array}$ & Big Horn Basin & 2008 & 40 & 50 & 300 & 130.00 \\
\hline 50050161 & Columbia Basin Continuous Gas & Eastern Oregon-Washington & 2006 & 40 & 120 & 200 & 120.00 \\
\hline 50700161 & Taylorsville Basin Continuous Gas & Atlantic Coastal Plain & 2011 & 40 & 80 & 240 & 120.00 \\
\hline 50700261 & Richmond Basin Continuous Gas & Atlantic Coastal Plain & 2011 & 40 & 80 & 240 & 120.00 \\
\hline 50700361 & South Newark Basin Continuous Gas & Atlantic Coastal Plain & 2011 & 40 & 80 & 240 & 120.00 \\
\hline 50700461 & Deep River Basin Continuous Gas & Atlantic Coastal Plain & 2011 & 40 & 80 & 240 & 120.00 \\
\hline 50701061 & Dan River-Danville Basin Continuous Gas & Atlantic Coastal Plain & 2011 & 40 & 80 & 240 & 120.00 \\
\hline 50200361 & Piceance Basin Continuous Gas & Uinta-Piceance & 2000 & 30 & 79.05 & 240 & 116.35 \\
\hline 50200362 & Uinta Basin Continuous Gas & Uinta-Piceance & 2000 & 30 & 79.05 & 240 & 116.35 \\
\hline 50280167 & Bowdoin Dome & North-Central Montana & 2000 & 40 & 121.67 & 160 & 107.22 \\
\hline 50370861 & Lance-Fort Union Continuous Gas & Southwestern Wyoming & 2002 & 20 & 40 & 200 & 86.67 \\
\hline 50200264 & Piceance Basin Transitional Gas & Uinta-Piceance & 2000 & 20 & 55 & 180 & 85.00 \\
\hline 50370461 & Hilliard-Baxter-Mancos Continuous Gas & Southwestern Wyoming & 2002 & 20 & 55 & 180 & 85.00 \\
\hline 50370562 & Rock Springs-Ericson Continuous Gas & Southwestern Wyoming & 2002 & 20 & 55 & 180 & 85.00 \\
\hline 50670364 & Tuscarora Basin Center & Appalachian Basin & 2002 & 40 & 53.33 & 160 & 84.44 \\
\hline 50340264 & Mesaverde Sandstone Continuous Gas & Big Horn Basin & 2008 & 20 & 50 & 180 & 83.33 \\
\hline 50350264 & Mesaverde-Meeteetse Sandstone Gas & Wind River Basin & 2005 & 20 & 50 & 180 & 83.33 \\
\hline 50350265 & Lance-Fort Union Sandstone Gas & Wind River Basin & 2005 & 20 & 60 & 160 & 80.00 \\
\hline 50200263 & Piceance Basin Continuous Gas & Uinta-Piceance & 2000 & 20 & 20.39 & 180 & 73.46 \\
\hline 50670465 & Catskill Sandstones and Siltstones & Appalachian Basin & 2002 & 10 & 41.54 & 140 & 63.85 \\
\hline 50670361 & Clinton-Medina Basin Center & Appalachian Basin & 2002 & 10 & 12 & 110 & 44.00 \\
\hline 50670362 & Clinton-Medina Transitional Northeast & Appalachian Basin & 2002 & 10 & 12 & 110 & 44.00 \\
\hline 50670363 & Clinton-Medina Transitional & Appalachian Basin & 2002 & 10 & 12 & 110 & 44.00 \\
\hline 50670466 & Berea Sandstone & Appalachian Basin & 2002 & 10 & 34.29 & 80 & 41.43 \\
\hline
\end{tabular}


Table 5. Input data for estimated area of cells (drainage areas) for United States continuous-oil assessment units, values in acres.

[AU, assessment unit]

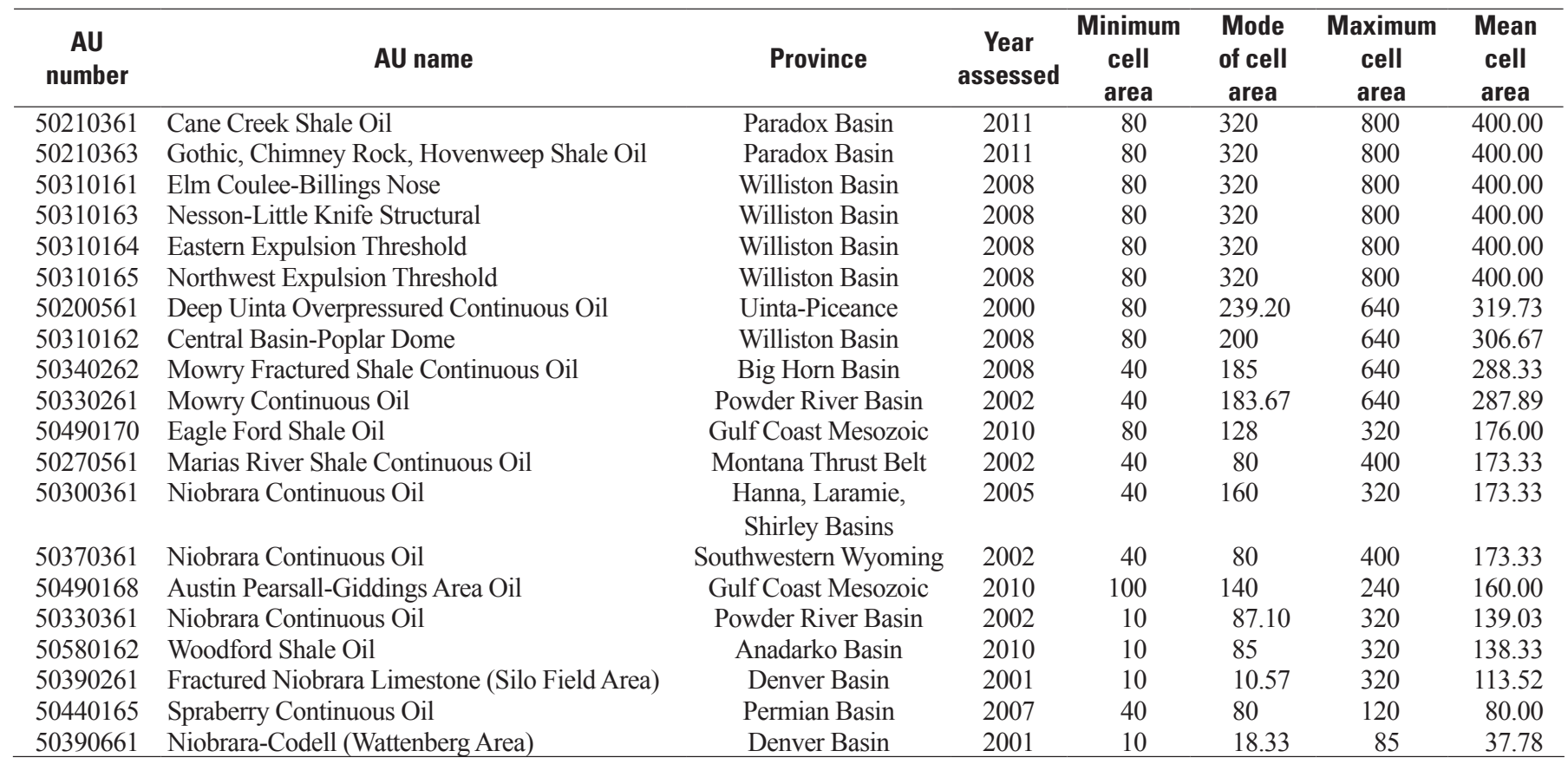


Table 6. Input data for estimated percent of untested area in sweet spots for United States shale-gas assessment units.

[AU, assessment unit; \%, percent]

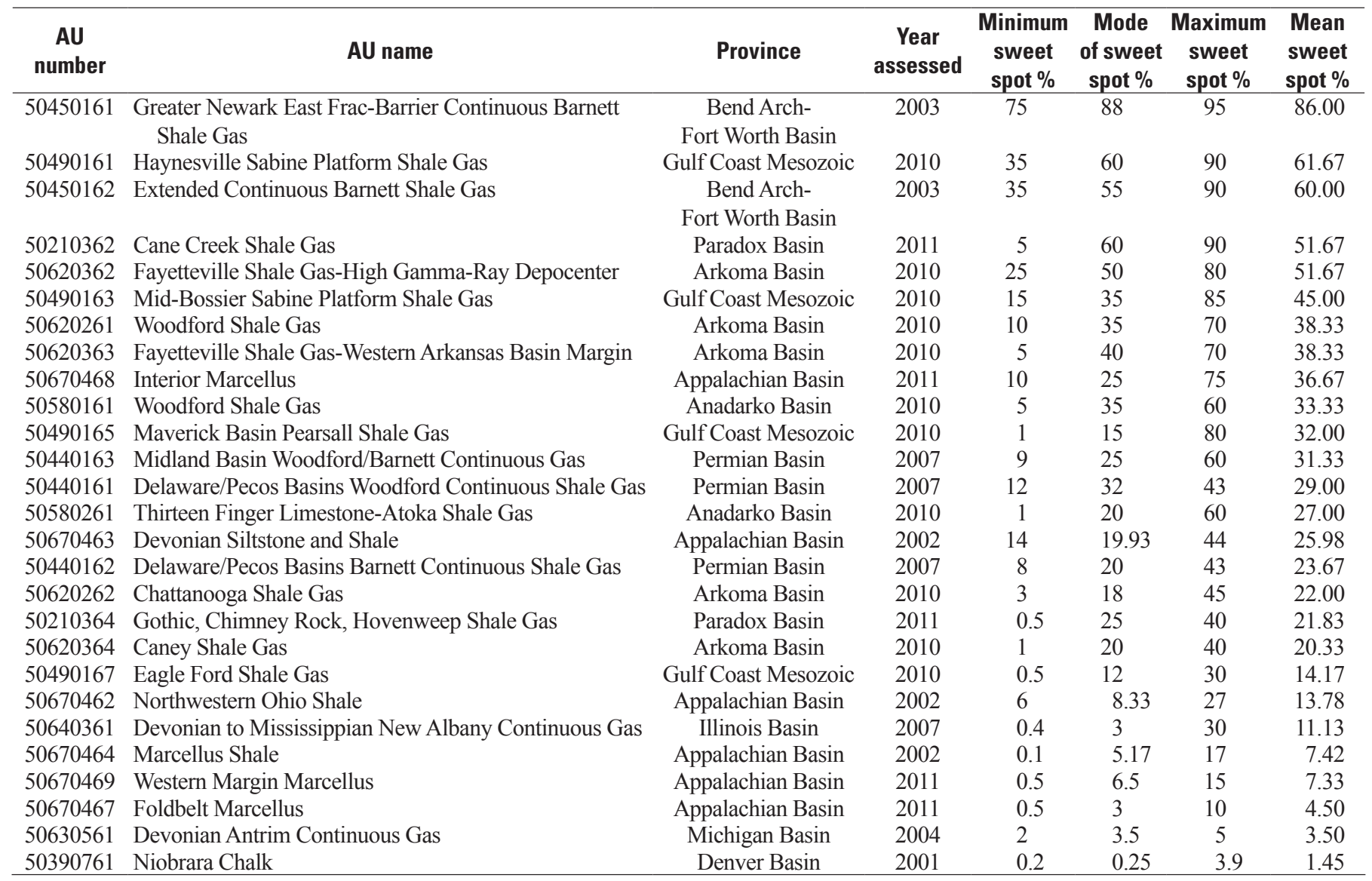


Table 7. Input data for estimated percent of untested area in sweet spots for United States coalbed-gas assessment units.

[AU, assessment unit; \%, percent]

\begin{tabular}{|c|c|c|c|c|c|c|c|}
\hline $\begin{array}{c}\text { AU } \\
\text { number }\end{array}$ & AU name & Province & $\begin{array}{c}\text { Year } \\
\text { assessed }\end{array}$ & $\begin{array}{c}\text { Minimum } \\
\text { sweet } \\
\text { spot } \%\end{array}$ & $\begin{array}{c}\text { Mode } \\
\text { of sweet } \\
\text { spot } \%\end{array}$ & $\begin{array}{c}\text { Maximum } \\
\text { sweet } \\
\text { spot } \%\end{array}$ & $\begin{array}{l}\text { Mean } \\
\text { sweet } \\
\text { spot \% }\end{array}$ \\
\hline 50220181 & Fruitland Fairway Coalbed Gas & San Juan Basin & 2002 & 93 & 95 & 97 & 95.00 \\
\hline 50200181 & Northern Coal Fairway/Drunkards Wash & Uinta-Piceance & 2000 & 10 & 68.70 & 79 & 52.57 \\
\hline 50670581 & Pocahontas Basin & Appalachian Basin & 2002 & 35 & 42 & 60 & 45.67 \\
\hline 50200182 & Central Coal Fairway/Buzzards Bench & Uinta-Piceance & 2000 & 5 & 48.56 & 55 & 36.19 \\
\hline 50330182 & Upper Fort Union Formation & Powder River Basin & 2000 & 10 & 31.96 & 58 & 33.32 \\
\hline 50200183 & Southern Coal Fairway & Uinta-Piceance & 2000 & 1 & 48.18 & 50 & 33.06 \\
\hline 50410182 & Vermejo Coalbed Gas & $\begin{array}{c}\text { Raton Basin- } \\
\text { Sierra Grande Uplift }\end{array}$ & 2004 & 10 & 25 & 50 & 28.33 \\
\hline 50650281 & Warrior Basin & Warrior Basin & 2002 & 9.2 & 30.66 & 39.4 & 26.42 \\
\hline 50030281 & Cook Inlet Coalbed Gas & Southern Alaska & 2011 & 0.5 & 6 & 63 & 23.17 \\
\hline 50010181 & Nanushuk Formation Coalbed Gas & Northern Alaska & 2006 & 0.5 & 7.5 & 38 & 15.33 \\
\hline 50010183 & Sagavanirktok Formation Coalbed Gas & Northern Alaska & 2006 & 0.3 & 8 & 35 & 14.43 \\
\hline 50330181 & Wasatch Formation & Powder River Basin & 2000 & 1 & 13.52 & 24 & 12.84 \\
\hline 53000281 & Rio Escondido Basin Olmos Coalbed Gas & Burgos Basin & 2007 & 1 & 11 & 25 & 12.33 \\
\hline 50350281 & Mesaverde Coalbed Gas & Wind River Basin & 2005 & 1 & 7 & 27 & 11.67 \\
\hline 50370882 & Fort Union Coalbed Gas & Southwestern Wyoming & 2002 & 3 & 8.24 & 20 & 10.41 \\
\hline 50370581 & Mesaverde Coalbed Gas & Southwestern Wyoming & 2002 & 1 & 9.47 & 20 & 10.16 \\
\hline 50370681 & Mesaverde Coalbed Gas & Southwestern Wyoming & 2002 & 1 & 9.47 & 20 & 10.16 \\
\hline 50220381 & Menefee Coalbed Gas & San Juan Basin & 2002 & 1 & 2.08 & 27 & 10.03 \\
\hline 50470281 & Cretaceous Olmos Coalbed Gas & Gulf Coast Cenozoic & 2007 & 1 & 8 & 20 & 9.67 \\
\hline 50040381 & Eocene Coalbed Gas & $\begin{array}{l}\text { Western Oregon- } \\
\text { Washington }\end{array}$ & 2009 & 1 & 3.10 & 22 & 8.70 \\
\hline 50200282 & Mesaverde Group Coalbed Gas & Uinta-Piceance & 2000 & 1 & 1.54 & 14 & 5.51 \\
\hline 50350283 & Fort Union Coalbed Gas & Wind River Basin & 2005 & 0.5 & 3 & 13 & 5.50 \\
\hline 50370682 & Fort Union Coalbed Gas & Southwestern Wyoming & 2002 & 1 & 2 & 10 & 4.33 \\
\hline 50330183 & Lower Fort Union-Lance Formations & Powder River Basin & 2000 & 0.002 & 1.00 & 9 & 3.33 \\
\hline 50370881 & Lance Coalbed Gas & Southwestern Wyoming & 2002 & 1 & 1.67 & 7 & 3.22 \\
\hline 50311081 & Fort Union Coalbed Gas & Williston Basin & 2008 & 0.01 & 2 & 7 & 3.00 \\
\hline 50340282 & Fort Union Formation Coalbed Gas & Big Horn Basin & 2008 & 0.1 & 1 & 3 & 1.37 \\
\hline
\end{tabular}


Table 8. Input data for estimated percent of untested area in sweet spots for United States tight-gas assessment units.

[AU, assessment unit; \%, percent]

\begin{tabular}{|c|c|c|c|c|c|c|c|}
\hline $\begin{array}{c}\text { AU } \\
\text { number }\end{array}$ & AU name & Province & $\begin{array}{c}\text { Year } \\
\text { assessed }\end{array}$ & $\begin{array}{c}\text { Minimum } \\
\text { sweet } \\
\text { spot } \% \\
\end{array}$ & $\begin{array}{c}\text { Mode } \\
\text { of sweet } \\
\text { spot } \%\end{array}$ & $\begin{array}{c}\text { Maximum } \\
\text { sweet } \\
\text { spot } \% \\
\end{array}$ & $\begin{array}{c}\text { Mean } \\
\text { sweet } \\
\text { spot } \% \\
\end{array}$ \\
\hline 50220362 & Mancos Sandstones Continuous Gas & San Juan Basin & 2002 & 35 & 66.25 & 75 & 58.75 \\
\hline 50670363 & Clinton-Medina Transitional & Appalachian Basin & 2002 & 40 & 50.84 & 77 & 55.95 \\
\hline 50670461 & Greater Big Sandy & Appalachian Basin & 2002 & 14 & 61.35 & 85 & 53.45 \\
\hline 50370561 & Almond Continuous Gas & Southwestern Wyoming & 2002 & 35 & 47.90 & 76 & 52.97 \\
\hline 50370761 & Lewis Continuous Gas & Southwestern Wyoming & 2002 & 18 & 40.41 & 69 & 42.47 \\
\hline 50030161 & Tuxedni-Naknek Continuous Gas & Southern Alaska & 2011 & 0.5 & 24 & 95 & 39.83 \\
\hline 50220161 & Pictured Cliffs Continuous Gas & San Juan Basin & 2002 & 14 & 46.06 & 47 & 35.69 \\
\hline 50700261 & Richmond Basin Continuous Gas & Atlantic Coastal Plain & 2011 & 7.5 & 21 & 76 & 34.83 \\
\hline 50700361 & South Newark Basin Continuous Gas & Atlantic Coastal Plain & 2011 & 1 & 21 & 81 & 34.33 \\
\hline 50220261 & Lewis Continuous Gas & San Juan Basin & 2002 & 23 & 37.24 & 40 & 33.41 \\
\hline 50700161 & Taylorsville Basin Continuous Gas & Atlantic Coastal Plain & 2011 & 6 & 19 & 60 & 28.33 \\
\hline 50200363 & Uinta-Piceance Transitional and Migrated Gas & Uinta-Piceance & 2000 & 20 & 29.14 & 34 & 27.71 \\
\hline 50370661 & Mesaverde-Lance-Fort Union Continuous Gas & Southwestern Wyoming & 2002 & 14 & 16.55 & 45 & 25.18 \\
\hline 50370861 & Lance-Fort Union Continuous Gas & Southwestern Wyoming & 2002 & 5 & 27.86 & 40 & 24.29 \\
\hline 50620161 & Arkoma-Ouachita Foredeep Continuous & Arkoma Basin & 2010 & 2 & 20 & 50 & 24.00 \\
\hline 50050161 & Columbia Basin Continuous Gas & Eastern Oregon-Washington & 2006 & 5 & 20 & 40 & 21.67 \\
\hline 50220361 & Mesaverde Central-Basin Continuous Gas & San Juan Basin & 2002 & 15 & 23.91 & 26 & 21.64 \\
\hline 50670466 & Berea Sandstone & Appalachian Basin & 2002 & 3 & 5.15 & 55 & 21.05 \\
\hline 50200262 & Uinta Basin Transitional Gas & Uinta-Piceance & 2000 & 12 & 13.08 & 38 & 21.03 \\
\hline 50200263 & Piceance Basin Continuous Gas & Uinta-Piceance & 2000 & 8 & 18.33 & 35 & 20.44 \\
\hline 50280167 & Bowdoin Dome & North-Central Montana & 2000 & 8 & 20 & 32 & 20.00 \\
\hline 50200361 & Piceance Basin Continuous Gas & Uinta-Piceance & 2000 & 4 & 6.29 & 49 & 19.76 \\
\hline 50670362 & Clinton-Medina Transitional Northeast & Appalachian Basin & 2002 & 2 & 4.63 & 50 & 18.88 \\
\hline 50340263 & Cody Sandstone Continuous Gas & Big Horn Basin & 2008 & 0.3 & 3 & 19.6 & 7.63 \\
\hline 50280161 & Judith River Formation & North-Central Montana & 2000 & 0.1 & 0.30 & 20 & 6.80 \\
\hline 50350265 & Lance-Fort Union Sandstone Gas & Wind River Basin & 2005 & 2 & 4 & 12 & 6.00 \\
\hline 50280163 & Eagle Sandstone and Claggett Shale West & North-Central Montana & 2000 & 0.8 & 2.51 & 13 & 5.44 \\
\hline 50330461 & Shallow Continuous Biogenic Gas & Powder River Basin & 2002 & 1 & 2.72 & 12.5 & 5.41 \\
\hline 50350261 & Frontier-Muddy Continuous Gas & Wind River Basin & 2005 & 0.7 & 1.6 & 9 & 3.77 \\
\hline 50340264 & Mesaverde Sandstone Continuous Gas & Big Horn Basin & 2008 & 0.2 & 2.1 & 8.5 & 3.60 \\
\hline 50350262 & Cody Sandstones Continuous Gas & Wind River Basin & 2005 & 0.8 & 1.4 & 8 & 3.40 \\
\hline 50350264 & Mesaverde-Meeteetse Sandstone Gas & Wind River Basin & 2005 & 0.5 & 1.5 & 7 & 3.00 \\
\hline 50280162 & Eagle Sandstone and Claggett Shale East & North-Central Montana & 2000 & 0.1 & 1.33 & 5 & 2.14 \\
\hline 50280166 & Greenhorn-Upper Belle Fourche & North-Central Montana & 2000 & 0.1 & 0.16 & 3.1 & 1.12 \\
\hline 50670364 & Tuscarora Basin Center & Appalachian Basin & 2002 & 0.1 & 0.29 & 2.6 & 1.00 \\
\hline 50280165 & Greenhorn-Lower Belle Fourche & North-Central Montana & 2000 & 0.1 & 0.14 & 2.1 & 0.78 \\
\hline 50280164 & Niobrara-Carlile & North-Central Montana & 2000 & 0.01 & 0.04 & 1 & 0.35 \\
\hline
\end{tabular}


Table 9. Input data for estimated percent of untested area in sweet spots for United States continuous-oil assessment units.

[AU, assessment unit; \%, percent]

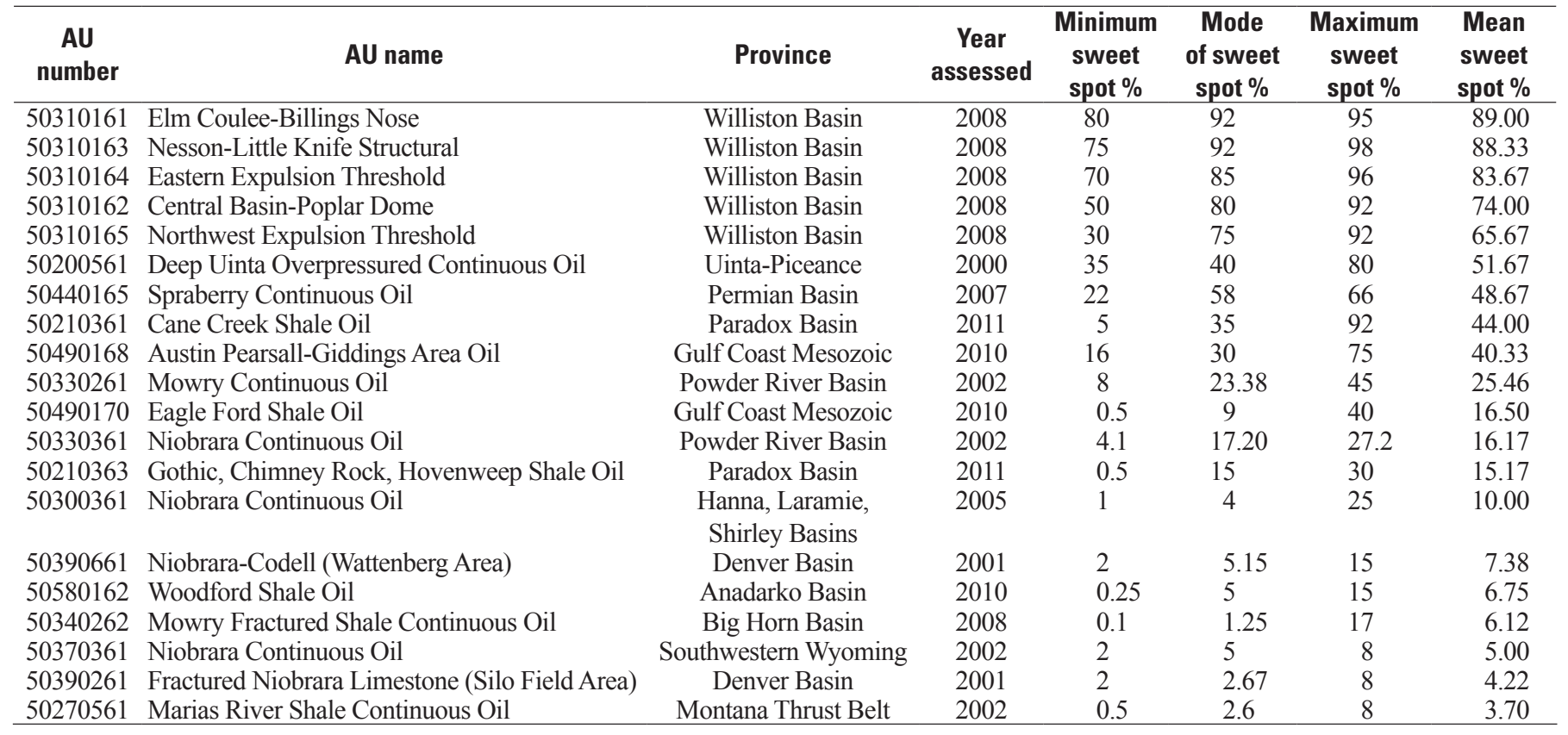

Table 10. Input data for estimated ultimate recovery distributions for United States shale-gas assessment units, values in billions of cubic feet of natural gas.

[AU, assessment unit; EUR, estimated ultimate recovery]

\begin{tabular}{|c|c|c|c|c|c|c|c|}
\hline $\begin{array}{c}\mathrm{AU} \\
\text { number }\end{array}$ & AU name & Province & $\begin{array}{c}\text { Year } \\
\text { assessed }\end{array}$ & $\begin{array}{l}\text { Minimum } \\
\text { EUR }\end{array}$ & $\begin{array}{l}\text { Median } \\
\text { EUR }\end{array}$ & $\begin{array}{l}\text { Maximum } \\
\text { EUR }\end{array}$ & $\begin{array}{l}\text { Mean } \\
\text { EUR }\end{array}$ \\
\hline 50490163 & Mid-Bossier Sabine Platform Shale Gas & Gulf Coast Mesozoic & 2010 & 0.02 & 1 & 10 & 1.308 \\
\hline 50670468 & Interior Marcellus & Appalachian Basin & 2011 & 0.02 & 0.8 & 12 & 1.158 \\
\hline 50490167 & Eagle Ford Shale Gas & Gulf Coast Mesozoic & 2010 & 0.02 & 0.8 & 10 & 1.104 \\
\hline 50620362 & $\begin{array}{l}\text { Fayetteville Shale Gas-High Gamma- } \\
\text { Ray Depocenter }\end{array}$ & Arkoma Basin & 2010 & 0.02 & 0.8 & 10 & 1.104 \\
\hline 50440161 & Delaware/Pecos Basins Woodford Continuous Shale Gas & Permian Basin & 2007 & 0.02 & 0.6 & 8 & 0.842 \\
\hline 50440162 & Delaware/Pecos Basins Barnett Continuous Shale Gas & Permian Basin & 2007 & 0.02 & 0.6 & 8 & 0.842 \\
\hline 50580261 & Thirteen Finger Limestone-Atoka Shale Gas & Anadarko Basin & 2010 & 0.02 & 0.5 & 10 & 0.785 \\
\hline 50620261 & Woodford Shale Gas & Arkoma Basin & 2010 & 0.02 & 0.5 & 10 & 0.785 \\
\hline 50210364 & Gothic, Chimney Rock, Hovenweep Shale Gas & Paradox Basin & 2011 & 0.02 & 0.4 & 10 & 0.672 \\
\hline 50450162 & Extended Continuous Barnett Shale Gas & $\begin{array}{l}\text { Bend Arch- } \\
\text { Fort Worth Basin }\end{array}$ & 2003 & 0.02 & 0.2 & 5 & 0.334 \\
\hline 50390761 & Niobrara Chalk & Denver Basin & 2001 & 0.025 & 0.2 & 2 & 0.261 \\
\hline 50620262 & Chattanooga Shale Gas & Arkoma Basin & 2010 & 0.02 & 0.1 & 6 & 0.223 \\
\hline 50670467 & Foldbelt Marcellus & Appalachian Basin & 2011 & 0.02 & 0.1 & 5 & 0.208 \\
\hline 50620364 & Caney Shale Gas & Arkoma Basin & 2010 & 0.02 & 0.08 & 5 & 0.179 \\
\hline 50670469 & Western Margin Marcellus & Appalachian Basin & 2011 & 0.02 & 0.05 & 5 & 0.129 \\
\hline 50640361 & Devonian to Mississippian New Albany Continuous Gas & Illinois Basin & 2007 & 0.01 & 0.08 & 1 & 0.110 \\
\hline 50670462 & Northwestern Ohio Shale & Appalachian Basin & 2002 & 0.01 & 0.04 & 0.5 & 0.055 \\
\hline 50670463 & Devonian Siltstone and Shale & Appalachian Basin & 2002 & 0.01 & 0.03 & 0.5 & 0.044 \\
\hline 50670464 & Marcellus Shale & Appalachian Basin & 2002 & 0.01 & 0.03 & 0.5 & 0.044 \\
\hline
\end{tabular}


Table 11. Input data for estimated ultimate recovery distributions for United States coalbed-gas assessment units, values in billions of cubic feet of natural gas.

[AU, assessment unit; EUR, estimated ultimate recovery]

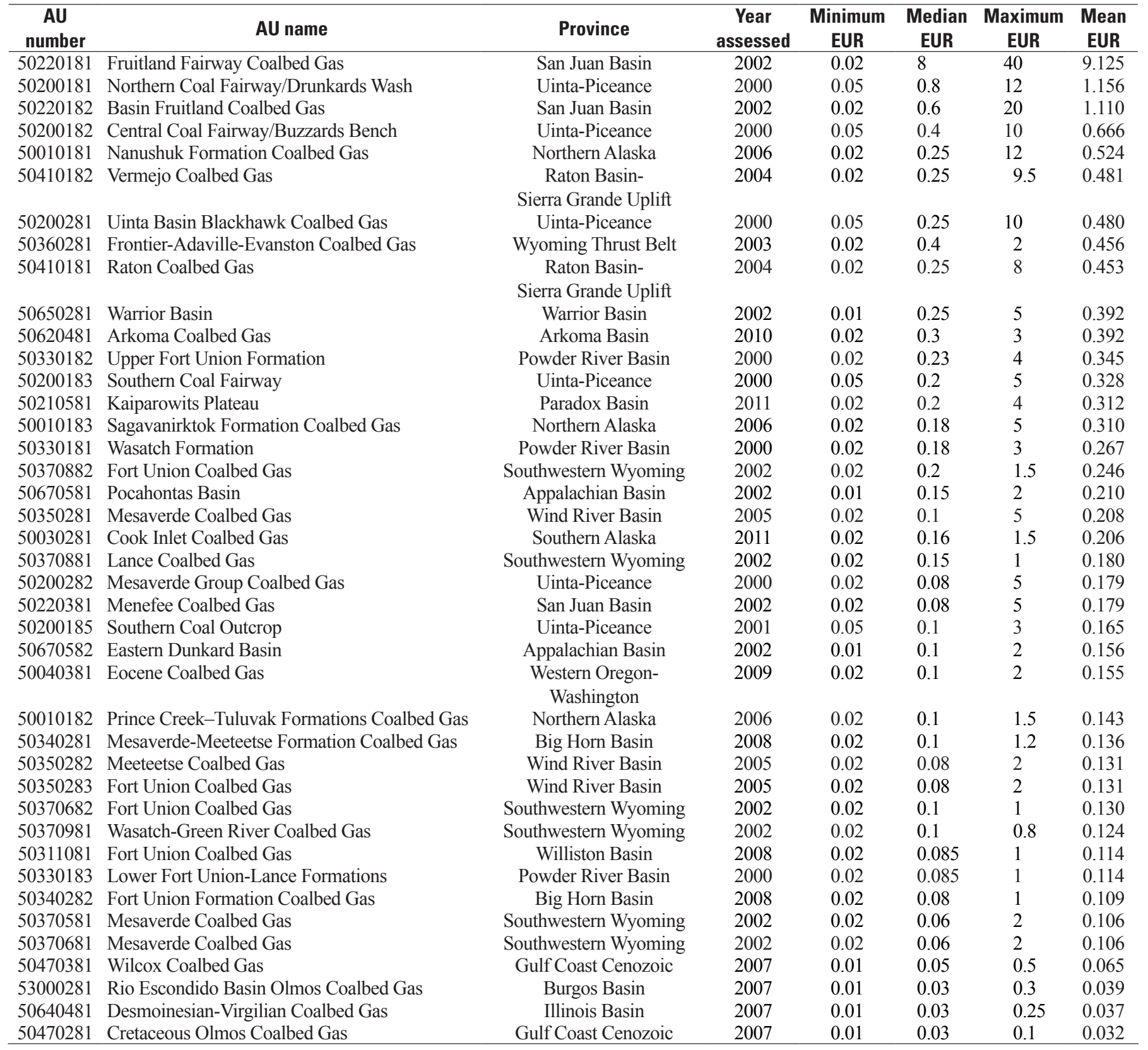


Table 12. Input data for estimated ultimate recovery distributions for United States tight-gas assessment units, values in billions of cubic feet of natural gas.

[AU, assessment unit; EUR, estimated ultimate recovery]

\begin{tabular}{|c|c|c|c|c|c|c|c|}
\hline $\begin{array}{c}\text { AU } \\
\text { number }\end{array}$ & AU name & Province & $\begin{array}{c}\text { Year } \\
\text { assessed }\end{array}$ & $\begin{array}{c}\text { Minimum } \\
\text { EUR }\end{array}$ & $\begin{array}{c}\text { Median } \\
\text { EUR }\end{array}$ & $\begin{array}{l}\text { Maximum } \\
\text { EUR }\end{array}$ & $\begin{array}{c}\text { Mean } \\
\text { EUR }\end{array}$ \\
\hline 50370561 & Almond Continuous Gas & Southwestern Wyoming & 2002 & 0.02 & 0.9 & 20 & 1.460 \\
\hline 50030161 & Tuxedni-Naknek Continuous Gas & Southern Alaska & 2011 & 0.02 & 0.6 & 30 & 1.286 \\
\hline 50620161 & Arkoma-Ouachita Foredeep Continuous & Arkoma Basin & 2010 & 0.02 & 0.6 & 30 & 1.286 \\
\hline 50350261 & Frontier-Muddy Continuous Gas & Wind River Basin & 2005 & 0.02 & 0.7 & 15 & 1.123 \\
\hline 50370861 & Lance-Fort Union Continuous Gas & Southwestern Wyoming & 2002 & 0.02 & 0.8 & 10 & 1.104 \\
\hline 50370761 & Lewis Continuous Gas & Southwestern Wyoming & 2002 & 0.02 & 0.6 & 15 & 1.009 \\
\hline 50200362 & Uinta Basin Continuous Gas & Uinta-Piceance & 2000 & 0.02 & 0.5 & 16 & 0.911 \\
\hline 50200263 & Piceance Basin Continuous Gas & Uinta-Piceance & 2000 & 0.02 & 0.5 & 15 & 0.892 \\
\hline 50350264 & Mesaverde-Meeteetse Sandstone Gas & Wind River Basin & 2005 & 0.02 & 0.5 & 15 & 0.892 \\
\hline 50350262 & Cody Sandstones Continuous Gas & Wind River Basin & 2005 & 0.02 & 0.4 & 20 & 0.855 \\
\hline 50370461 & Hilliard-Baxter-Mancos Continuous Gas & Southwestern Wyoming & 2002 & 0.02 & 0.4 & 8 & 0.627 \\
\hline 50700261 & Richmond Basin Continuous Gas & Atlantic Coastal Plain & 2011 & 0.02 & 0.4 & 8 & 0.627 \\
\hline 50700461 & Deep River Basin Continuous Gas & Atlantic Coastal Plain & 2011 & 0.02 & 0.4 & 8 & 0.627 \\
\hline 50200161 & Deep (6,000 feet plus) Coal and Sandstone Gas & Uinta-Piceance & 2000 & 0.2 & 0.5 & 4 & 0.617 \\
\hline 50200262 & Uinta Basin Transitional Gas & Uinta-Piceance & 2000 & 0.02 & 0.25 & 15 & 0.570 \\
\hline 50340261 & $\begin{array}{l}\text { Muddy-Frontier Sandstone and Mowry } \\
\text { Fractured Shale Continuous Gas }\end{array}$ & Big Horn Basin & 2008 & 0.02 & 0.35 & 7.5 & 0.560 \\
\hline 50220362 & Mancos Sandstones Continuous Gas & San Juan Basin & 2002 & 0.02 & 0.35 & 5 & 0.499 \\
\hline 50370562 & Rock Springs-Ericson Continuous Gas & Southwestern Wyoming & 2002 & 0.02 & 0.4 & 3 & 0.491 \\
\hline 50200361 & Piceance Basin Continuous Gas & Uinta-Piceance & 2000 & 0.02 & 0.25 & 10 & 0.490 \\
\hline 50280163 & Eagle Sandstone and Claggett Shale West & North-Central Montana & 2000 & 0.01 & 0.25 & 9 & 0.475 \\
\hline 50220161 & Pictured Cliffs Continuous Gas & San Juan Basin & 2002 & 0.02 & 0.25 & 7 & 0.434 \\
\hline 50280165 & Greenhorn-Lower Belle Fourche & North-Central Montana & 2000 & 0.01 & 0.25 & 2.5 & 0.327 \\
\hline 50050161 & Columbia Basin Continuous Gas & $\begin{array}{l}\text { Eastern Oregon- } \\
\text { Washington }\end{array}$ & 2006 & 0.02 & 0.2 & 3 & 0.288 \\
\hline 50390662 & Dakota Group Basin-Center Gas & Denver Basin & 2001 & 0.02 & 0.2 & 2.5 & 0.275 \\
\hline 50670461 & Greater Big Sandy & Appalachian Basin & 2002 & 0.01 & 0.15 & 2 & 0.210 \\
\hline 50701061 & Dan River-Danville Basin Continuous Gas & Atlantic Coastal Plain & 2011 & 0.02 & 0.1 & 2.5 & 0.165 \\
\hline 50330461 & Shallow Continuous Biogenic Gas & Powder River Basin & 2002 & 0.01 & 0.08 & 1.5 & 0.122 \\
\hline 50670361 & Clinton-Medina Basin Center & Appalachian Basin & 2002 & 0.01 & 0.08 & 1.2 & 0.115 \\
\hline 50670465 & Catskill Sandstones and Siltstones & Appalachian Basin & 2002 & 0.01 & 0.07 & 1.5 & 0.111 \\
\hline 50280161 & Judith River Formation & North-Central Montana & 2000 & 0.01 & 0.06 & 2 & 0.109 \\
\hline 50280164 & Niobrara-Carlile & North-Central Montana & 2000 & 0.01 & 0.07 & 1 & 0.099 \\
\hline 50670363 & Clinton-Medina Transitional & Appalachian Basin & 2002 & 0.01 & 0.06 & 1 & 0.089 \\
\hline 50670362 & Clinton-Medina Transitional Northeast & Appalachian Basin & 2002 & 0.01 & 0.06 & 0.9 & 0.086 \\
\hline 50670466 & Berea Sandstone & Appalachian Basin & 2002 & 0.01 & 0.03 & 0.5 & 0.044 \\
\hline
\end{tabular}


Table 13. Input data for estimated ultimate recovery distributions for United States continuous-oil assessment units, values in millions of barrels of oil.

[AU, assessment unit; EUR, estimated ultimate recovery]

\begin{tabular}{|c|c|c|c|c|c|c|c|}
\hline $\begin{array}{c}\text { AU } \\
\text { number }\end{array}$ & $\begin{array}{c}\mathrm{AU} \\
\text { name }\end{array}$ & Province & $\begin{array}{c}\text { Year } \\
\text { assessed }\end{array}$ & $\begin{array}{c}\text { Minimum } \\
\text { EUR }\end{array}$ & $\begin{array}{c}\text { Median } \\
\text { EUR }\end{array}$ & $\begin{array}{l}\text { Maximum } \\
\text { EUR }\end{array}$ & $\begin{array}{c}\text { Mean } \\
\text { EUR }\end{array}$ \\
\hline 50310163 & Nesson-Little Knife Structural & Williston Basin & 2008 & 0.002 & 0.09 & 4 & 0.185 \\
\hline 50310165 & Northwest Expulsion Threshold & Williston Basin & 2008 & 0.002 & 0.065 & 4 & 0.151 \\
\hline 50310161 & Elm Coulee-Billings Nose & Williston Basin & 2008 & 0.002 & 0.08 & 2 & 0.135 \\
\hline 50270561 & Marias River Shale Continuous Oil & $\begin{array}{l}\text { Montana } \\
\text { Thrust Belt }\end{array}$ & 2002 & 0.001 & 0.08 & 1.6 & 0.126 \\
\hline 50300361 & Niobrara Continuous Oil & $\begin{array}{c}\text { Hanna, Laramie, } \\
\text { Shirley Basins }\end{array}$ & 2005 & 0.001 & 0.04 & 1.6 & 0.079 \\
\hline 50310162 & Central Basin-Poplar Dome & Williston Basin & 2008 & 0.002 & 0.025 & 2 & 0.064 \\
\hline 50210363 & Gothic, Chimney Rock, Hovenweep Shale Oil & Paradox Basin & 2011 & 0.002 & 0.03 & 1.5 & 0.064 \\
\hline 50580162 & Woodford Shale Oil & Anadarko Basin & 2010 & 0.003 & 0.03 & 1.5 & 0.064 \\
\hline 50490168 & Austin Pearsall-Giddings Area Oil & $\begin{array}{l}\text { Gulf Coast } \\
\text { Mesozoic }\end{array}$ & 2010 & 0.002 & 0.04 & 0.5 & 0.055 \\
\hline 50330361 & Niobrara Continuous Oil & $\begin{array}{c}\text { Powder River } \\
\text { Basin }\end{array}$ & 2002 & 0.002 & 0.028 & 0.5 & 0.042 \\
\hline 50330261 & Mowry Continuous Oil & $\begin{array}{c}\text { Powder River } \\
\text { Basin }\end{array}$ & 2002 & 0.002 & 0.025 & 0.35 & 0.035 \\
\hline 50340262 & Mowry Fractured Shale Continuous Oil & Big Horn Basin & 2008 & 0.002 & 0.025 & 0.35 & 0.035 \\
\hline 50390261 & Fractured Niobrara Limestone (Silo Field Area) & Denver Basin & 2001 & 0.002 & 0.022 & 0.4 & 0.033 \\
\hline 50390661 & Niobrara-Codell (Wattenberg Area) & Denver Basin & 2001 & 0.003 & 0.008 & 0.1 & 0.011 \\
\hline
\end{tabular}




\section{References Cited}

Charpentier, R.R., and Cook, T.A., 2010, Improved USGS methodology for assessing continuous petroleum resources: U.S. Geological Survey Data Series 547, 22 p. and program, http://pubs.usgs.gov/ds/547/.

Crovelli, R.A., 2000, Analytical resource assessment method for continuous (unconventional) oil and gas accumulationsThe "ACCESS" Method: U.S. Geological Survey Open-File Report 00-044, 34 p., http://pubs.er.usgs.gov/publication/ ofr0044.

Crovelli, R.A., 2012, Analytical resource assessment method for continuous (unconventional) oil and gas accumulationsThe "ACCESS" Method: U.S. Geological Survey Open-File Report 2012-1146, 32 p., http://pubs.usgs.gov/of/2012/1146. [Revised by Charpentier, R.R.]

Klett, T.R., and Charpentier, R.R., 2003, FORSPAN model users guide: U.S. Geological Survey Open-File Report 03-354, 37 p., http://pubs.usgs.gov/of/2003/ofr-03-354/.
Klett, T.R., and Schmoker, J.W., 2003, U.S. Geological Survey input-data form and operational procedure for the assessment of continuous petroleum accumulations, chap. 18 of USGS Uinta-Piceance Assessment Team, Petroleum systems and geologic assessment of oil and gas in the Uinta-Piceance Province, Utah and Colorado: U.S. Geological Survey Digital Data Series DDS-69-B, 8 p., http://pubs.usgs.gov/dds/dds-069/ dds-069-b/REPORTS/Chapter_18.pdf.

Schmoker, J.W., 2003, U.S. Geological Survey assessment concepts for continuous petroleum accumulations, chap. 17 of USGS Uinta-Piceance Assessment Team, Petroleum systems and geologic assessment of oil and gas in the Uinta-Piceance Province, Utah and Colorado: U.S. Geological Survey Digital Data Series DDS-69-B, 7 p., http://pubs.usgs.gov/dds/ dds-069/dds-069-b/REPORTS/Chapter_17.pdf.

U.S. Geological Survey Oil and Gas Assessment Team, 2012, Variability of distributions of well-scale estimated ultimate recovery for continuous (unconventional) oil and gas resources in the United States: U.S. Geological Survey Open-File Report 2012-1118, 18 p., http://pubs.usgs.gov/of/2012/1118/. 


\section{Appendix 1. Publications Presenting Results of Assessments Used in this Report}

\section{CD-ROMs}

Higley, D.K., compiler, 2007, Petroleum systems and assessment of undiscovered oil and gas in the Raton Basin-Sierra Grande Uplift Province, Colorado and New Mexico-USGS Province 41: U.S. Geological Survey Digital Data Series DDS-69-N, 141 p.,1 CD-ROM, http://pubs.usgs.gov/dds/ dds-069/dds-069-n/.

Higley, D.K., compiler, 2007, Petroleum systems and assessment of undiscovered oil and gas in the Denver Basin Province, Colorado, Kansas, Nebraska, South Dakota, and WyomingUSGS Province 39: U.S. Geological Survey Digital Data Series DDS-69-P., 1 CD-ROM, http://pubs.usgs.gov/dds/ dds-069/dds-069-p/.

Roberts, S.B., compiler, 2008, Geologic assessment of undiscovered, technically recoverable coalbed-gas resources in Cretaceous and Tertiary rocks, North Slope and adjacent State waters, Alaska: U.S. Geological Survey Digital Data Series DDS-69-S, 4 chapters, 1 CD-ROM, http://pubs.usgs.gov/ dds/dds-069/dds-069-s/.

U.S. Geological Survey Bighorn Basin Assessment Team, 2010, Petroleum systems and geologic assessment of oil and gas in the Bighorn Basin Province, Wyoming and Montana: U.S. Geological Survey Digital Data Series DDS-69-V, 8 chapters, pages variable, 1 CD-ROM, http://pubs.usgs.gov/ dds/dds-069/dds-069-v/.

U.S. Geological Survey Black Warrior Basin Province Assessment Team, 2007, Geologic assessment of undiscovered oil and gas resources of the Black Warrior Basin Province, Alabama and Mississippi: U.S. Geological Survey Digital Data Series DDS-69-I, 5 chapters, 76 pages, 1 CD-ROM, http://pubs.usgs.gov/dds/dds-069/dds-069-i/.

U.S. Geological Survey Eastern Oregon and Washington Province Assessment Team, 2008, Geologic assessment of undiscovered gas resources of the Eastern Oregon and Washington Province: U.S. Geological Survey Digital Data Series DDS-69-O, 5 chapters, 1 CD-ROM, http://pubs.usgs.gov/ dds/dds-069/dds-069-o/.

U.S. Geological Survey Hanna, Laramie, and Shirley Basins Province Assessment Team, 2007, Petroleum systems and geologic assessment of undiscovered oil and gas, Hanna, Laramie, and Shirley Basins Province, Wyoming and Colorado: U.S. Geological Survey Digital Data Series DDS-69-K, 1 CD-ROM, http://pubs.usgs.gov/dds/dds-069/ dds-069-k/.
U.S. Geological Survey Powder River Basin Assessment Team., 2009, Total petroleum systems and geologic assessment of oil and gas resources in the Powder River Basin Province, Wyoming and Montana: U.S. Geological Survey Digital Data Series DDS-69-U, 3 chapters, 1 CD-ROM, http://pubs.usgs.gov/dds/dds-069/dds-069-u/. [Revised April 2010]

U.S. Geological Survey Powder River Basin Province Assessment Team, 2004, Total petroleum system and assessment of coalbed gas in the Powder River Basin Province, Wyoming and Montana: U.S. Geological Survey Digital Data Series DDS-69-C, 1 CD-ROM, http://pubs.usgs.gov/dds/ dds-069/dds-069-c/.

U.S. Geological Survey San Juan Basin Assessment Team, 2013, Total petroleum systems and geologic assessment of undiscovered oil and gas resources in the San Juan Basin Province, exclusive of Paleozoic rocks, New Mexico and Colorado: U.S. Geological Survey Digital Data Series 69-F, 7 chapters, variously paged, 1 CD-ROM, http://pubs.usgs.gov/dds/ dds-069/dds-069-f/.

U.S. Geological Survey Southwestern Wyoming Province Assessment Team, 2005, Petroleum systems and geologic assessment of oil and gas in the Southwestern Wyoming Province, Wyoming, Colorado and Utah: U.S. Geological Survey Digital Data Series DDS-69-D, 1 CD-ROM, http://pubs.usgs.gov/dds/dds-069/dds-069-d/.

U.S. Geological Survey Uinta-Piceance Assessment Team, compilers, 2003, Petroleum systems and geologic assessment of oil and gas in the Uinta-Piceance Province, Utah and Colorado: U.S. Geological Survey Digital Data Series DDS-69-B, 1 CD-ROM, http://pubs.usgs.gov/dds/dds-069/ dds-069-b/.

U.S. Geological Survey Western Gulf Province Assessment Team, 2006, Petroleum systems and geologic assessment of undiscovered oil and gas, Navarro and Taylor Groups, Western Gulf Province, Texas: U.S. Geological Survey Digital Data Series DDS-69-H, 4 chapters, 1 CD-ROM, http://pubs.usgs.gov/dds/dds-069/dds-069-h/.

U.S. Geological Survey Western Oregon and Washington Province Assessment Team, 2011, Geologic assessment of undiscovered hydrocarbon resources of the Western Oregon and Washington Province: U.S. Geological Survey Digital Data Series DDS-69-X, 4 chapters 1 CD-ROM, http://pubs.usgs.gov/dds/dds-069/dds-069-x/. 
U.S. Geological Survey Williston Basin Province Assessment Team, 2011, Assessment of undiscovered oil and gas resources of the Williston Basin Province of North Dakota, Montana, and South Dakota, 2010: U.S. Geological Survey Digital Data Series DDS-69-W, 7 chapters, 1 CD-ROM, http://pubs.usgs.gov/dds/dds-069/dds-069-w/.

U.S. Geological Survey Wind River Basin Province Assessment Team, 2007, Petroleum systems and geologic assessment of oil and gas in the Wind River Basin Province, Wyoming: U.S. Geological Survey Digital Data Series DDS-69-J, 1 CD-ROM, http://pubs.usgs.gov/dds/dds-069/ dds-069-j/.

\section{Fact Sheets}

Anna, L.O., Charpentier, R.R., Cook, T.A., Klett, T.R., Pollastro, R.M., and Schenk, C.J., 2006, Assessment of undiscovered oil and gas resources of the Powder River Basin Province of Wyoming and Montana-2006 update: U.S. Geological Survey Fact Sheet 2006-3135, 2 p., http://pubs.usgs.gov/fs/2006/3135/.

Anna, L.O., Pollastro, R.M., Gaswirth, S.B., Lewan, M.D., Lillis, P.G., Roberts, L.N.R., Schenk, C.J., Charpentier, R.R., Cook, T.A., and Klett, T.R., 2008, Assessment of undiscovered oil and gas resources of the Williston Basin Province of North Dakota, Montana, and South Dakota, 2008: U.S. Geological Survey Fact Sheet 2008-3092, 2 p., http://pubs.usgs.gov/fs/2008/3092/.

Brownfield, M.E., Charpentier, R.R., Cook, T.A., Klett, T.R., Pollastro, R.M., and Schenk, C.J., 2009, Assessment of undiscovered hydrocarbon resources of the Western Oregon and Washington Province: U.S. Geological Survey Fact Sheet 2009-3060, 2 p., http://pubs.usgs.gov/fs/2009/3060/.

Brownfield, M.E., Tennyson, M.E., Ahlbrandt, T.S., Charpentier, R.R., Cook, T.A., Klett, T.R., Pollastro, R.M., and Schenk, C.J., 2006, Assessment of undiscovered gas resources of the Eastern Oregon and Washington Province, 2006: U.S. Geological Survey Fact Sheet 2006-3091, 2 p., http://pubs.usgs.gov/fs/2006/3091/.

Coleman, J.L., Milici, R.C., Cook, T.A., Charpentier, R.R., Kirschbaum, Mark, Klett, T.R., Pollastro, R.M., and Schenk, C.J., 2011, Assessment of undiscovered oil and gas resources of the Devonian Marcellus Shale of the Appalachian Basin Province, 2011: U.S. Geological Survey Fact Sheet 2011-3092, 2 p., http://pubs.usgs.gov/fs/2011/3092/.

Coleman, J.L., Swezey, C.S., Ryder, R.T., Charpentier, R.R., Milici, R.C., Hatch, J.R., Cook, T.A., Klett, T.R., Pollastro, R.M., Schenk, C.J., and Schmoker, J.W., 2006, Undiscovered oil and gas resources underlying the U.S. portions of the Great Lakes, 2005: U.S. Geological Survey Fact Sheet 2006-3049, 4 p., http://pubs.usgs.gov/fs/2006/3049/.
Dubiel, R.F., Pitman, J.K., Pearson, O.N., Pearson, Krystal, Kinney, S.A., Lewan, M.D., Burke, Lauri, Biewick, L.R.H., Charpentier, R.R., Cook, T.A., Klett, T.R., Pollastro, R.M., and Schenk, C.J., 2012, Assessment of undiscovered oil and gas resources in conventional and continuous petroleum systems in the Upper Cretaceous Eagle Ford Group, U.S. Gulf Coast Region, 2011: U.S. Geological Survey Fact Sheet 2012-3003, 2 p., http://pubs.usgs.gov/fs/2012/3003/.

Dubiel, R.F., Pitman, J.K., Pearson, O.N., Warwick, P.D., Karlsen, A.W., Coleman, J.L., Hackley, P.C., Hayba, D.O., Swanson, S.M., Charpentier, R.R., Cook, T.A., Klett, T.R., Pollastro, R.M., and Schenk, C.J., 2007, Assessment of undiscovered oil and gas resources in Tertiary strata of the Gulf Coast, 2007: U.S. Geological Survey Fact Sheet 2007-3066, 4 p., http://pubs.usgs.gov/fs/2007/3066/.

Dubiel, R.F., Warwick, P.D., Swanson, Sharon, Burke, Lauri, Biewick, L.R.H., Charpentier, R.R., Coleman, J.L., Cook, T.A., Dennen, Kris, Doolan, Colin, Enomoto, Catherine, Hackley, P.C., Karlsen, A.W., Klett, T.R., Kinney, S.A., Lewan, M.D., Merrill, Matt, Pearson, Krystal, Pearson, O.N., Pitman, J.K., Pollastro, R.M., Rowan, E.L., Schenk, C.J., and Valentine, Brett, 2011, Assessment of undiscovered oil and gas resources in Jurassic and Cretaceous strata of the Gulf Coast, 2010: U.S. Geological Survey Fact Sheet 2011-3020, 4 p., http://pubs.usgs.gov/fs/2011/3020/.

Dyman, T.S., Condon, S.M., Ahlbrandt, T.S., Charpentier, R.R., Cook, T.A., Klett, T.R., Lewan, M.D., Lillis, P.G., Pawlewicz, M.J., Pollastro, R.M., and Schenk, C.J., 2006, 2005 assessment of undiscovered oil and gas resources in Hanna, Laramie, Shirley Basins Province, Wyoming: U.S. Geological Survey Fact Sheet 2005-3125, 2 p., http://pubs.usgs.gov/fs/2005/3125/.

Flores, R.M., Anna, L.O., Dolton, G.L., Fox, J.E., French, C.D., Charpentier, R.R., Cook, T.A., Crovelli, R.A., Klett, T.R., Pollastro, R.M., and Schenk, C.J., 2002, Assessment of undiscovered oil and gas resources of the Powder River Basin Province of Wyoming and Montana, 2002: U.S. Geological Survey Fact Sheet 146-02, 2 p, http://pubs.usgs.gov/ fs/fs-146-02/.

Hatch, J.R., Pawlewicz, M.J., Charpentier, R.R., Cook, T.A., Crovelli, R.A., Klett, T.R., Pollastro, R.M., and Schenk, C.J., 2003, Assessment of undiscovered oil and gas resources of the Black Warrior Basin Province, 2002: U.S. Geological Survey Fact Sheet 038-03, 2 p., http://pubs.usgs.gov/fs/ fs-038-03/.

Higley, Debra, Charpentier, R.R., Cook, Troy, Klett, T.R., Pollastro, Richard, Schmoker, J.W., and Schenk, C.J., 2003, 2002 USGS assessment of oil and gas resource potential of the Denver Basin Province of Colorado, Kansas, Nebraska, South Dakota, and Wyoming: U.S. Geological Survey Fact Sheet 002-03, 4 p., http://pubs.usgs.gov/fs/fs-002-03/. 
Higley, D.K., Cook, T.A., Pollastro, R.M., Charpentier, R.R., Klett, T.R., and Schenk, C.J., 2005, Assessment of undiscovered oil and gas resources of the Raton Basin-Sierra Grande Uplift Province of New Mexico and Colorado, 2004: U.S. Geological Survey Fact Sheet 2005-3027, 2 p., http://pubs.usgs.gov/fs/2005/3027/.

Higley, D.K., Gaswirth, S.B., Abbott, M.M., Charpentier, R.R., Cook, T.A., Ellis, G.S., Gianoutsos, N.J., Hatch, J.R., Klett, T.R., Nelson, Philip, Pawlewicz, M.J., Pearson, O.N., Pollastro, R.M., and Schenk, C.J., 2011, Assessment of undiscovered oil and gas resources of the Anadarko Basin Province of Oklahoma, Kansas, Texas, and Colorado, 2010: U.S. Geological Survey Fact Sheet 2011-3003, 2 p., http://pubs.usgs.gov/fs/2011/3003/.

Houseknecht, D.W., Coleman, J.L., Milici, R.C., Garrity, C.P., Rouse, W.A., Fulk, B.R., Paxton, S.T., Abbott, M.M., Mars, J.C., Cook, T.A., Schenk, C.J., Charpentier, R.R., Klett, T.R., Pollastro, R.M., and Ellis, G.S., 2010, Assessment of undiscovered natural gas resources of the Arkoma Basin Province and geologically related areas: U.S. Geological Survey Fact Sheet 2010-3043, 4 p., http://pubs.usgs.gov/ fs/2010/3043/.

Kirschbaum, M.A., Anna, Larry, Collett, T.S., Cook, Troy, Dubiel, R.F., Finn, T.M., Hettinger, R.D., Henry, Mitchell, Johnson, E.A., Johnson, R.C., Lillis, P.G., Nelson, P.H., Nuccio, V.F., Rice, C.A., Roberts, L.N.R., and Roberts, S.B., 2002, Assessment of undiscovered oil and gas resources of the Uinta-Piceance Province of Colorado and Utah, 2002: U.S. Geological Survey Fact Sheet 026-02, 2 p., http://pubs.usgs.gov/fs/fs-0026-02/.

Kirschbaum, M.A., Anna, Larry, Collett, T.S., Cook, Troy, Dubiel, R.F., Finn, T.M., Hettinger, R.D., Henry, Mitchell, Johnson, E.A., Johnson, R.C., Lillis, P.G., Nelson, P.H., Nuccio, V.F., Rice, C.A., Roberts, L.N.R., and Roberts, S.B., 2003, Assessment of undiscovered oil and gas resources of the Uinta-Piceance Province of Colorado and Utah, 2002: U.S. Geological Survey Fact Sheet 157-02, 2 p., http://pubs.usgs.gov/fs/fs-157-02/.

Kirschbaum, M.A., Charpentier, R.R., Crovelli, R.A., Klett, T.R., Pollastro, R.M., and Schenk, C.J., 2004, Assessment of undiscovered oil and gas resources of the Wyoming Thrust Belt Province, 2003: U.S. Geological Survey Fact Sheet 2004-3025, 2 p., http://pubs.usgs.gov/fs/2004/3025/.

Kirschbaum, M.A., Condon, S.M., Finn, T.M., Johnson, R.C., Lillis, P.G., Nelson, P.H., Roberts, L.N.R., Roberts, S.B., Charpentier, R.R., Cook, Troy, Klett, T.R., Pollastro, R.M., and Schenk, C.J., 2008, Assessment of undiscovered oil and gas resources of the Bighorn Basin Province, Wyoming and Montana, 2008: U.S. Geological Survey Fact Sheet 2008-3050, 2 p., http://pubs.usgs.gov/fs/2008/3050/.
Kirschbaum, Mark, Finn, T.M., Hettinger, R.D., Johnson, E.A., Johnson, R.C., Kibler, Joyce, Lillis, P.G., Nelson, P.H., Roberts, L.N.R., Roberts, S.B., Charpentier, R.R., Cook, T.A., Crovelli, R.A., Klett, T.R., Pollastro, R.M., and Schenk, C.J., 2002, Assessment of undiscovered oil and gas resources of the Southwestern Wyoming Province, 2002: U.S. Geological Survey Fact Sheet 145-02, 2 p., http://pubs.usgs.gov/fs/fs-145-02/.

Kirschbaum, M.A., Finn, T.M., Johnson, R.C., Kibler, Joyce, Lillis, P.G., Nelson, P.H., Roberts, L.N.R., Roberts, S.B., Charpentier, R.R., Cook, Troy, Klett, T.R., Pollastro, R.M., and Schenk, C.J., 2005, Assessment of undiscovered oil and gas resources of the Wind River Basin Province, 2005: U.S. Geological Survey Fact Sheet 2005-3141, 2 p., http://pubs.usgs.gov/fs/2005/3141/.

Milici, R.C., Coleman, J.L., Rowan, E.L., Cook, T.A., Charpentier, R.R., Kirschbaum, M.A., Klett, T.R., Pollastro, R.M., and Schenk, C.J., 2012, Assessment of undiscovered oil and gas resources of the East Coast Mesozoic basins of the Piedmont, Blue Ridge Thrust Belt, Atlantic Coastal Plain, and New England Provinces, 2011: U.S. Geological Survey Fact Sheet 2012-3075, 2 p., http://pubs.usgs.gov/ fs/2012/3075/.

Milici, R.C., and Hatch, J.R., 2004, Assessment of undiscovered Carboniferous coal-bed gas resources of the Appalachian Basin and Black Warrior Basin Provinces, 2002: U.S. Geological Survey Fact Sheet 2004-3092, 2 p., http://pubs.usgs.gov/fs/2004/3092/.

Milici, R.C., Ryder, R.T., Swezey, C.S., Charpentier, R.R., Cook, T.A., Crovelli, R.A., Klett, T.R., Pollastro, R.M., and Schenk, C.J., 2003, Assessment of undiscovered oil and gas resources of the Appalachian Basin Province, 2002: U.S. Geological Survey Fact Sheet 009-03, 2 p., http://pubs.usgs.gov/fs/fs-009-03/.

Pearson, Krystal, Dubiel, R.F., Pearson, O.N., Pitman, J.K., Charpentier, R.R., Cook, T.A., Klett, T.R., Pollastro, R.M., and Schenk, C.J., 2011, Assessment of undiscovered oil and gas resources of the Upper Cretaceous Austin Chalk and Tokio and Eutaw Formations, Gulf Coast, 2010: U.S. Geological Survey Fact Sheet 2011-3046, 2 p., http://pubs.usgs.gov/ fs/2011/3046/.

Pollastro, R.M., Cook, T.A., Roberts, L.N.R., Schenk, C.J., Lewan, M.D., Anna, L.O., Gaswirth, S.B., Lillis, P.G., Klett, T.R., and Charpentier, R.R., 2008, Assessment of undiscovered oil resources in the Devonian-Mississippian Bakken Formation, Williston Basin Province, Montana and North Dakota, 2008: U.S. Geological Survey Fact Sheet 2008-3021, 2 p., http://pubs.usgs.gov/fs/2008/3021/. 
Pollastro, R.M., Hill, R.J., Ahlbrandt, T.A., Charpentier, R.R., Cook, T.A., Klett, T.R., Henry, M.E., and Schenk, C.J., 2004, Assessment of undiscovered oil and gas resources of the Bend Arch-Fort Worth Basin Province of north-central Texas and southwestern Oklahoma, 2003: U.S. Geological Survey Fact Sheet 2004-3022, 2 p., http://pubs.usgs.gov/ fs/2004/3022/.

Ridgley, J.L., Anna, L.O., Condon, S.M., Fishman, N.S., Hester, T.C., Lillis, P.G., Rowan, E.L., Charpentier, R.R., Cook, T.A., Crovelli, R.A., Klett, T.R., and Schenk, C.J., 2008, Assessment of undiscovered biogenic gas resources, North-Central Montana Province: U.S. Geological Survey Fact Sheet 2008-3036, 2 p., http://pubs.usgs.gov/ fs $/ 2008 / 3036 /$.

Ridgley, J.L., Condon, S.M., Dubiel, R.F., Charpentier, R.R., Cook, T.A., Crovelli, R.A., Klett, T.R., Pollastro, R.M., and Schenk, C.J., 2002, Assessment of undiscovered oil and gas resources of the San Juan Basin Province of New Mexico and Colorado, 2002: U.S. Geological Survey Fact Sheet 147-02, 2 p., http://pubs.usgs.gov/fs/fs-147-02/.

Roberts, Steve, Barker, C.E., Bird, K.J., Charpentier, R.R., Cook, Troy, Houseknecht, D.W., Klett, T.R., Pollastro, R.M., and Schenk, C.J., 2006, Assessment of coalbed gas resources in Cretaceous and Tertiary rocks on the North Slope, Alaska, 2006: U.S. Geological Survey Fact Sheet 2006-3105, 2 p., http://pubs.usgs.gov/fs/2006/3105/.

Schenk, C.J., Charpentier, R.R., Cook, T.A., Dyman, T.S., French, C.D., Henry, M.E., Klett, T.R., Perry, W.J., Pollastro, R.M., and Potter, C.J., 2002, Assessment of undiscovered oil and gas resources of the Montana Thrust Belt Province, 2002: U.S. Geological Survey Fact Sheet 148-02, 2 p., http://pubs.usgs.gov/fs/fs-148-02/.

Schenk, C.J., Pollastro, R.M., Cook, T.A., Pawlewicz, M.J., Klett, T.R., Charpentier, R.R., and Cook, H.E., 2008, Assessment of undiscovered oil and gas resources of the Permian Basin Province of west Texas and southeast New Mexico, 2007: U.S. Geological Survey Fact Sheet 20073115, 4 p., http://pubs.usgs.gov/fs/2007/3115/.
Stanley, R.G., Ahlbrandt, T.S., Charpentier, R.R., Cook, T.A., Crews, J.M., Klett, T.R.; Lillis, P.G., Morin, R.L., Phillips, J.D., Pollastro, R.M., Rowan, E.L., Saltus, R.W., Schenk, C.J., Simpson, M.K., Till, A.B., and Troutman, S.M., 2004, Oil and gas assessment of Yukon Flats, east-central Alaska, 2004: U.S. Geological Survey Fact Sheet 2004-3121, 2 p., http://pubs.usgs.gov/fs/2004/3121/.

Stanley, R.G., Charpentier, R.R., Cook, T.A., Houseknecht, D.W., Klett, T.R., Lewis, K.A., Lillis, P.G., Nelson, P.H., Phillips, J.D., Pollastro, R.M., Potter, C.J., Rouse, W.A., Saltus, R.W., Schenk, C.J., Shah, A.K., and Valin, Z.C., 2011, Assessment of undiscovered oil and gas resources of the Cook Inlet region, south-central Alaska, 2011: U.S. Geological Survey Fact Sheet 2011-3068, 2 p., http://pubs.usgs.gov/fs/2011/3068/.

Swezey, C.S., Hatch, J.R., Brennan, S.T., East, J.A., Rowan, E.L., Repetski, J.E., Charpentier, R.R., Cook, T.A., Klett, T.R., Pollastro, R.M., and Schenk, C.J., 2007, Assessment of undiscovered oil and gas resources of the Illinois Basin, 2007: U.S. Geological Survey Fact Sheet 2007-3058, 2 p., http://pubs.usgs.gov/fs/2007/3058/.

Swezey, C.S., Hatch, J.R., Hayba, D.O., Repetski, J.E., Charpentier, R.R., Cook, T.A., Klett, T.R., Pollastro, R.M., and Schenk, C.J., 2005, Assessment of undiscovered oil and gas resources of the U.S. portion of the Michigan Basin, 2004: U.S. Geological Survey Fact Sheet 2005-3070, 2 p., http://pubs.usgs.gov/fs/2005/3070/.

Warwick, P.D., Charpentier, R.R., Cook, T.A., Klett, T.R., Pollastro, R.M., and Schenk, C.J., 2007, Assessment of undiscovered oil and gas resources in Cretaceous-Tertiary coal beds of the Gulf Coast Region, 2007: U.S. Geological Survey Fact Sheet 2007-3039, 2 p., http://pubs.usgs.gov/ fs/2007/3039/.

Whidden, K.J., Anna, L.O., Pearson, K.M., Lillis, P.G., Charpentier, R.R., Cook, T.A., Klett, T.R., Pollastro, R.M., Dubiel, R.F., and Schenk, C.J., 2012, Assessment of undiscovered oil and gas resources in the Paradox Basin Province, Utah, Colorado, New Mexico, and Arizona, 2011: U.S. Geological Survey Fact Sheet 2012-3031, 4 p., http://pubs.usgs.gov/fs/2012/3031/. 


\section{Appendix 2. Structure of the Files Presented in this Report}

The Main Input file contains input data from the FORSPAN Assessment Model for Continuous Accumulations: Basic Input Data Form used in this assessment. There are records for 186 Assessment Units (AUs), 139 of which were quantitatively assessed. In the Microsoft Excel version of this file, AUs that were not quantitatively assessed are colored purple; green cells mark major changes from previously published versions, as noted in the main text of this report. Blank cells represent no data. The Main Input file is designed to incorporate data from several versions of the input form. Many of the triangular distributions were originally described using a median as input. This later changed to a mode as input. For comparison across these differences, calculated values of the median, mode, and mean are given for many of the distributions. These calculated values would be either the variable value as entered on the input form (if given in that version) or a value calculated using the other parameters. This table contains 147 columns. Data columns are as follows:

1. AU Number: assessment unit code number.

2. AU: assessment unit name.

3. Version: version of assessment input form.

4. Reservoir Type: shale gas, coalbed gas, tight gas, or continuous oil.

5. Assessment Geologist: assessing geologist's name.

6. Date: date of assessment.

7. Region Number: region code number.

8. Region: region name.

9. Province Number: province code number.

10. Province: province name.

11. TPS Number: total petroleum system (TPS) code number.

12. TPS: total petroleum system name.

13. Based on Data 1: data sources used to aid in completing the data-input form.

14. Based on Data 2: data sources used to aid in completing the data-input form.

15. Notes from Assessor 1: additional explanatory notes. Two references cited in this column are:

Jorjorian, Thomas, Liro, L.M., and Katz, B.J., 1989, Geochemical and well-log investigation of an actively generating source rock sequence-Waltman Shale, Wind River Basin, Wyoming [abs.]: American Association of Petroleum Geologists Bulletin, v. 73, no. 9, p. 1162.
Katz, B.J., and Liro, L.M., 1993, The Waltman Shale Member, Fort Union Formation, Wind River Basin-A Paleocene clastic lacustrine source system, in Keefer, W.R., Metzger, W.J., and Godwin, L.H., eds., Wyoming Geological Association Special Symposium on Oil and Gas and Other Resources of the Wind River Basin, Wyoming, 1993: Wyoming Geological Association, Casper, Wyoming, p. 163-174.

16. Notes from Assessor 2: additional explanatory notes.

17. AU Type: assessment unit type, the primary commodity type in the assessment unit, based on the gas-to-oil ratio (GOR) of the petroleum endowment, which includes both the discovered and undiscovered petroleum. An assessment unit is characterized as being oil prone if the GOR is less than 20,000 cubic feet of gas per barrel of oil; otherwise, it is gas prone.

18. Minimum Total Recovery: minimum total recovery per cell considered for assessment, in million barrels of oil (MMBO) for oil assessment units or billion cubic feet of gas (BCFG) for gas assessment units.

19. Number of Tested Cells: number of tested cells in the assessment unit.

20. Number of Tested Cells $>$ Minimum: number of tested cells in the assessment unit that have total recoveries equal to or larger than the specified minimum total recovery per cell.

21. Established: assessment unit maturity, the exploration maturity of the assessment unit. Assessment unit maturity is classified as "established" if more than 24 cells exceed the minimum total recovery.

22. Frontier: assessment unit maturity, the exploration maturity of the assessment unit. Assessment unit maturity is classified as "frontier" if 1 to 24 cells exceed the minimum total recovery.

23. Hypothetical: assessment-unit maturity, the exploration maturity of the assessment unit. Assessment-unit maturity is classified as "hypothetical" if no cells exceed the minimum total recovery.

24. Exploration Maturity: assessment-unit maturity from columns 21 to 23 .

25. Median of First Third: median total recovery per cell of the set of tested cells equal to or greater than the minimum total recovery that constitute the first third of the total number of cells ranked according to date of discovery within the assessment unit, in million barrels of oil (MMBO) for oil assessment units or billion cubic feet of gas (BCFG) for gas assessment units. 
26. Median of Second Third: median total recovery per cell of the set of tested cells equal to or greater than the minimum total recovery that constitute the second third of the total number of cells ranked according to date of discovery within the assessment unit, in million barrels of oil (MMBO) for oil assessment units or billion cubic feet of gas (BCFG) for gas assessment units.

27. Median of Third Third: median total recovery per cell of the set of tested cells equal to or greater than the minimum total recovery that constitute the third third of the total number of cells ranked according to date of discovery within the assessment unit, in million barrels of oil (MMBO) for oil assessment units or billion cubic feet of gas (BCFG) for gas assessment units.

28. Charge: charge probability, the probability for adequate petroleum charge for at least one untested cell equal to or larger than the minimum total recovery, somewhere in the assessment unit, having the potential to be added to reserves. Charge probability is given as a fractional value from 0 to 1.0 .

29. Rocks: rocks probability, the probability for adequate reservoirs, traps, and seals for at least one untested cell equal to or larger than the minimum total recovery, somewhere in the assessment unit, having the potential to be added to reserves. Rocks probability is given as a fractional value from 0 to 1.0 .

30. Timing: timing probability, the probability for favorable geologic timing for at least one untested cell equal to or larger than the minimum total recovery, somewhere in the assessment unit, having the potential to be added to reserves. Timing probability is given as a fractional value from 0 to 1.0 .

31. AU Probability: geologic probability, the product of charge, rocks, and timing probabilities. Geologic probability is given as a fractional value from 0 to 1.0 .

32. Access: accessibility probability, the probability for adequate location for necessary petroleum-related activities to discover at least one untested cell equal to or larger than the minimum total recovery, somewhere in the assessment unit, having the potential to be added to reserves. Accessibility probability is given as a fractional value from 0 to 1.0 .

33. AU Area-minimum: the estimated minimum (F100) area of the assessment unit. The area is given in acres.

34. AU Area-median: the estimated median (F50) area of the assessment unit, as written on the input form. The area is given in acres.

35. AU Area-calculated median: the estimated median (F50) area of the assessment unit, as calculated from the parameters on the input form. The area is given in acres.
36. AU Area-mode: the estimated mode (most likely value) of the area of the assessment unit, as written on the input form. The area is given in acres.

37. AU Area-calculated mode: the estimated mode (most likely value) of the area of the assessment unit, as calculated from the parameters on the input form. The area is given in acres.

38. AU Area-maximum: the estimated maximum (F0) area of the assessment unit. The area is given in acres.

39. AU Area-mean: the estimated mean area of the assessment unit, as written on the input form. The area is given in acres.

40. AU Area-calculated mean: the estimated mean area of the assessment unit, as calculated from the parameters on the input form. The area is given in acres.

41. Cell Area-minimum: minimum area per cell of untested cells with potential, the estimated minimum (F100) area per cell of untested cells having the potential for additions to reserves in the assessment unit. This area is equivalent to the drainage area of wells. This area is given in acres.

42. Cell Area-median: the estimated median (F50) area per cell of untested cells having the potential for additions to reserves in the assessment unit, as written on the input form. This area is equivalent to the drainage area of wells. This area is given in acres.

43. Cell Area-calculated median: the estimated median (F50) area per cell of untested cells having the potential for additions to reserves in the assessment unit, as calculated from the parameters on the input form. This area is equivalent to the drainage area of wells. This area is given in acres.

44. Cell Area-mode: the estimated mode (most likely value) of the area per cell of untested cells with potential for additions to reserves in the assessment unit, as written on the input form. This area is equivalent to the drainage area of wells. This area is given in acres.

45. Cell Area-calculated mode: the estimated mode (most likely value) of the area per cell of untested cells with potential for additions to reserves in the assessment unit, as calculated from the parameters on the input form. This area is equivalent to the drainage area of wells. This area is given in acres.

46. Cell Area-maximum: maximum area per cell of untested cells with potential; the estimated maximum (F0) area per cell of untested cells having the potential for additions to reserves in the assessment unit. This area is equivalent to the drainage area of wells. This area is given in acres.

47. Cell Area-mean: the estimated mean area per cell of untested cells having the potential for additions to reserves in the assessment unit, as written on the input form. This area is equivalent to the drainage area of wells. This area is given in acres. 
48. Cell Area-calculated mean: the estimated mean area per cell of untested cells having the potential for additions to reserves in the assessment unit, as calculated from the parameters on the input form. This area is equivalent to the drainage area of wells. This area is given in acres.

49. Cell Area-minimum of mean: the estimated minimum value of the distribution of uncertainty of the mean area per cell of untested cells having the potential for additions to reserves in the assessment unit. This area is equivalent to the drainage area of wells. This area is given in acres.

50. Cell Area-maximum of mean: the estimated maximum value of the distribution of uncertainty of the mean area per cell of untested cells having the potential for additions to reserves in the assessment unit. This area is equivalent to the drainage area of wells. This area is given in acres.

51. Untested \%-minimum: estimated minimum (F100) percentage of the total assessment-unit area that is untested.

52. Untested \%-median: estimated median (F50) percentage of the total assessment-unit area that is untested, as written on the input form.

53. Untested \%-calculated median: estimated median (F50) percentage of the total assessment-unit area that is untested, as calculated from the parameters on the input form.

54. Untested \%-mode: estimated mode (most likely value) of the percentage of the total assessment-unit area that is untested, as written on the input form.

55. Untested \%-calculated mode: estimated mode (most likely value) of the percentage of the total assessment-unit area that is untested, as calculated from the parameters on the input form.

56. Untested \%-maximum: estimated maximum (F0) percentage of the total assessment-unit area that is untested.

57. Untested \%-mean: estimated mean percentage of the total assessment-unit area that is untested, as written on the input form.

58. Untested \%-calculated mean: estimated mean percentage of the total assessment-unit area that is untested, as calculated from the parameters on the input form.

59. Sweet Spot \%-minimum: estimated minimum (F100) percentage of the untested area in the assessment unit having the potential for additions to reserves.

60. Sweet Spot \%-median: estimated median (F50) percentage of the untested area in the assessment unit having the potential for additions to reserves, as written on the input form.
61. Sweet Spot \%-calculated median: estimated median (F50) percentage of the untested area in the assessment unit having the potential for additions to reserves, as calculated from the parameters on the input form.

62. Sweet Spot \%-mode: estimated mode (most likely value) of the percentage of the untested area in the assessment unit having the potential for additions to reserves, as written on the input form.

63. Sweet Spot \%-calculated mode: estimated mode (most likely value) of the percentage of the untested area in the assessment unit having the potential for additions to reserves, as calculated from the parameters on the input form.

64. Sweet Spot \%-maximum: estimated maximum (F0) percentage of the untested area in the assessment unit having the potential for additions to reserves.

65. Sweet Spot \%-mean: estimated mean percentage of the untested area in the assessment unit having the potential for additions to reserves, as written on the input form.

66. Sweet Spot \%-calculated mean: estimated mean percentage of the untested area in the assessment unit having the potential for additions to reserves, as calculated from the parameters on the input form.

67. Geologic Evidence: geologic rationale for distribution estimated for sweet spot percent.

68. Total Recovery per Cell-minimum: estimated minimum (F100) total recovery per cell for untested cells in the assessment unit having the potential for additions to reserves. This volume is given as million barrels of oil (MMBO) for oil assessment units and billion cubic feet of gas (BCFG) for gas assessment units.

69. Total Recovery per Cell-median: estimated median (F50) total recovery per cell for untested cells in the assessment unit having the potential for additions to reserves. This volume is given as million barrels of oil (MMBO) for oil assessment units and billion cubic feet of gas (BCFG) for gas assessment units.

70. Total Recovery per Cell-maximum: estimated maximum (F0) total recovery per cell for untested cells in the assessment unit having the potential for additions to reserves. This volume is given as million barrels of oil (MMBO) for oil assessment units and billion cubic feet of gas (BCFG) for gas assessment units.

71. Total Recovery per Cell-mean: estimated mean total recovery per cell for untested cells in the assessment unit having the potential for additions to reserves. This volume is given as million barrels of oil (MMBO) for oil assessment units and billion cubic feet of gas (BCFG) for gas assessment units. 
72. GOR-minimum: estimated minimum (F100) gas to oil ratio (GOR), in cubic feet of gas per barrel of oil (CFG/BO), of untested cells equal to or larger than the minimum total recovery in oil assessment units.

73. GOR-median: estimated median (F50) gas to oil ratio (GOR), in cubic feet of gas per barrel of oil (CFG/BO), of untested cells equal to or larger than the minimum total recovery in oil assessment units, as written on the input form.

74. GOR-calculated median: estimated median (F50) gas to oil ratio (GOR), in cubic feet of gas per barrel of oil (CFG/BO), of untested cells equal to or larger than the minimum total recovery in oil assessment units, as calculated from the parameters on the input form.

75. GOR-mode: estimated mode (most likely value) of the gas to oil ratio (GOR), in cubic feet of gas per barrel of oil (CFG/BO), of untested cells equal to or larger than the minimum total recovery in oil assessment units, as written on the input form.

76. GOR-calculated mode: estimated mode (most likely value) of the gas to oil ratio (GOR), in cubic feet of gas per barrel of oil (CFG/BO), of untested cells equal to or larger than the minimum total recovery in oil assessment units, as calculated from the parameters on the input form.

77. GOR-maximum: estimated maximum (F0) gas to oil ratio (GOR), in cubic feet of gas per barrel of oil (CFG/BO), of untested cells equal to or larger than the minimum total recovery in oil assessment units.

78. NGLGR-minimum: estimated minimum (F100) natural gas liquids (NGL) to gas ratio (NGLGR), in barrels of natural gas liquids per million cubic feet of gas (BNGL/ $\mathrm{MMCFG}$ ), of untested cells equal to or larger than the minimum total recovery in oil assessment units.

79. NGLGR-median: estimated median (F50) natural gas liquids (NGL) to gas ratio (NGLGR), in barrels of natural gas liquids per million cubic feet of gas (BNGL/MMCFG), of untested cells equal to or larger than the minimum total recovery in oil assessment units, as written on the input form.

80. NGLGR-calculated median: estimated median (F50) natural gas liquids (NGL) to gas ratio (NGLGR), in barrels of natural gas liquids per million cubic feet of gas (BNGL/MMCFG), of untested cells equal to or larger than the minimum total recovery in oil assessment units, as calculated from the parameters on the input form.

81. NGLGR-mode: estimated mode (most likely value) of the natural gas liquids (NGL) to gas ratio (NGLGR), in barrels of natural gas liquids per million cubic feet of gas (BNGL/MMCFG), of untested cells equal to or larger than the minimum total recovery in oil assessment units, as written on the input form.
82. NGLGR-calculated mode: estimated mode (most likely value) of the natural gas liquids (NGL) to gas ratio (NGLGR), in barrels of natural gas liquids per million cubic feet of gas (BNGL/MMCFG), of untested cells equal to or larger than the minimum total recovery in oil assessment units, as calculated from the parameters on the input form.

83. NGLGR-maximum: estimated maximum (F0) natural gas liquids (NGL) to gas ratio (NGLGR), in barrels of natural gas liquids per million cubic feet of gas (BNGL/MMCFG), of untested cells equal to or larger than the minimum total recovery in oil assessment units.

84. LGR-minimum: estimated minimum (F100) liquids (oil plus natural gas liquids) to gas ratio (LGR), in barrels of liquids per million cubic feet of gas (BNGL/MMCFG), of untested cells equal to or larger than the minimum total recovery in gas assessment units.

85. LGR-median: estimated median (F50) liquids (oil plus natural gas liquids) to gas ratio (LGR), in barrels of liquids per million cubic feet of gas (BNGL/MMCFG), of untested cells equal to or larger than the minimum total recovery in gas assessment units, as written on the input form.

86. LGR-calculated median: estimated median (F50) liquids (oil plus natural gas liquids) to gas ratio (LGR), in barrels of liquids per million cubic feet of gas (BNGL/MMCFG), of untested cells equal to or larger than the minimum total recovery in gas assessment units, as calculated from the parameters on the input form.

87. LGR-mode: estimated mode (most likely value) of the liquids (oil plus natural gas liquids) to gas ratio (LGR), in barrels of liquids per million cubic feet of gas (BNGL/MMCFG), of untested cells equal to or larger than the minimum total recovery in gas assessment units, as written on the input form.

88. LGR-calculated mode: estimated mode (most likely value) of the liquids (oil plus natural gas liquids) to gas ratio (LGR), in barrels of liquids per million cubic feet of gas (BNGL/MMCFG), of untested cells equal to or larger than the minimum total recovery in gas assessment units, as calculated from the parameters on the input form.

89. LGR-maximum: estimated maximum (F0) liquids (oil plus natural gas liquids) to gas ratio (LGR), in barrels of liquids per million cubic feet of gas (BNGL/MMCFG), of untested cells equal to or larger than the minimum total recovery in gas assessment units.

90. API-minimum: estimated minimum (F100) API (American Petroleum Institute) gravity, in degrees, of oil in untested cells in oil assessment units.

91. API-median: estimated median (F50) API (American Petroleum Institute) gravity, in degrees, of oil in untested cells in oil assessment units. 
92. API-mode: estimated mode (most likely value) of the API (American Petroleum Institute) gravity, in degrees, of oil in untested cells in oil assessment units.

93. API-maximum: estimated maximum (F0) API (American Petroleum Institute) gravity, in degrees, of oil in untested cells in oil assessment units.

94. Sulfur \%-minimum: estimated minimum (F100) sulfur content, in percent, of oil in untested cells in oil assessment units.

95. Sulfur \%-median: estimated median (F50) sulfur content, in percent, of oil in untested cells in oil assessment units.

96. Sulfur \%-mode: estimated mode (most likely value) of the sulfur content, in percent, of oil in untested cells in oil assessment units.

97. Sulfur \%-maximum: estimated maximum (F0) sulfur content, in percent, of oil in untested cells in oil assessment units.

98. (Oil) Water Depth-minimum: estimated minimum (F100) water depth, in meters, of oil in untested cells in oil assessment units (ocean, bays, or lakes; if applicable).

99. (Oil) Water Depth-median: estimated median (F50) water depth, in meters, of oil in untested cells in oil assessment units (ocean, bays, or lakes; if applicable).

100. (Oil) Water Depth-mode: estimated mode (most likely value) of the water depth, in meters, of oil in untested cells in oil assessment units (ocean, bays, or lakes; if applicable).

101. (Oil) Water Depth-maximum: estimated maximum (F0) water depth, in meters, of oil in untested cells in oil assessment units (ocean, bays, or lakes; if applicable).

102. (Oil) Drilling Depth-minimum: estimated minimum (F100) drilling depth, in meters, of oil in untested cells in oil assessment units.

103. (Oil) Drilling Depth-F75: estimated F75 drilling depth, in meters, of oil in untested cells in oil assessment units. An estimated 75 percent of the wells will be deeper than this value.

104. (Oil) Drilling Depth-median: estimated median (F50) drilling depth, in meters, of oil in untested cells in oil assessment units.

105. (Oil) Drilling Depth-mode: estimated mode (most likely value) of the drilling depth, in meters, of oil in untested cells in oil assessment units.

106. (Oil) Drilling Depth-F25: estimated F25 drilling depth, in meters, of oil in untested cells in oil assessment units. An estimated 25 percent of the wells will be deeper than this value.
107. (Oil) Drilling Depth-maximum: estimated maximum (F0) drilling depth, in meters, of oil in untested cells in oil assessment units.

108. Inert Gas \%-minimum: estimated minimum (F100) inert gas content, in percent, of gas in untested cells in gas assessment units (nitrogen and helium, and so forth).

109. Inert Gas \%-median: estimated median (F50) inert gas content, in percent, of gas in untested cells in gas assessment units (nitrogen and helium, and so forth).

110. Inert Gas \%-mode: estimated mode (most likely value) of the inert gas content, in percent, of gas in untested cells in gas assessment units (nitrogen and helium, and so forth).

111. Inert Gas \%-maximum: estimated maximum (F0) inert gas content, in percent, of gas in untested cells in gas assessment units (nitrogen and helium, and so forth).

112. CO2 \%-minimum: estimated minimum (F100) carbon dioxide content, in percent, of gas in untested cells in gas assessment units.

113. CO2 \%-median: estimated median (F50) carbon dioxide content, in percent, of gas in untested cells in gas assessment units.

114. CO2 \%-mode: estimated mode (most likely value) of the carbon dioxide content, in percent, of gas in untested cells in gas assessment units.

115. $\mathrm{CO} 2 \%$-maximum: estimated maximum (F0) carbon dioxide content, in percent, of gas in untested cells in gas assessment units.

116. H2S \%-minimum: estimated minimum (F100) hydrogen sulfide content, in percent, of gas in untested cells in gas assessment units.

117. H2S \%-median: estimated median (F50) hydrogen sulfide content, in percent, of gas in untested cells in gas assessment units.

118. H2S \%-mode: estimated mode (most likely value) of the hydrogen sulfide content, in percent, of gas in untested cells in gas assessment units.

119. H2S \%-maximum: estimated maximum (F0) hydrogen sulfide content, in percent, of gas in untested cells in gas assessment units.

120. BTU-minimum: estimated minimum (F100) heating value of gas, in BTU, of gas in untested cells in gas assessment units.

121. BTU-median: estimated median (F50) heating value of gas, in BTU, of gas in untested cells in gas assessment units. 
122. BTU-mode: estimated mode (most likely value) of the heating value of gas, in BTU, of gas in untested cells in gas assessment units.

123. BTU-maximum: estimated maximum (F0) heating value of gas, in BTU, of gas in untested cells in gas assessment units.

124. (Gas) Water Depth-minimum: estimated minimum (F100) water depth, in meters, of gas in untested cells in gas assessment units (ocean, bays, or lakes; if applicable)

125. (Gas) Water Depth-median: estimated median (F50) water depth, in meters, of gas in untested cells in gas assessment units (ocean, bays, or lakes; if applicable).

126. (Gas) Water Depth-mode: estimated mode (most likely value) of the water depth, in meters, of gas in untested cells in gas assessment units (ocean, bays, or lakes; if applicable).

127. (Gas) Water Depth-maximum: estimated maximum (F0) water depth, in meters, of gas in untested cells in gas assessment units (ocean, bays, or lakes; if applicable).

128. (Gas) Drilling Depth-minimum: estimated minimum (F100) drilling depth, in meters, of gas in untested cells in gas assessment units.

129. (Gas) Drilling Depth-F75: estimated F75 drilling depth, in meters, of gas in untested cells in gas assessment units. An estimated 75 percent of the wells will be deeper than this value.

130. (Gas) Drilling Depth-median: estimated median (F50) drilling depth, in meters, of gas in untested cells in gas assessment units.

131. (Gas) Drilling Depth-mode: estimated mode (most likely value) of the drilling depth, in meters, of gas in untested cells in gas assessment units.

132. (Gas) Drilling Depth-F25: estimated F25 drilling depth, in meters, of gas in untested cells in gas assessment units. An estimated 25 percent of the wells will be deeper than this value.

133. (Gas) Drilling Depth-maximum: estimated maximum (F0) drilling depth, in meters, of gas in untested cells in gas assessment units.

134. Future Success Ratio-minimum: estimated minimum (F100) future success ratio, as percent.

135. Future Success Ratio-median: estimated median (F50) future success ratio, as percent, as written on the input form.

136. Future Success Ratio-calculated median: estimated median (F50) future success ratio, as percent, as calculated from the parameters on the input form.
137. Future Success Ratio-mode: estimated mode (most likely value) of the future success ratio, as percent, as written on the input form.

138. Future Success Ratio-calculated mode: estimated mode (most likely value) of the future success ratio, as percent, as calculated from the parameters on the input form.

139. Future Success Ratio-maximum: estimated maximum (F100) future success ratio, as percent.

140. Future Success Ratio-mean: estimated mean future success ratio, as percent, as written on the input form.

141. Future Success Ratio-calculated mean: estimated mean future success ratio, as percent, as calculated from the parameters on the input form.

142. Historic Success Ratio: historical success ratio, as percent.

143. Completion 1: typical well-completion practices (conventional, open hole, open cavity, other).

144. Completion 2: fraction of wells drilled that are typically stimulated.

145. Completion 3: predominant type of stimulation (none, frac, acid, other).

146. Completion 4: fraction of wells drilled that are horizontal.

147. Program Version: which version of the ACCESS program (version 1, 2, or 3) was used to perform the calculations.

The Ecosystem Allocations, Federal Land Allocations, Land Ownership Allocations, and State Allocations files contain volume-percent data of undiscovered petroleum allocated to ecosystem regions, Federal lands, general land-ownership parcels, and States. Cells are left blank if data are unavailable. Ecosystem allocation is based on the Bailey ecosystems (http://www.fs.fed.us/rm/ecoregions/products/map-ecoregionsunited-states/). The land ownership (including Federal ownership) information has come from several sources over the period in which these assessments were conducted. Currently the U.S. Geological Survey (USGS) Protected Areas Database of the United States (PADUS) is used (http://gis1.usgs.gov/arcgis/ rest/services/gap/PADUS_Owner/MapServer), but previously land-ownership data came primarily from Bureau of Land Management state offices.

The Ecosystem Allocations file contains 65 columns. There are records for 186 AUs, 139 of which were quantitatively assessed. In the Microsoft Excel version of this file, AUs that were not quantitatively assessed are colored purple; green cells mark major changes from previously published versions, as noted in the main text of this report. The sum of the percentages should equal those for the total area (excluding offshore) in the Land Ownership Allocations file. Data columns for these files are as follows: 
1. AU Number: assessment-unit code number.

2. AU: assessment-unit name.

3. Province Number: province code number.

4. Province: province name.

5. Area: area of the assessment unit in square kilometers.

6. Ecosystem 1 Name: name of first ecosystem that occupies all or part of the assessment-unit area.

7. Ecosystem 1 Area \%: percentage of assessment-unit area that is occupied by ecosystem 1 .

8. Ecosystem 1 Oil Volume \%: estimated percentage of undiscovered oil volume allocated to ecosystem 1.

9. Ecosystem 1 Gas Volume \%: estimated percentage of undiscovered gas volume allocated to ecosystem 1 .

10. Ecosystem 2 Name: name of second ecosystem that occupies part of the assessment-unit area.

11. Ecosystem 2 Area \%: percentage of assessment-unit area that is occupied by ecosystem 2 .

12. Ecosystem 2 Oil Volume \%: estimated percentage of undiscovered oil volume allocated to ecosystem 2 .

13. Ecosystem 2 Gas Volume \%: estimated percentage of undiscovered gas volume allocated to ecosystem 2 .

14. Ecosystem 3 Name: name of third ecosystem that occupies part of the assessment-unit area.

15. Ecosystem 3 Area \%: percentage of assessment-unit area that is occupied by ecosystem 3 .

16. Ecosystem 3 Oil Volume \%: estimated percentage of undiscovered oil volume allocated to ecosystem 3 .

17. Ecosystem 3 Gas Volume \%: estimated percentage of undiscovered gas volume allocated to ecosystem 3 .

18. Ecosystem 4 Name: name of fourth ecosystem that occupies part of the assessment-unit area.

19. Ecosystem 4 Area \%: percentage of assessment-unit area that is occupied by ecosystem 4 .

20. Ecosystem 4 Oil Volume \%: estimated percentage of undiscovered oil volume allocated to ecosystem 4 .

21. Ecosystem 4 Gas Volume \%: estimated percentage of undiscovered gas volume allocated to ecosystem 4 .

22. Ecosystem 5 Name: name of fifth ecosystem that occupies part of the assessment-unit area.

23. Ecosystem 5 Area \%: percentage of assessment-unit area that is occupied by ecosystem 5 .
24. Ecosystem 5 Oil Volume \%: estimated percentage of undiscovered oil volume allocated to ecosystem 5 .

25. Ecosystem 5 Gas Volume \%: estimated percentage of undiscovered gas volume allocated to ecosystem 5.

26. Ecosystem 6 Name: name of sixth ecosystem that occupies part of the assessment-unit area.

27. Ecosystem 6 Area \%: percentage of assessment-unit area that is occupied by ecosystem 6 .

28. Ecosystem 6 Oil Volume \%: estimated percentage of undiscovered oil volume allocated to ecosystem 6 .

29. Ecosystem 6 Gas Volume \%: estimated percentage of undiscovered gas volume allocated to ecosystem 6 .

30. Ecosystem 7 Name: name of seventh ecosystem that occupies part of the assessment-unit area.

31. Ecosystem 7 Area \%: percentage of assessment-unit area that is occupied by ecosystem 7 .

32. Ecosystem 7 Oil Volume \%: estimated percentage of undiscovered oil volume allocated to ecosystem 7 .

33. Ecosystem 7 Gas Volume \%: estimated percentage of undiscovered gas volume allocated to ecosystem 7.

34. Ecosystem 8 Name: name of eighth ecosystem that occupies part of the assessment-unit area.

35. Ecosystem 8 Area \%: percentage of assessment-unit area that is occupied by ecosystem 8 .

36. Ecosystem 8 Oil Volume \%: estimated percentage of undiscovered oil volume allocated to ecosystem 8 .

37. Ecosystem 8 Gas Volume \%: estimated percentage of undiscovered gas volume allocated to ecosystem 8 .

38. Ecosystem 9 Name: name of ninth ecosystem that occupies part of the assessment-unit area.

39. Ecosystem 9 Area \%: percentage of assessment-unit area that is occupied by ecosystem 9 .

40. Ecosystem 9 Oil Volume \%: estimated percentage of undiscovered oil volume allocated to ecosystem 9.

41. Ecosystem 9 Gas Volume \%: estimated percentage of undiscovered gas volume allocated to ecosystem 9 .

42. Ecosystem 10 Name: name of tenth ecosystem that occupies part of the assessment-unit area.

43. Ecosystem 10 Area \%: percentage of assessment-unit area that is occupied by ecosystem 10 .

44. Ecosystem 10 Oil Volume \%: estimated percentage of undiscovered oil volume allocated to ecosystem 10. 
45. Ecosystem 10 Gas Volume \%: estimated percentage of undiscovered gas volume allocated to ecosystem 10 .

46. Ecosystem 11 Name: name of eleventh ecosystem that occupies part of the assessment-unit area.

47. Ecosystem 11 Area \%: percentage of assessment-unit area that is occupied by ecosystem 11 .

48. Ecosystem 11 Oil Volume \%: estimated percentage of undiscovered oil volume allocated to ecosystem 11.

49. Ecosystem 11 Gas Volume \%: estimated percentage of undiscovered gas volume allocated to ecosystem 11.

50. Ecosystem 12 Name: name of twelfth ecosystem that occupies part of the assessment-unit area.

51. Ecosystem 12 Area \%: percentage of assessment-unit area that is occupied by ecosystem 12 .

52. Ecosystem 12 Oil Volume \%: estimated percentage of undiscovered oil volume allocated to ecosystem 12.

53. Ecosystem 12 Gas Volume \%: estimated percentage of undiscovered gas volume allocated to ecosystem 12 .

54. Ecosystem 13 Name: name of thirteenth ecosystem that occupies part of the assessment-unit area.

55. Ecosystem 13 Area \%: percentage of assessment-unit area that is occupied by ecosystem 13 .

56. Ecosystem 13 Oil Volume \%: estimated percentage of undiscovered oil volume allocated to ecosystem 13.

57. Ecosystem 13 Gas Volume \%: estimated percentage of undiscovered gas volume allocated to ecosystem 13 .

58. Ecosystem 14 Name: name of fourteenth ecosystem that occupies part of the assessment-unit area.

59. Ecosystem 14 Area \%: percentage of assessment-unit area that is occupied by ecosystem 14 .

60. Ecosystem 14 Oil Volume \%: estimated percentage of undiscovered oil volume allocated to ecosystem 14.

61. Ecosystem 14 Gas Volume \%: estimated percentage of undiscovered gas volume allocated to ecosystem 14 .

62. Ecosystem 15 Name: name of fifteenth ecosystem that occupies part of the assessment-unit area.

63. Ecosystem 15 Area \%: percentage of assessment-unit area that is occupied by ecosystem 15 .

64. Ecosystem 15 Oil Volume \%: estimated percentage of undiscovered oil volume allocated to ecosystem 15.

65. Ecosystem 15 Gas Volume \%: estimated percentage of undiscovered gas volume allocated to ecosystem 15.
The Federal Land Allocations file contains 85 columns. There are records for 186 AUs, 139 of which were quantitatively assessed. In the Microsoft Excel version of this file, AUs that were not quantitatively assessed are colored purple; green cells mark major changes from previously published versions, as noted in the main text of this report. The sum of the percentages should equal those for Federal lands in the Land Ownership Allocations file. Data columns for these files are:

1. AU Number: assessment-unit code number.

2. AU: assessment-unit name.

3. Province Number: province code number.

4. Province: province name.

5. Area: area of the assessment unit in square kilometers.

6. BLM: "Bureau of Land Management (BLM)," name of Federal land that occupies all or part of the assessmentunit area.

7. BLM Area \%: percentage of assessment-unit area that is occupied by Bureau of Land Management lands.

8. BLM Oil Volume \%: estimated percentage of undiscovered oil volume allocated to Bureau of Land Management lands.

9. BLM Gas Volume \%: estimated percentage of undiscovered gas volume allocated to Bureau of Land Management lands.

10. BLMW: "BLM Wilderness Areas (BLMW)," name of Federal land that occupies all or part of the assessmentunit area.

11. BLMW Area \%: percentage of assessment-unit area that is occupied by Bureau of Land Management Wilderness Areas.

12. BLMW Oil Volume \%: estimated percentage of undiscovered oil volume allocated to Bureau of Land Management Wilderness Areas.

13. BLMW Gas Volume \%: estimated percentage of undiscovered gas volume allocated to Bureau of Land Management Wilderness Areas.

14. BLMR: "BLM Roadless Areas (BLMR)," name of Federal land that occupies all or part of the assessment-unit area.

15. BLMR Area \%: percentage of assessment-unit area that is occupied by Bureau of Land Management Roadless Areas.

16. BLMR Oil Volume \%: estimated percentage of undiscovered oil volume allocated to Bureau of Land Management Roadless Areas. 
17. BLMR Gas Volume \%: estimated percentage of undiscovered gas volume allocated to Bureau of Land Management Roadless Areas.

18. NPS: "National Park Service (NPS)," name of Federal land that occupies all or part of the assessment-unit area.

19. NPS Area \%: percentage of assessment-unit area that is occupied by National Park Service lands.

20. NPS Oil Volume \%: estimated percentage of undiscovered oil volume allocated to National Park Service lands.

21. NPS Gas Volume \%: estimated percentage of undiscovered gas volume allocated to National Park Service lands.

22. NPSW: "NPS Wilderness Areas (NPSW)," name of Federal land that occupies all or part of the assessment-unit area.

23. NPSW Area \%: percentage of assessment-unit area that is occupied by National Park Service Wilderness Areas.

24. NPSW Oil Volume \%: estimated percentage of undiscovered oil volume allocated to National Park Service Wilderness Areas.

25. NPSW Gas Volume \%: estimated percentage of undiscovered gas volume allocated to National Park Service Wilderness Areas.

26. NPSP: "NPS Withdrawals (NPSP)," name of Federal land that occupies all or part of the assessment-unit area.

27. NPSP Area \%: percentage of assessment-unit area that is occupied by National Park Service Withdrawals.

28. NPSP Oil Volume \%: estimated percentage of undiscovered oil volume allocated to National Park Service Withdrawals.

29. NPSP Gas Volume \%: estimated percentage of undiscovered gas volume allocated to National Park Service Withdrawals.

30. FS: "Forest Service (FS)," name of Federal land that occupies all or part of the assessment-unit area.

31. FS Area \%: percentage of assessment-unit area that is occupied by USDA Forest Service lands.

32. FS Oil Volume \%: estimated percentage of undiscovered oil volume allocated to USDA Forest Service lands.

33. FS Gas Volume \%: estimated percentage of undiscovered gas volume allocated to USDA Forest Service lands.

34. FSW: "FS Wilderness Areas (FSW)," name of Federal land that occupies all or part of the assessment-unit area.

35. FSW Area \%: percentage of assessment-unit area that is occupied by USDA Forest Service Wilderness Areas.
36. FSW Oil Volume \%: estimated percentage of undiscovered oil volume allocated to USDA Forest Service Wilderness Areas.

37. FSW Gas Volume \%: estimated percentage of undiscovered gas volume allocated to USDA Forest Service Wilderness Areas.

38. FSR: "FS Roadless Areas (FSR)," name of Federal land that occupies all or part of the assessment-unit area.

39. FSR Area \%: percentage of assessment-unit area that is occupied by USDA Forest Service Roadless Areas.

40. FSR Oil Volume \%: estimated percentage of undiscovered oil volume allocated to USDA Forest Service Roadless Areas.

41. FSR Gas Volume \%: estimated percentage of undiscovered gas volume allocated to USDA Forest Service Roadless Areas.

42. FSP: "FS Protected Withdrawals (FSP)," name of Federal land that occupies all or part of the assessment-unit area.

43. FSP Area \%: percentage of assessment-unit area that is occupied by USDA Forest Service Protected Withdrawals.

44. FSP Oil Volume \%: estimated percentage of undiscovered oil volume allocated to USDA Forest Service Protected Withdrawals.

45. FSP Gas Volume \%: estimated percentage of undiscovered gas volume allocated to USDA Forest Service Protected Withdrawals.

46. FWS: "U.S. Fish and Wildlife Service (USFWS)," name of Federal land that occupies all or part of the assessmentunit area.

47. FWS Area \%: percentage of assessment-unit area that is occupied by U.S. Fish and Wildlife Service lands.

48. FWS Oil Volume \%: estimated percentage of undiscovered oil volume allocated to U.S. Fish and Wildlife Service lands.

49. FWS Gas Volume \%: estimated percentage of undiscovered gas volume allocated to U.S. Fish and Wildlife Service lands.

50. FWSW: "USFWS Wilderness Areas (USFWSW)," name of Federal land that occupies all or part of the assessmentunit area.

51. FWSW Area \%: percentage of assessment-unit area that is occupied by U.S. Fish and Wildlife Service Wilderness Areas. 
52. FWSW Oil Volume \%: estimated percentage of undiscovered oil volume allocated to U.S. Fish and Wildlife Service Wilderness Areas.

53. FWSW Gas Volume \%: estimated percentage of undiscovered gas volume allocated to U.S. Fish and Wildlife Service Wilderness Areas.

54. FWSP: "USFWS Protected Withdrawals (USFWSP)," name of Federal land that occupies all or part of the assessment-unit area.

55. FWSP Area \%: percentage of assessment-unit area that is occupied by U.S. Fish and Wildlife Service Protected Withdrawals.

56. FWSP Oil Volume \%: estimated percentage of undiscovered oil volume allocated to U.S. Fish and Wildlife Service Protected Withdrawals.

57. FWSP Gas Volume \%: estimated percentage of undiscovered gas volume allocated to U.S. Fish and Wildlife Service Protected Withdrawals.

58. WS: "Wilderness Study Areas (WS)," name of Federal land that occupies all or part of the assessment-unit area.

59. WS Area \%: percentage of assessment-unit area that is occupied by Wilderness Study Areas.

60. WS Oil Volume \%: estimated percentage of undiscovered oil volume allocated to Wilderness Study Areas.

61. WS Gas Volume \%: estimated percentage of undiscovered gas volume allocated to Wilderness Study Areas.

62. DOE: "Department of Energy (DOE)," name of Federal land that occupies all or part of the assessment-unit area.

63. DOE Area \%: percentage of assessment-unit area that is occupied by Department of Energy lands.

64. DOE Oil Volume \%: estimated percentage of undiscovered oil volume allocated to Department of Energy lands.

65. DOE Gas Volume \%: estimated percentage of undiscovered gas volume allocated to Department of Energy lands.

66. DOD: "Department of Defense (DOD)," name of Federal land that occupies all or part of the assessment-unit area.

67. DOD Area \%: percentage of assessment-unit area that is occupied by Department of Defense lands.

68. DOD Oil Volume \%: estimated percentage of undiscovered oil volume allocated to Department of Defense lands.

69. DOD Gas Volume \%: estimated percentage of undiscovered gas volume allocated to Department of Defense lands.
70. BOR: "Bureau of Reclamation (BOR)," name of Federal land that occupies all or part of the assessment-unit area.

71. BOR Area \%: percentage of assessment-unit area that is occupied by Bureau of Reclamation lands.

72. BOR Oil Volume \%: estimated percentage of undiscovered oil volume allocated to Bureau of Reclamation lands.

73. BOR Gas Volume \%: estimated percentage of undiscovered gas volume allocated to Bureau of Reclamation lands.

74. TVA: "Tennessee Valley Authority (TVA)," name of Federal land that occupies all or part of the assessment-unit area.

75. TVA Area \%: percentage of assessment-unit area that is occupied by Tennessee Valley Authority lands.

76. TVA Oil Volume \%: estimated percentage of undiscovered oil volume allocated to Tennessee Valley Authority lands.

77. TVA Gas Volume \%: estimated percentage of undiscovered gas volume allocated to Tennessee Valley Authority lands.

78. Other: "Other Federal," other unspecified Federal lands that occupy all part of the assessment-unit area.

79. Other Area \%: percentage of assessment-unit area that is occupied by other unspecified Federal lands.

80. Other Oil Volume \%: estimated percentage of undiscovered oil volume allocated to other unspecified Federal lands.

81. Other Gas Volume \%: estimated percentage of undiscovered gas volume allocated to other unspecified Federal lands.

82. Fed 20: name of additional specified Federal lands that occupy all or part of the assessment-unit area.

83. Fed 20 Area \%: percentage of assessment-unit area that is occupied by additional specified Federal lands.

84. Fed 20 Oil Volume \%: estimated percentage of undiscovered oil volume allocated to additional specified Federal lands.

85. Fed 20 Gas Volume \%: estimated percentage of undiscovered gas volume allocated to additional specified Federal lands.

The Land Ownership Allocations file contains 57 columns. There are records for 186 AUs, 139 of which were quantitatively assessed. In the Microsoft Excel version of this file, AUs that were not quantitatively assessed are colored purple; green cells mark major changes from previously published versions, as noted in the main text of this report. The sum of the percentages should equal 100. Data columns for these files are as follows: 
1. AU Number: assessment-unit code number.

2. AU: assessment-unit name.

3. Province Number: province code number.

4. Province: province name.

5. Area: area of the assessment unit in square kilometers.

6. Federal: "Federal Lands," all Federal lands that occupy all or part of the assessment-unit area.

7. Federal Area \%: percentage of assessment-unit area that is occupied by Federal lands.

8. Federal Oil Volume \%: estimated percentage of undiscovered oil volume allocated to Federal lands.

9. Federal Gas Volume \%: estimated percentage of undiscovered gas volume allocated to Federal lands.

10. Private: "Private Lands," all private lands that occupy all or part of the assessment-unit area.

11. Private Area \%: percentage of assessment-unit area that is occupied by private lands.

12. Private Oil Volume \%: estimated percentage of undiscovered oil volume allocated to private lands.

13. Private Gas Volume \%: estimated percentage of undiscovered gas volume allocated to private lands.

14. Tribal: "Tribal Lands," all tribal lands that occupy all or part of the assessment-unit area.

15. Tribal Area \%: percentage of assessment-unit area that is occupied by tribal lands.

16. Tribal Oil Volume \%: estimated percentage of undiscovered oil volume allocated to tribal lands.

17. Tribal Gas Volume \%: estimated percentage of undiscovered gas volume allocated to tribal lands.

18. Other: name of other unspecified lands or offshore areas that occupy all or part of the assessment-unit area.

19. Other Area \%: percentage of assessment-unit area that is occupied by other unspecified lands or offshore areas.

20. Other Oil Volume \%: estimated percentage of undiscovered oil volume allocated to other unspecified lands or offshore areas.

21. Other Gas Volume \%: estimated percentage of undiscovered gas volume allocated to other unspecified lands or offshore areas.

22. State 1: name of first State category which State-owned lands or waters occupy all or part of the assessment-unit area.
23. State 1 Area \%: percentage of assessment-unit area that is occupied by State 1-owned lands or waters.

24. State 1 Oil Volume \%: estimated percentage of undiscovered oil volume allocated to State 1-owned lands or waters.

25. State 1 Gas Volume \%: estimated percentage of undiscovered gas volume allocated to State 1-owned lands or waters.

26. State 2: name of second State category which Stateowned lands or waters occupy all or part of the assessment-unit area.

27. State 2 Area \%: percentage of assessment-unit area that is occupied by State 2-owned lands or waters.

28. State 2 Oil Volume \%: estimated percentage of undiscovered oil volume allocated to State 2-owned lands or waters.

29. State 2 Gas Volume \%: estimated percentage of undiscovered gas volume allocated to State 2-owned lands or waters.

30. State 3: name of third State category which State-owned lands or waters occupy all or part of the assessment-unit area.

31. State 3 Area \%: percentage of assessment-unit area that is occupied by State 3-owned lands or waters.

32. State 3 Oil Volume \%: estimated percentage of undiscovered oil volume allocated to State 3-owned lands or waters.

33. State 3 Gas Volume \%: estimated percentage of undiscovered gas volume allocated to State 3-owned lands or waters.

34. State 4: name of fourth State category which State-owned lands or waters occupy all or part of the assessment-unit area.

35. State 4 Area \%: percentage of assessment-unit area that is occupied by State 4-owned lands or waters.

36. State 4 Oil Volume \%: estimated percentage of undiscovered oil volume allocated to State 4-owned lands or waters.

37. State 4 Gas Volume \%: estimated percentage of undiscovered gas volume allocated to State 4-owned lands or waters.

38. State 5: name of fifth State category which State-owned lands or waters occupy all or part of the assessment-unit area. 
39. State 5 Area \%: percentage of assessment-unit area that is occupied by State 5-owned lands or waters.

40. State 5 Oil Volume \%: estimated percentage of undiscovered oil volume allocated to State 5-owned lands or waters.

41. State 5 Gas Volume \%: estimated percentage of undiscovered gas volume allocated to State 5-owned lands or waters.

42. State 6: name of sixth State category which State-owned lands or waters occupy all or part of the assessment-unit area.

43. State 6 Area $\%$ : percentage of assessment-unit area that is occupied by State 6-owned lands or waters.

44. State 6 Oil Volume \%: estimated percentage of undiscovered oil volume allocated to State 6-owned lands or waters.

45. State 6 Gas Volume \%: estimated percentage of undiscovered gas volume allocated to State 6-owned lands or waters.

46. State 7: name of seventh State category which Stateowned lands or waters occupy all or part of the assessment-unit area.

47. State 7 Area \%: percentage of assessment-unit area that is occupied by State 7-owned lands or waters.

48. State 7 Oil Volume \%: estimated percentage of undiscovered oil volume allocated to State 7-owned lands or waters.

49. State 7 Gas Volume \%: estimated percentage of undiscovered gas volume allocated to State 7-owned lands or waters.

50. State 8: name of eighth State category which State-owned lands or waters occupy all or part of the assessment-unit area.

51. State 8 Area \%: percentage of assessment-unit area that is occupied by State 8-owned lands or waters.

52. State 8 Oil Volume \%: estimated percentage of undiscovered oil volume allocated to State 8-owned lands or waters.

53. State 8 Gas Volume \%: estimated percentage of undiscovered gas volume allocated to State 8-owned lands or waters.

54. State 9: name of ninth State category which State-owned lands or waters occupy all or part of the assessment-unit area.
55. State 9 Area \%: percentage of assessment-unit area that is occupied by State 9-owned lands or waters.

56. State 9 Oil Volume \%: estimated percentage of undiscovered oil volume allocated to State 9-owned lands or waters.

57. State 9 Gas Volume \%: estimated percentage of undiscovered gas volume allocated to State 9-owned lands or waters.

The State Allocations file contains 53 columns. There are records for 186 AUs, 139 of which were quantitatively assessed. In the Microsoft Excel version of this file, AUs that were not quantitatively assessed are colored purple; green cells mark major changes from previously published versions, as noted in the main text of this report. The sum of the percentages should equal 100. Data columns for these files are as follows:

1. AU Number: assessment-unit code number.

2. AU: assessment-unit name.

3. Province Number: province code number.

4. Province: province name.

5. Area: area of the assessment unit in square kilometers.

6. State 1 Name: name of first State (onshore and offshore) that occupies all or part of the assessment-unit area.

7. State 1 Area \%: percentage of assessment-unit area that is occupied by State 1.

8. State 1 Oil Volume \%: estimated percentage of undiscovered oil volume allocated to State 1.

9. State 1 Gas Volume \%: estimated percentage of undiscovered gas volume allocated to State 1.

10. State 2 Name: name of second State (onshore and offshore) that occupies part of the assessment-unit area.

11. State 2 Area $\%$ : percentage of assessment-unit area that is occupied by State 2.

12. State 2 Oil Volume \%: estimated percentage of undiscovered oil volume allocated to State 2.

13. State 2 Gas Volume \%: estimated percentage of undiscovered gas volume allocated to State 2.

14. State 3 Name: name of third State (onshore and offshore) that occupies part of the assessment-unit area.

15. State 3 Area \%: percentage of assessment-unit area that is occupied by State 3.

16. State 3 Oil Volume \%: estimated percentage of undiscovered oil volume allocated to State 3.

17. State 3 Gas Volume \%: estimated percentage of undiscovered gas volume allocated to State 3 . 
18. State 4 Name: name of fourth State (onshore and offshore) that occupies part of the assessment-unit area.

19. State 4 Area \%: percentage of assessment-unit area that is occupied by State 4 .

20. State 4 Oil Volume \%: estimated percentage of undiscovered oil volume allocated to State 4.

21. State 4 Gas Volume \%: estimated percentage of undiscovered gas volume allocated to State 4 .

22. State 5 Name: name of fifth State (onshore and offshore) that occupies part of the assessment-unit area.

23. State 5 Area \%: percentage of assessment-unit area that is occupied by State 5 .

24. State 5 Oil Volume \%: estimated percentage of undiscovered oil volume allocated to State 5 .

25. State 5 Gas Volume \%: estimated percentage of undiscovered gas volume allocated to State 5 .

26. State 6 Name: name of sixth State (onshore and offshore) that occupies part of the assessment-unit area.

27. State 6 Area \%: percentage of assessment-unit area that is occupied by State 6 .

28. State 6 Oil Volume \%: estimated percentage of undiscovered oil volume allocated to State 6.

29. State 6 Gas Volume \%: estimated percentage of undiscovered gas volume allocated to State 6.

30. State 7 Name: name of seventh State (onshore and offshore) that occupies part of the assessment-unit area.

31. State 7 Area \%: percentage of assessment-unit area that is occupied by State 7 .

32. State 7 Oil Volume \%: estimated percentage of undiscovered oil volume allocated to State 7.

33. State 7 Gas Volume \%: estimated percentage of undiscovered gas volume allocated to State 7 .

34. State 8 Name: name of eighth State (onshore and offshore) that occupies part of the assessment-unit area.

35. State 8 Area \%: percentage of assessment-unit area that is occupied by State 8 .

36. State 8 Oil Volume \%: estimated percentage of undiscovered oil volume allocated to State 8 .

37. State 8 Gas Volume \%: estimated percentage of undiscovered gas volume allocated to State 8 .

38. State 9 Name: name of ninth State (onshore and offshore) that occupies part of the assessment-unit area.
39. State 9 Area \%: percentage of assessment-unit area that is occupied by State 9 .

40. State 9 Oil Volume \%: estimated percentage of undiscovered oil volume allocated to State 9.

41. State 9 Gas Volume \%: estimated percentage of undiscovered gas volume allocated to State 9 .

42. State 10 Name: name of tenth State (onshore and offshore) that occupies part of the assessment-unit area.

43. State 10 Area \%: percentage of assessment-unit area that is occupied by State 10 .

44. State 10 Oil Volume \%: estimated percentage of undiscovered oil volume allocated to State 10 .

45. State 10 Gas Volume \%: estimated percentage of undiscovered gas volume allocated to State 10.

46. State 11 Name: name of eleventh State (onshore and offshore) that occupies part of the assessment-unit area.

47. State 11 Area \%: percentage of assessment-unit area that is occupied by State 11 .

48. State 11 Oil Volume \%: estimated percentage of undiscovered oil volume allocated to State 11.

49. State 11 Gas Volume \%: estimated percentage of undiscovered gas volume allocated to State 11 .

50. State 12 Name: name of twelfth State (onshore and offshore) that occupies part of the assessment-unit area.

51. State 12 Area \%: percentage of assessment-unit area that is occupied by State 12 .

52. State 12 Oil Volume \%: estimated percentage of undiscovered oil volume allocated to State 12.

53. State 12 Gas Volume \%: estimated percentage of undiscovered gas volume allocated to State 12 .

The Continuous Results file contains 49 columns. There are records for the 139 AUs that were quantitatively assessed. Data columns for these files are as follows:

1. AU Number: USGS assessment-unit code number.

2. AU: USGS assessment unit name

3. Province Number: province code number.

4. Province: province name.

5. AU Type: assessment unit type, the primary commodity type in the assessment unit, based on the gas-to-oil ratio (GOR) of the petroleum endowment, which includes both the discovered and undiscovered petroleum. An assessment unit is characterized as being oil prone if the gas-tooil ratio (GOR) is less than 20,000 cubic feet of gas per barrel of oil; otherwise, it is gas prone. 
6. Date: date of assessment.

7. AU Probability: the probability that there exists the potential for at least one well equal to or larger than the minimum well size somewhere in the assessment unit. Assessment unit probability is given as a fractional value from 0 to 1.0 .

8. Oil in Oil Deposit (MMBO), Mean: the estimated mean (average) value of undrilled oil in the assessment unit. The volume is given in millions of barrels of oil (MMBO).

9. Oil in Oil Deposit (MMBO), Std. Dev.: the estimated standard deviation of the distribution of undrilled oil in the assessment unit. The volume is given in millions of barrels of oil (MMBO).

10. Oil in Oil Deposit (MMBO), F95: the estimated value of undrilled oil such that there is a 95 percent probability that this amount or more exists in the assessment unit. The volume is given in millions of barrels of oil (MMBO).

11. Oil in Oil Deposit (MMBO), F75: the estimated value of undrilled oil such that there is a 75 percent probability that this amount or more exists in the assessment unit. The volume is given in millions of barrels of oil (MMBO).

12. Oil in Oil Deposit (MMBO), F50: the estimated value of undrilled oil such that there is a 50 percent probability that this amount or more exists in the assessment unit. This is the median value. The volume is given in millions of barrels of oil (MMBO).

13. Oil in Oil Deposit (MMBO), F25: the estimated value of undrilled oil such that there is a 25 percent probability that this amount or more exists in the assessment unit. The volume is given in millions of barrels of oil (MMBO).

14. Oil in Oil Deposit (MMBO), F5: the estimated value of undrilled oil such that there is a 5 percent probability that this amount or more exists in the assessment unit. The volume is given in millions of barrels of oil (MMBO).

15. Gas in Oil Deposit (BCFG), Mean: the estimated mean (average) value of undrilled associated/dissolved gas in the assessment unit. The volume is given in billions of cubic feet of gas (BCFG).

16. Gas in Oil Deposit (BCFG), Std. Dev.: the estimated standard deviation of the distribution of undrilled associated/ dissolved gas in the assessment unit. The volume is given in billions of cubic feet of gas (BCFG).

17. Gas in Oil Deposit (BCFG), F95: the estimated value of undrilled associated/dissolved gas such that there is a 95 percent probability that this amount or more exists in the assessment unit. The volume is given in billions of cubic feet of gas (BCFG).
18. Gas in Oil Deposit (BCFG), F75: the estimated value of undrilled associated/dissolved gas such that there is a 75 percent probability that this amount or more exists in the assessment unit. The volume is given in billions of cubic feet of gas (BCFG).

19. Gas in Oil Deposit (BCFG), F50: the estimated value of undrilled associated/dissolved gas such that there is a 50 percent probability that this amount or more exists in the assessment unit. This is the median value. The volume is given in billions of cubic feet of gas (BCFG).

20. Gas in Oil Deposit (BCFG), F25: the estimated value of undrilled associated/dissolved gas such that there is a 25 percent probability that this amount or more exists in the assessment unit. The volume is given in billions of cubic feet of gas (BCFG).

21. Gas in Oil Deposit (BCFG), F5: the estimated value of undrilled associated/dissolved gas such that there is a 5 percent probability that this amount or more exists in the assessment unit. The volume is given in billions of cubic feet of gas (BCFG).

22. NGL in Oil Deposit (MMBNGL), Mean: the estimated mean (average) value of undrilled NGL in the assessment unit. The volume is given in millions of barrels of NGL (MMBNGL).

23. NGL in Oil Deposit (MMBNGL), Std. Dev.: the estimated standard deviation of the distribution of undrilled NGL in the assessment unit. The volume is given in millions of barrels of NGL (MMBNGL).

24. NGL in Oil Deposit (MMBNGL), F95: the estimated value of undrilled NGL such that there is a 95 percent probability that this amount or more exists in the assessment unit. The volume is given in millions of barrels of NGL (MMBNGL).

25. NGL in Oil Deposit (MMBNGL), F75: the estimated value of undrilled NGL such that there is a 75 percent probability that this amount or more exists in the assessment unit. The volume is given in millions of barrels of NGL (MMBNGL).

26. NGL in Oil Deposit (MMBNGL), F50: the estimated value of undrilled NGL such that there is a 50 percent probability that this amount or more exists in the assessment unit. This is the median value. The volume is given in millions of barrels of NGL (MMBNGL).

27. NGL in Oil Deposit (MMBNGL), F25: the estimated value of undrilled NGL such that there is a 25 percent probability that this amount or more exists in the assessment unit. The volume is given in millions of barrels of NGL (MMBNGL). 
28. NGL in Oil Deposit (MMBNGL), F5: the estimated value of undrilled NGL such that there is a 5 percent probability that this amount or more exists in the assessment unit. The volume is given in millions of barrels of NGL (MMBNGL).

29. Gas in Gas Deposit (BCFG), Mean: the estimated mean (average) value of undrilled nonassociated gas in the assessment unit. The volume is given in billions of cubic feet of gas (BCFG).

30. Gas in Gas Deposit (BCFG), Std. Dev.: the estimated standard deviation of the distribution of undrilled nonassociated gas in the assessment unit. The volume is given in billions of cubic feet of gas (BCFG).

31. Gas in Gas Deposit (BCFG), F95: the estimated value of undrilled nonassociated gas such that there is a 95 percent probability that this amount or more exists in the assessment unit. The volume is given in billions of cubic feet of gas (BCFG).

32. Gas in Gas Deposit (BCFG), F75: the estimated value of undrilled nonassociated gas such that there is a 75 percent probability that this amount or more exists in the assessment unit. The volume is given in billions of cubic feet of gas (BCFG).

33. Gas in Gas Deposit (BCFG), F50: the estimated value of undrilled nonassociated gas such that there is a 50 percent probability that this amount or more exists in the assessment unit. This is the median value. The volume is given in billions of cubic feet of gas (BCFG).

34. Gas in Gas Deposit (BCFG), F25: the estimated value of undrilled nonassociated gas such that there is a 25 percent probability that this amount or more exists in the assessment unit. The volume is given in billions of cubic feet of gas (BCFG).

35. Gas in Gas Deposit (BCFG), F5: the estimated value of undrilled nonassociated gas such that there is a 5 percent probability that this amount or more exists in the assessment unit. The volume is given in billions of cubic feet of gas (BCFG).

36. Liquids in Gas Deposit (MMBL), Mean: the estimated mean (average) value of undrilled liquids in the assessment unit. The volume is given in millions of barrels of liquids (MMBL).

37. Liquids in Gas Deposit (MMBL), Std. Dev.: the estimated standard deviation of the distribution of undrilled liquids in the assessment unit. The volume is given in millions of barrels of liquids (MMBL).

38. Liquids in Gas Deposit (MMBL), F95: the estimated value of undrilled liquids such that there is a 95 percent probability that this amount or more exists in the assessment unit. The volume is given in millions of barrels of liquids (MMBL).
39. Liquids in Gas Deposit (MMBL), F75: the estimated value of undrilled liquids such that there is a 75 percent probability that this amount or more exists in the assessment unit. The volume is given in millions of barrels of liquids (MMBL).

40. Liquids in Gas Deposit (MMBL), F50: the estimated value of undrilled liquids such that there is a 50 percent probability that this amount or more exists in the assessment unit. This is the median value. The volume is given in millions of barrels of liquids (MMBL).

41. Liquids in Gas Deposit (MMBL), F25: the estimated value of undrilled liquids such that there is a 25 percent probability that this amount or more exists in the assessment unit. The volume is given in millions of barrels of liquids (MMBL).

42. Liquids in Gas Deposit (MMBL), F5: the estimated value of undrilled liquids such that there is a 5 percent probability that this amount or more exists in the assessment unit. The volume is given in millions of barrels of liquids (MMBL).

43. Number of Cells, Mean: the estimated mean (average) value of number of untested cells with resource potential in the assessment unit.

44. Number of Cells, Std. Dev.: the estimated standard deviation of the distribution of number of untested cells with resource potential in the assessment unit.

45. Number of Cells, F95: the estimated value of number of untested cells with resource potential such that there is a 95 percent probability that this amount or more exists in the assessment unit.

46. Number of Cells, F75: the estimated value of number of untested cells with resource potential such that there is a 75 percent probability that this amount or more exists in the assessment unit.

47. Number of Cells, F50: the estimated value of number of untested cells with resource potential such that there is a 50 percent probability that this amount or more exists in the assessment unit. This is the median value.

48. Number of Cells, F25: the estimated value of number of untested cells with resource potential such that there is a 25 percent probability that this amount or more exists in the assessment unit.

49. Number of Cells, F5: the estimated value of number of untested cells with resource potential such that there is a 5 percent probability that this amount or more exists in the assessment unit. 
The Code List file contains the USGS numeric codes for provinces (4 digits), total petroleum systems (6 digits), and assessment units (8 digits). Codes for ecosystem names are in the Ecosystem Codes file. This table contains 3 columns. Data columns are as follows:

1. Code: USGS code number

2. Name: USGS area name

3. Name, Unit, and Code: the USGS area name, comma, space, the hierarchical unit name (province, total petroleum system, or assessment unit), and the USGS code number

The Ecosystem Codes file contains the USGS codes for ecosystem names. This table contains 3 columns. Data columns are as follows:

1. Ecosystem Code: USGS four-letter code

2. Ecosystem Name: ecosystem name

3. Ecosystem Name and Code: the ecosystem name followed by the USGS code in parentheses

The Cloud Plots file contains 110 columns. There are three records for each of the 139 AUs that were quantitatively assessed (one record for each of three variables: cell size, estimated ultimate recovery, and sweet spot percent). The .tab file includes the data variables described below. The Microsoft Excel version includes not only a worksheet with the variables described below but also separate worksheets and plots for the 12 combinations of reservoir type and variable. In the plots, each blue line represents the distribution for a single assessment unit and the black diamond represents the mean of the distribution. Data columns for these files are as follows:

1. AU Number: USGS assessment-unit code number.

2. AU: USGS assessment unit name

3. Province Number: province code number.

4. Province: province name.

5. Reservoir Type: shale gas, coalbed gas, tight gas, or continuous oil.

6. Date: date of assessment.

7. Variable: cell size, EUR (estimated ultimate recovery), or sweet spot percent.

8. Fractile for Mean: the fractile that corresponds to the mean value of the distribution.

9. Mean: the mean value of the distribution.

10-110. F100 to F0: fractiles of the distribution. F95 represents a 95 percent chance of at least the amount tabulated. Other fractiles are defined similarly.

Central Energy Resources Science Center

Publishing support provided by:

Denver Publishing Service Center

For more information concerning this publication, contact:

Center Director, USGS Central Energy Resources Science Center

Box 25046, Mail Stop 939

Denver, CO 80225

(303) 236-1647

Or visit the Central Energy Resources Science Center Web site at:

http://energy.usgs.gov/

This publication is available online at:

http://dx.doi.org/10.3133/ds69MM 


\section{$\frac{\mathbb{2}}{83}$}

S

衰

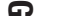

몽

음.

造

章

$\stackrel{2}{a}$

ร

产

\section{.}

